\title{
IDENTIFICATION OF SEDIMENT-RELATED DISASTER BASED ON SEISMIC AND ACOUSTIC SIGNALS ("MM-IDENTIFICATION")
}

\author{
FinAL REPORT \\ Research Initiative "Earth System Sciences" (ESS)
}

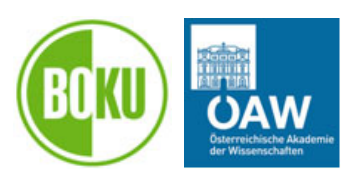

Authors:

Andreas Schimmel

Institute of Mountain Risk Engineering (IAN)

University of Natural Resources and Life Sciences (BOKU), Vienna

ISBN13_Online: 978-3-7001-8286-3

DOI: ESS-MMIdentification 


\section{Contents}

1 Introduction $\quad 1$

2 Detection and identification system 3

2.1 Hardware setup . . . . . . . . . . . . . . . . . 3

2.2 Software design . . . . . . . . . . . . . . . . . . 5 5

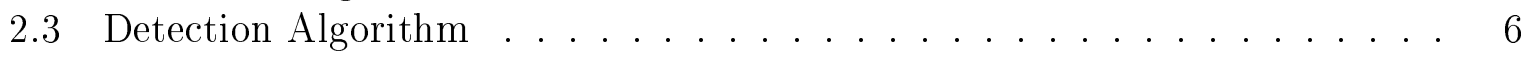

2.4 Magnitude estimation . . . . . . . . . . . . . . . . . . 9

3 Test Sites 12

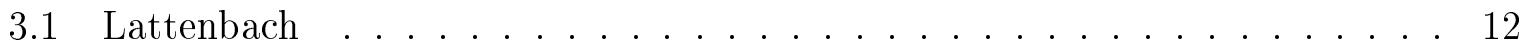

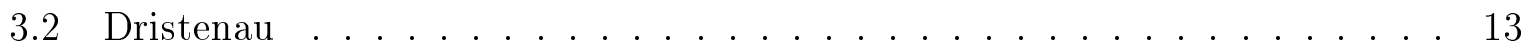

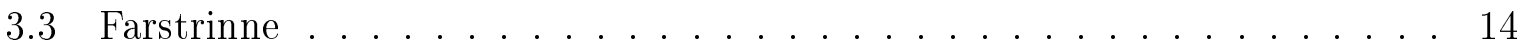

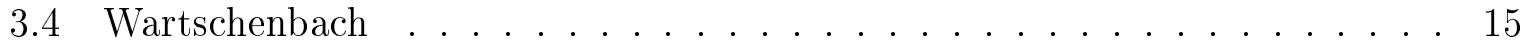

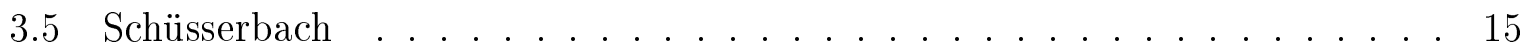

3.6 Gadria . . . . . . . . . . . . . . . . . 16

3.7 Illgraben . . . . . . . . . . . . . . . . . . 17

3.8 Marderello . . . . . . . . . . . . . . . . . 17

3.9 Lueger Hausgraben . . . . . . . . . . . . . . . . . . . . 19

3.10 Punta Negra . . . . . . . . . . . . . . . . . . 19

3.11 Rosensteinergraben . . . . . . . . . . . . . . . . 20

4 Example Events $\quad 21$

4.1 Events Lattenbach . . . . . . . . . . . . . . . . . . . . . . . . . . . . .

4.2 Events Farstrinne . . . . . . . . . . . . . . . . 29

4.3 Events Schüsserbach . . . . . . . . . . . . . . . . . . . . . . . . . . . . 31

4.4 Events Gadria . . . . . . . . . . . . . . . 34

4.5 Events Illgraben . . . . . . . . . . . . . . . . . . 37

4.6 Events Marderello...................... 40

5 Results and Discussion $\quad 42$

6 Conclusion $\quad 45$ 


\section{Introduction}

With the proceeding colonization of the Alpine space and the climatic change an increase in problems with alpine mass movements, like landslides, debris flows and avalanches, causing fatalities and damage to infrastructure can be expected. Active measures (e.g. retention dams, etc.) as well as passive measures (e.g. land use planning, evacuations, closing of roads and railways) (Zschau et al. 2003) can be used to protect settlements and infrastructure. However, passive approaches require reliable data/information from monitoring and early warning systems. Knowledge of the occurrence and frequency of

alpine mass movements as well as information of its type and magnitude are essential to actively reduce the risk of such hazards. Therefore great effort is done to develop effective monitoring or warning system. The sediment related disasters which occurred every year in alpine regions showed the need of warning systems for natural hazards and they also highlighted, that the identification of the magnitude and the event type is an important task for warning. The fact that such mass movements emits seismic and acoustic waves in the low frequency range enables a detection of this events from a remote location unaffected by the process. Thus, several approaches for detection and warning systems based on seismic or infrasound signals has already been developed:

Monitoring and warning systems based on seismic signals are quite common and have been used to study debris floods and debris flows for many years. Various previous studies on debris flows (e.g. Huang et al. 2003, 2007; Vilajosana et al. 2008; Arattano et al. 2012, 2014; Coviello et al. 2015; Walter et al. 2017) and avalanches (e.g. Suriñach et al. 2000; Biescas et al. 2003; Bessason et al. 2007) have already shown that it is possible to detect and monitor these processes with geophones and that it is possible to distinguish them from other seismic sources. The first attempts of infrasound monitoring of debris flows (Zhang et al. 2004; Chou et al. 2007; Kogelnig et al. 2014) and landslides (Bedard 1996) have already proven the viability of infrasonic waves in the detection and monitoring of these types of mass movements. Infrasonic debris flow research is still in its early years compared to the efforts that have been made for avalanches (Chritin et al. 1996, Scott et al. 2007, Thüring et al. 2014, Marchetti et al. 2015). However, there are some studies of debris flow warning devices in China or Taiwan (Zhang et al. 2004; Chou et al. 2007) and several studies of infrasound monitoring of alpine mass movements has been investigated in Europe (Chritin et al. 1996; Adam et al. 1997; Kogelnig et al. 2009). Past studies combining seismic and infrasound signals for detection of torrential mass movements by Suriñach et al. 2009, Kogelnig et al. 2011; Kogelnig 2012, Schimmel et al. 2015, 2016, Hübl et al. 2013 provide a promising approach. For the identification of 
an event different methods for signal classification has already been analyzed: Leprette et al. 1998 developed an approach for seismic detection of snow avalanches based on the fusion of data derived from the analysis of the signal in three domains: time, time frequency and polarizations. Bessason et al. 2007 used a database of observed avalanches to derive ten characteristic parameters that are determined from the time series and power spectrum. These parameters are used for automatically detection. Alasonati et al. 2006 developed a pattern recognition system using wavelet transform for the feature extraction and hidden Markov models for the classification of seismic signals of volcanic origin. Chou et al. 2010 used the Hilbert-Huang transform (HHT) approach to analyze the infrasound and geophone signals induced by debris flows. For stony debris flows, occurred in Houyenshan, the peak acoustic frequencies ranged from 15-40 Hz for most surges, and the corresponding geophone responses exhibit peak frequencies within 15$50 \mathrm{~Hz}$. Huang et al. 2007 compared the ground vibrations generated by debris flows in a channel to explore the characteristics of ground vibrations. They found that ground vibrations caused by individual rocks were $10-150 \mathrm{~Hz}$ and that larger stones generated ground vibrations with lower peak frequencies. The location of mass movements can be determined by using arrays of infrasound or seismic sensors and using standard arrayprocessing techniques like cross-correlation, back-azimuth calculation, apparent velocity etc.. Yamada, et al. 2012, Lin et al. 2010 and Walter et al. 2017 used seismic sensor arrays to locate landslides or debris flows. Ernest Scott and his team (Scott 2006), ? and Marchetti et al. 2015 detected avalanches with arrays of infrasound sensors. All of these approaches provided satisfying results in their specific field of application but for a combination of seismic and infrasonic sensors used for the automatic detection and identification of avalanches, debris flow and debris flood a different method was needed. To this end, this work presents the development of a new approach for a detection and identification system by the combination of seismic and infrasound sensors. The developed detection system considers both the infrasonic and the seismic wave field generated by alpine mass movements to detect events with high accuracy in real time directly at the sensor site and will also provide basic information on process type and magnitude and can therefore help to reduce risk for population and infrastructure. 


\section{Detection and identification system}

The description of the detection and identification methode in this section can also be found in Schimmel et al. 2018. The driving idea of this work was to design a detection and identification system for different kinds of alpine mass movements which is low cost and can be easily installed. These requirement leads to a combination of one seismic and one infrasound sensor together with a microcontroller, where the detection algorithm can be executed. This detection system can be extended to a warning system which can be used for different applications: Protection of traffic lines by controlling a traffic light, protection of construction sites inside torrents (e.g. for cleaning up a basin after an event), or at sites where the necessary funding for expensive torrent and avalanche barriers is not available.

\subsection{Hardware setup}

For the current setup three different infrasound sensors and two different geophones are used. One infrasound sensor used at three test sites is the Chaparral Model 24 which has a sensitivity of $2 \mathrm{~V} / \mathrm{Pa}$ and a frequency range form 0.1 to $200 \mathrm{~Hz}$. As a second sensor we use the Chinese infrasound microphone MK-224 with a frequency range of $3 \mathrm{~Hz}$ to $200 \mathrm{~Hz}$ and a sensitivity of $50 \mathrm{mV} / \mathrm{Pa}$. Since both sensors are rather expensive, a cheaper alternative was found with an Electret-microphone of the type KECG2742WBL-25-L. Due to the use of this microphone the overall system costs could be reduced by a factor of six compared to the system cost with a Chaparral sensor. This Electret-microphone has a sensitivity of $-38 \mathrm{~dB}+-3 \mathrm{~dB}$ in the used frequency range, which results in around $13 \mathrm{mV} / \mathrm{Pa}$ and a typical frequency range of $20 \mathrm{~Hz}$ to $20 \mathrm{kHz}$. Because we use this microphone below $20 \mathrm{~Hz}$ and it has a large variation of sensitivity, it has to be calibrated which is done by comparing the signal with the Chaparral Model 24. As seismic sensors we used the Sensor NL SM-6 with a sensitivity of $28.8 \mathrm{~V} / \mathrm{m} / \mathrm{s}$ and a natural frequency of $4.5 \mathrm{~Hz}$ as well as the Sercel geophone SG-5 with a sensitivity of $80 \mathrm{~V} / \mathrm{m} / \mathrm{s}$ and a natural frequency of $5 \mathrm{~Hz}$.

For the ADC-Input of the microcontroller the sensor signals have to be adapted which is done by a non-inverting OPV-circuit (except for the Chapperal Model 24 where an inverting OPV-circuit is used). This input circuit also has a band pass filtering with a lower cut-off frequency of around $150 \mathrm{mHz}$ (for acoustic sensors) and an upper cut-off frequency of $150 \mathrm{~Hz}$ (acoustic and seismic sensors) included. These input signals are sampled by the microcontroller ADC with a sample rate of $100 \mathrm{~Hz}$ whereby a 32x hardware oversampling is used to avoid aliasing effects. For the data processing and as data-logger a Stellaris Evaluation-Board with the microcontroller LM3S8962 is used. This microcontroller is 
based on the 32-bit ARM-Cortex-3 architecture with a processor frequency of $50 \mathrm{MHz}$, $64 \mathrm{~KB}$ RAM and a Flash storage of $256 \mathrm{~KB}$. The evaluation board has four ADCs, two UART (universal serial input/output), several GPIOs (general purpose input/output) which can be used as alarm-outputs, an OLED display and offers the possibility for an Ethernet connection. The data can be stored on a micro SD-card where up to four months of data can be recorded continuously on a $16 \mathrm{~GB}$ card with the used file structure described in Section 2.2. Beside the input of the sensor signals the free ADCs offer the possibility to log the flow height measured by a radar or ultrasonic gauge, which can be used for event verification, and also the power supply voltage can be measured to check low power situations. If the test site is equipped with standard internet connection the communication with the system can be done over the Ethernet interface. If there is no router available, we use a GSM-module of the type SparqEE CELLv1.0 which is controlled over UART by AT-commands. The time synchronisation of the station is done either by connection with a timeserver over Ethernet, or by a GPS-module which is also connected over the UART. An overview of the hardware components and the inputs and outputs of the system is given in Figure 1.

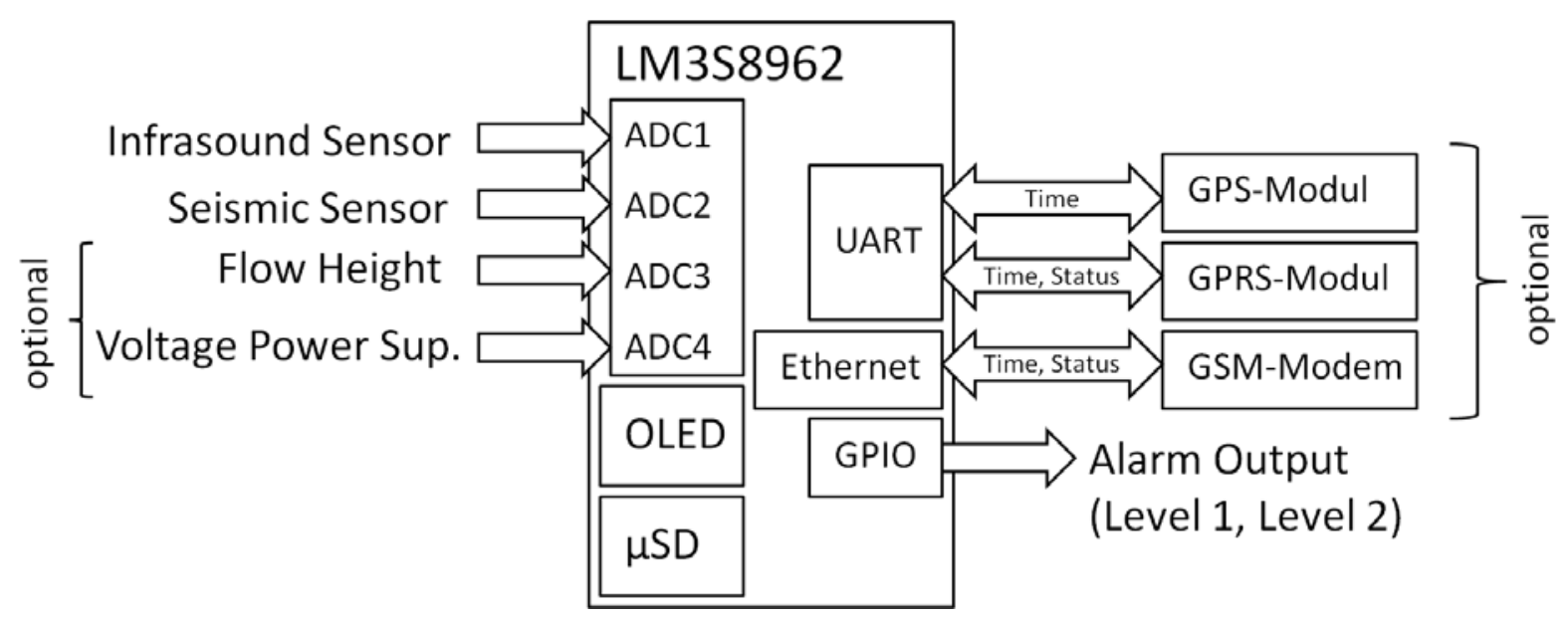

Figure 1: Overview system setup and components

The LM3S8962 operates with a voltage of $5 \mathrm{~V}$, which is provided by a DC-DC converter, which needs a power connection in a voltage range from 6,5 to $32 \mathrm{~V}$. The system has a power consumption below $1.5 \mathrm{~W}$ which makes this system very useful for stand-alone stations with solar power supply like it is typically used. The minimum solar power supply designed for this system should be based on $12 \mathrm{Wp}$ solar panel and a 16 Ah battery. 


\subsection{Software design}

The software for the microcontroller was written in $\mathrm{C}$ and is based on the open source runtime system FreeRTOS ${ }^{1}$. FreeRTOS offers the possibility to create several tasks with different priorities and cycling times. For this system six different tasks are used: The task with the highest priority is the measurement task, where the input signals are sampled with a sample rate of $100 \mathrm{~Hz}$, converted and stored in an array. This array offers the input for the detection task which is executed every second. This detection task is responsible for the signal processing (fast Fourier transform (FFT)) and runs the detection algorithm and identification methode which is described in Section 2.3 and 2.4. For the storage of the data to the micro-SD card a Log-Task is run every second. Three different files are created by this task: The raw data of the infrasound and seismic sensor are written into one text file and the output of the detection algorithm and ancillary data like flow height measured with an additional sensor and power supply voltage are written in another file. Both files are created every hour. Another file stores a summary of all log files and displays event detections or errors. For the control of the system time a time task is created. A control task controls the alarm outputs, the point in time for output messages and time synchronisation and reacts on inputs of the evaluation board keys. The output messages and the time synchronisation are done in a communication task where the Ethernet connection is used via LWIP (light-weight implementation of the TCP/IP protocol) or the GSM-module is controlled via UART. The system is designed to send a status message to a server every hour where the date of event detections or error messages are included. In case of an event the server creates e-mail alerts. On this server, a web server is installed as well, where the status and events at all Stations can be checked ${ }^{2}$. Table 1 shows a list of the used tasks, cycling time and their priorities in the FreeRTOS runtime.

\section{Table 1: FreeRTOS Tasks}

\begin{tabular}{c|c|c|c}
\hline Task Name & Description & Priority & Time Interval \\
\hline Measurement Task & Receiving signals from ADC & 6 (highest) & $10 \mathrm{~ms}$ \\
Detection Task & Calculate FFT, execute detection algorithm & 5 & $1 \mathrm{~s}$ \\
Time Task & Controls system time & 4 & $1 \mathrm{~s}$ \\
Log Task & Data logging to SD-card & 3 & $1 \mathrm{~s}$ \\
Control Task & Controls outputs and points in time for com. & 2 & $1 \mathrm{~s}$ \\
COM Task & Communication via Ethernet or UART & 1 (lowest) & 1s (on demand)
\end{tabular}

\footnotetext{
${ }^{1}$ www.freertos.org

${ }^{2}$ ian-infrasonic.boku.ac.at
} 


\subsection{Detection Algorithm}

The developed detection algorithm has to detect different kinds of events as soon as possible without many false alarms and with a relative low processing power, so that this algorithm can be executed on a resource-limited system like a microcontroller. This requirement leads to an algorithm which is based on an analysis of the temporal evolution of the frequency spectrum of the seismic and infrasound signals. Therefore the input signals which are sampled with $100 \mathrm{~Hz}$ are processed by fast Fourier transform (Bluestein FFT algorithm (Rabiner et al. 1969)) with 100 samples every second. Afterwards different frequency bands of the infrasound and seismic signals are analyzed and have to fulfil different detection criteria for a specific time span (detection time).

Three different criteria are applied to the infrasound signal: For the first criterion the average amplitude of a debris flow $\left(\bar{A}_{\text {DFlow }}\right)$ or debris flood $\left(\bar{A}_{\text {DFlood }}\right)$ frequency band has to exceed a threshold for the detection time. We use two different frequency bands for debris flow $(3-15 \mathrm{~Hz})$ and debris flood signals $(15-45 \mathrm{~Hz})$, because the peak frequency of the infrasound signals depend on the viscosity of the event (e.g. Kogelnig 2012). So these two frequency bands represent the typical signals of debris flows and debris floods. To distinguish between different event sizes two limits are used. Detections fulfilling the Level 1 - threshold $A_{\text {LimitL1 }}$ are mostly higher discharge with sediment transport or small debris floods, event detections at Level 2 (threshold $A_{\text {LimitL2 }}$ ) are typically "fully developed" debris flows and debris floods:

$$
\begin{aligned}
& \text { Level 1: } \bar{A}_{\text {DFlow }} \geq A_{\text {LimitL1 }} \text { or } \quad \bar{A}_{\text {DFlood }} \geq A_{\text {LimitL1 }} \\
& \text { Level 2: } \bar{A}_{\text {DFlow }} \geq A_{\text {LimitL2 }} \text { or } \quad \bar{A}_{\text {DFlood }} \geq A_{\text {LimitL2 }}
\end{aligned}
$$

As a second criterion the average infrasound amplitudes of the debris flow or debris flood frequency band has to be at least above a third (for debris flows) or a fourth (for debris floods) of the amplitudes of the frequency band below $\left(\bar{A}_{\text {low }}\right)$ :

$$
\bar{A}_{\text {DFlow }}>\frac{\bar{A}_{\text {low }}}{3} \text { or } \bar{A}_{\text {DFlood }}>\frac{\bar{A}_{\text {low }}}{4}
$$

This criteria mainly avoids false alarm due to wind which dominates this low frequency band. The wind produced amplitudes in this low frequency band $(\leq 2 \mathrm{~Hz})$ are usually at least three times higher than the amplitudes in the debris flow frequency band and at least four times higher than the amplitudes in the debris flood frequency band. In a former version (Schimmel et al. 2015, 2016) also a higher frequency band was used whose amplitudes had to be lower than the debris flow/debris floods bands amplitudes. Because 
debris floods with higher peak frequencies have not been detected by the algorithm including this criterion, it has been omitted and a larger detection time was chosen instead of this criterion.

The variance of amplitudes in the debris flow or debris flood frequency band is used by the third criterion of the detection algorithm. Since this variance of the amplitudes of the broad banded debris flow or debris flood signals is low compared to narrow banded signals from artificial sources (such as aircrafts, cars, machines...) this criterion efficiently reduces artificially caused false alarms. Therefore the variance of the amplitude $A_{\text {VarIS }}$ has to be under a certain limit $\left(A_{\text {VarLimit }}\right)$ :

$$
A_{\text {VarIS }} \leq A_{\text {VarLimit }}
$$

For the seismic signals only the amplitude and the variance criteria are used. Since the dependency of peak frequencies on the viscosity is not as significant as for infrasound signals, only one frequency band is used for debris flows and also for debris floods $\left(\bar{A}_{\text {DFlow/DFlood }}\right)$. For the classification of the event size, also two different limits $\left(A_{\text {LimitL1 }}, A_{\text {LimitL2 }}\right)$ are used:

$$
\begin{gathered}
\text { Level 1: } \bar{A}_{\text {DFlow/DFlood }} \geq A_{\text {LimitL1 }} \\
\text { Level 2: } \bar{A}_{\text {DFlow/DFlood }} \geq A_{\text {LimitL2 }} \\
A_{\text {VarGEO }} \geq A_{\text {VarLimit }}
\end{gathered}
$$

These criteria have to be fulfilled for the infrasound as well as for the seismic signals for the detection time threshold of $20 \mathrm{~s}$ to trigger an event detection. An illustration of this detection principle is shown in Figure 2 in a running spectrum of a debris flow infrasound signal.

With the combination of the seismic and infrasound signals we achieve a high detection ratio and a strong reduction of false alarms. For example at the test site Gadria in South Tyrol in 2016 the system would register more than hundred false alarms if only the infrasound or the seismic data is used. By the combination of both technologies, and the application of all criteria, the false alarms can be reduced to only two. If we omit the wind criterion (Equation 3), the false alarms will double, and if we omit the variance criterion (Equation 4), the false alarms will increase to 21 (Figure 3).

Because bedload transport processes as well as debris flows and debris floods can be detected, a further criterion is needed to enable identification of event type. Debris flows and debris floods typically occur in several surges and have a well-defined front compared 


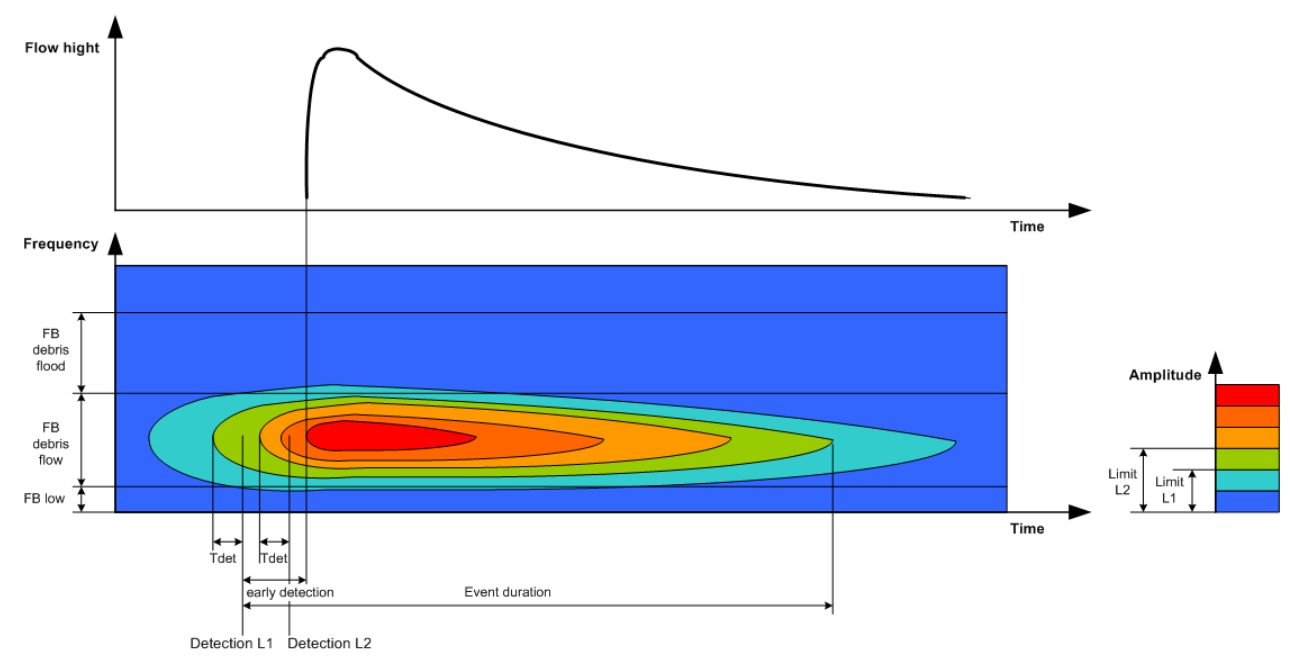

Figure 2: Illustration of an event detection depicted in a running spectrum of a debris flow infrasound signal

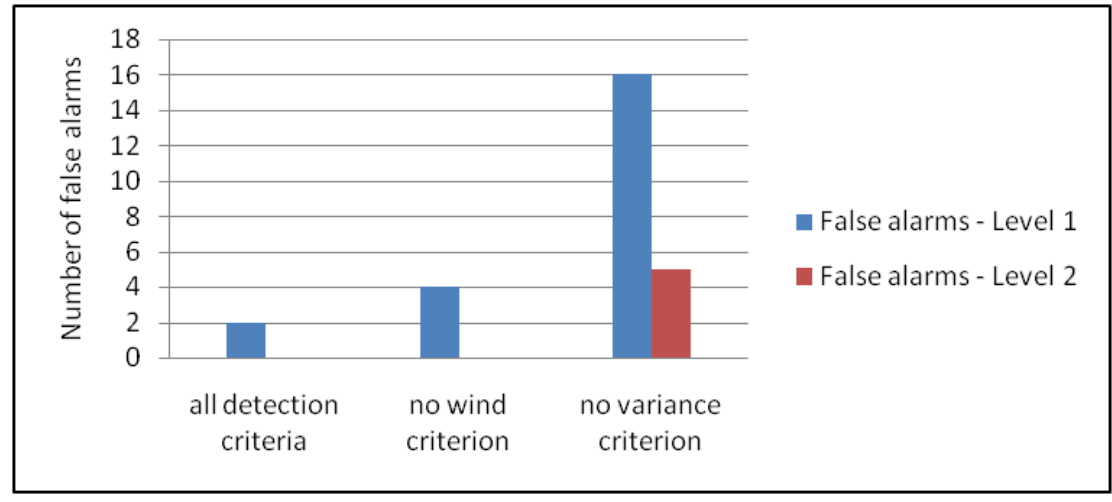

Figure 3: Effect of the different detection criteria on the false alarms at the test site Gadria in 2016

to bedload transport (e.g. Pierson 1986), so these event types can be identified by a rapid rise of the seismic or infrasound signal. For a debris flow/debris flood detection the seismic amplitude has to rise at least beyond the threshold used for the amplitude criterion during the detection time, whereby we also distinguish between Level $1\left(A_{\text {LimitL1 }}\right)$ and Level 2 ( $\left.A_{\text {LimitL2 }}\right)$ detections. Because the signal sequence of the seismic amplitudes is smoother than that for infrasound signals we use seismic amplitudes for this identification criteron. The parameters of the detection algorithm (Table 2) have been identified in an exhausting evaluation and optimization process and show good results at all test sites. Compared to the first version presented in Schimmel et al. 2016 we have adjusted the frequency bands of the infrasound signals in the low frequency range to ensure a better detection of very viscous debris flows which have their peak amplitudes in a low frequency range 
Table 2: Current settings for the detection algorithm

\begin{tabular}{c|c|c|c}
\hline & & Infrasound signal & Seismic signal \\
\hline Frequency band 1 & $F B 1_{\text {low }}-F B 1_{\text {high }}$ & 1 to $2 \mathrm{~Hz}$ & - \\
Frequency band 2 - debris flow & $F B 2_{\text {low }}-F B 2_{\text {high }}$ & 3 to $15 \mathrm{~Hz}$ & 10 to $30 \mathrm{~Hz}$ \\
Frequency band 3 - debris flood & $F B 3_{\text {low }}-F B 3_{\text {high }}$ & 15 to $45 \mathrm{~Hz}$ & 10 to $30 \mathrm{~Hz}$ \\
Limit for Amplitudes - Level 1 & $A_{\text {LimitL1 }}$ & $12 \mathrm{mPa}$ & $1 \mu \mathrm{m} / \mathrm{s}$ \\
Limit for Amplitudes - Level 2 & $A_{\text {LimitL1 }}$ & $30 \mathrm{mPa}$ & $2 \mu \mathrm{m} / \mathrm{s}$ \\
Limit for Variance & $A_{\text {VarLimit }}$ & \multicolumn{2}{|c}{0.8} \\
Time span for detection & $T_{\text {det }}$ & \multicolumn{2}{|c}{$20 \mathrm{~s}$} \\
\hline
\end{tabular}

$(<5 \mathrm{~Hz}$, Zhang et al. 2004). Furthermore the upper limit for the debris flood frequency band has been increased to enable better detection of certain debris floods with higher peak frequencies. For further applications of the system the parameters can be adapted to special requirements of the site, application and the background noise.

\subsection{Magnitude estimation}

The discharge of an event correlates with the infrasound and seismic energy (e.g. Hsu et al. 2011), so we compared the maximum infrasound and/or seismic amplitude with peak discharge of an event (Figure 4). The values for peak discharge and total volume used for this analysis are from Level 2 events of the test sites Lattenbach, Gadria and Illgraben (Table 3) and are estimated by flow height measurements and velocity estimations. Since all monitoring stations used for this study are rather close to the channel and the distances are nearly the same at every test site we neglected attenuation of the signals in the air or ground, the geometric spreading and effects of the topography or geology.

This analysis shows that for peak discharge, the infrasound amplitudes with a power curve fitting offers a good approach to find a first relationship between the recorded signals and this event parameter. This curve fitting provides an $R^{2}$ of 0.955 for peak discharge. The approximation for peak discharge $Q_{\text {peak }}\left(\mathrm{in}^{3} / \mathrm{s}\right)$ can be calculated based on the maximum infrasound amplitudes $A_{\mathrm{IS}(\max )}$ (in $\mathrm{mPa}$ ) according to Equation 8. The marked outlier in the upper range of the maximum amplitudes is produced by the event on 10.08.2015 at the test site Illgraben and has not been included in the curve fitting process.

$$
Q_{\text {peak }}=0.000732 A_{\mathrm{IS}(\max )}^{1.644}
$$

For an estimation of the total volume we sum up the discharge calculated with the relationship for peak discharge (Equation 8) for the entire detection time. Figure 5 compares the calculated values (vertical axis) for peak discharge and total volume to the observed 
Table 3: Peak discharge and total volume

\begin{tabular}{|c|c|c|c|}
\hline Test Site & Event-Date & $\begin{array}{c}\text { Peak-Discharge } \\
{\left[\mathrm{m}^{3} / \mathrm{s}\right]}\end{array}$ & $\begin{array}{c}\text { Total Volume } \\
{\left[\mathrm{m}^{3}\right]}\end{array}$ \\
\hline Lattenbach & 09.08 .2015 & 50 & 11500 \\
& 10.08 .2015 & 69 & 18500 \\
& 16.08 .2015 & 12 & 5000 \\
& 10.09 .2016 & 158 & 46000 \\
\hline Gadria & 15.07 .2014 & na & 10500 \\
& 08.06 .2015 & na & 9850 \\
& 12.07 .2016 & na & 1500 \\
\hline Illgraben & 22.07 .2015 & 17 & 8700 \\
& 10.08 .2015 & 7 & 6100 \\
& 14.08 .2015 & 7 & 25000 \\
& 15.08 .2015 & 3 & 2000 \\
& 12.07 .2016 & 15 & 10000 \\
& 12.07 .2016 & 65 & 60000 \\
& 22.07 .2016 & $50-90$ & $>10000$ \\
& 09.08 .2016 & 29 & $<10000$ \\
\hline
\end{tabular}

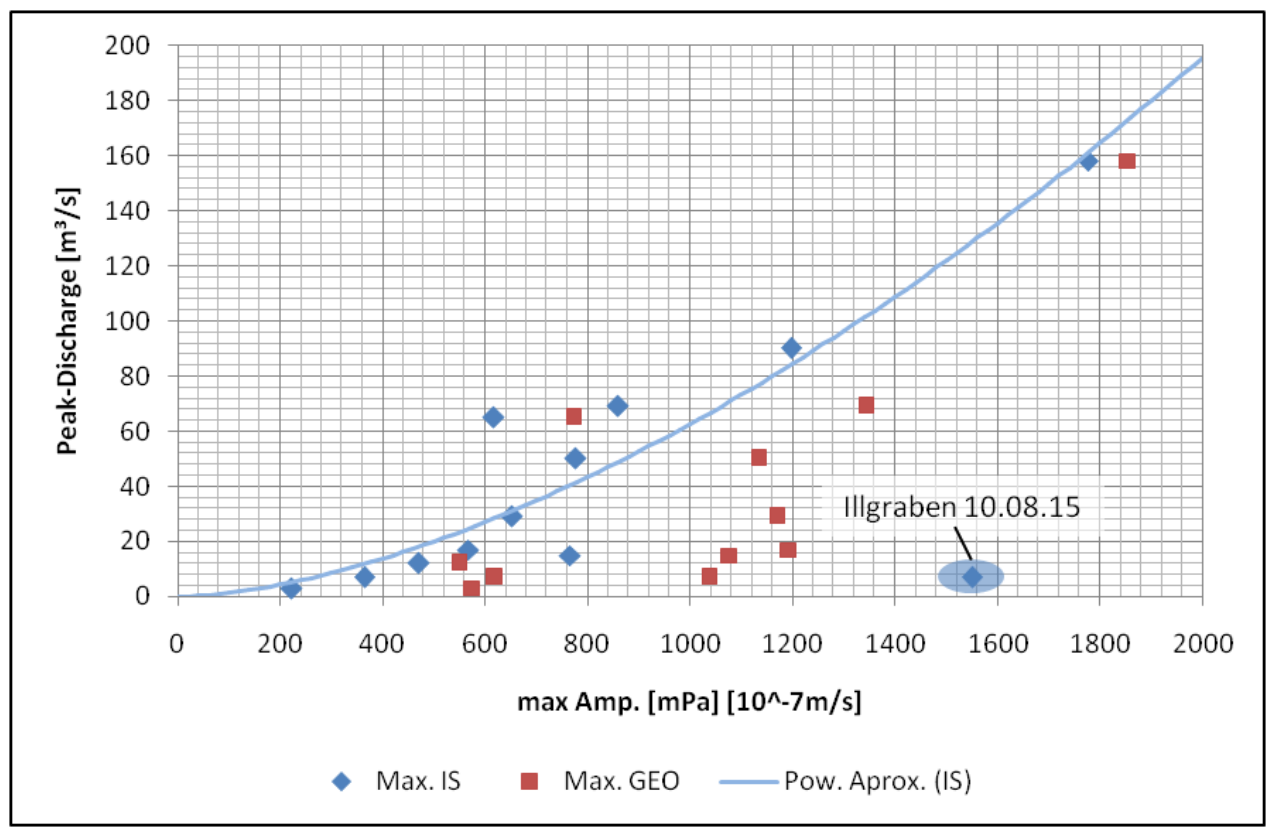

Figure 4: Peak discharge over maximum seismic (Max GEO) and infrasound amplitudes (Max IS) and the approximation based on infrasound data (Pow. Aprox.).

values (horizontal axis). The line represents the one-to-one relation.

Because the total volume is estimated by the sum over the event duration, this duration has to be defined based on the seismic and infrasound data which is done by the detection criteria. So the amplitude thresholds for the detection criteria also has an influence on the event duration and thus on the total volume estimation. 

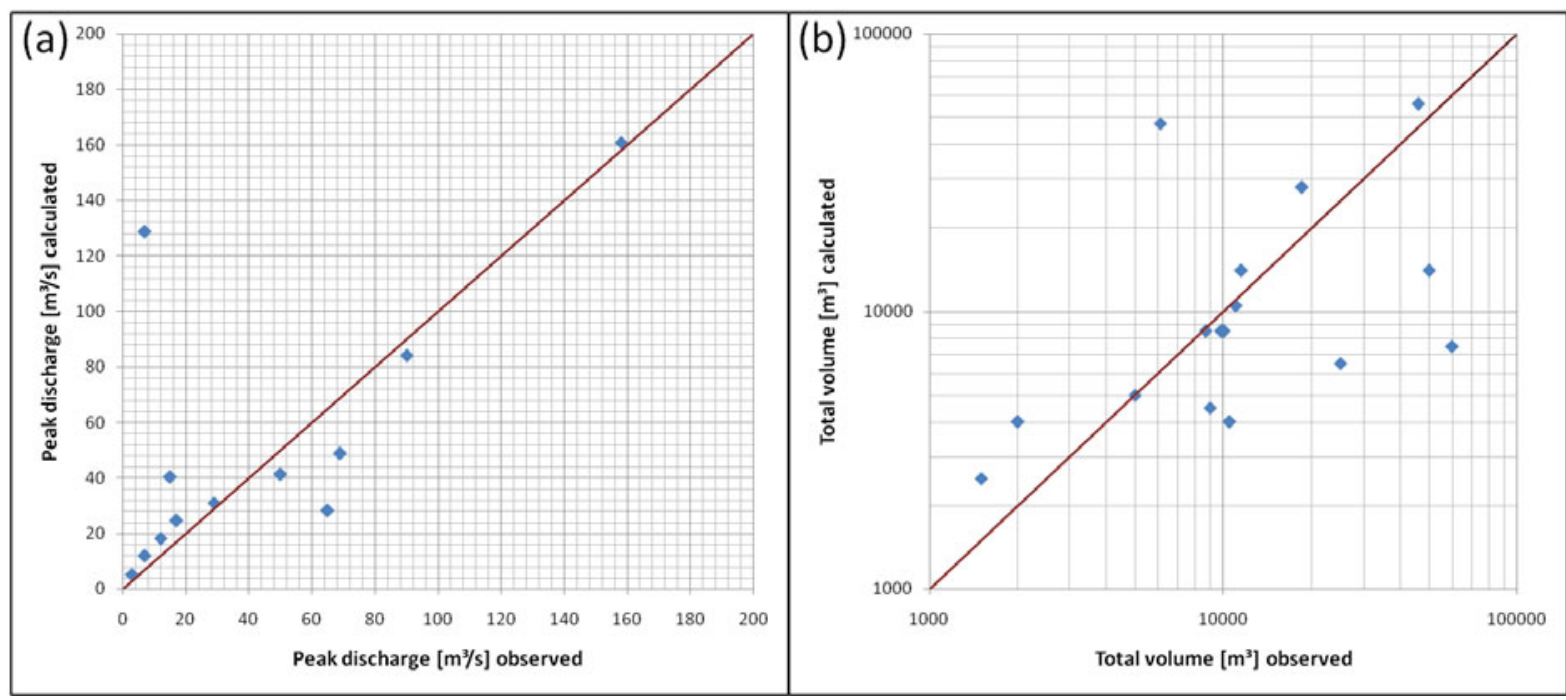

Figure 5: (a) Comparison of the calculated peak discharge to the observed values; (b) Comparison of the calculated total volume to the observed volume

Both diagrams suggest that it may be possible to obtain first-order estimates of the peak discharge and the total volume for debris flows and debris floods at different sites based on the infrasound amplitudes. The calculation of the peak discharge based on infrasound data offers a good approximation $\left(R^{2}=0.88\right)$, but for the calculation of the total volume this method shows a wide variance $\left(R^{2}=0.27\right)$. Additional data of different events will be necessary to develop a robust method for a magnitude identification. 


\section{Test Sites}

In the period from 2013 to 2017 up to eleven catchments (Figure 6) have been equipped with the system to detect and identify sediment related disasters.

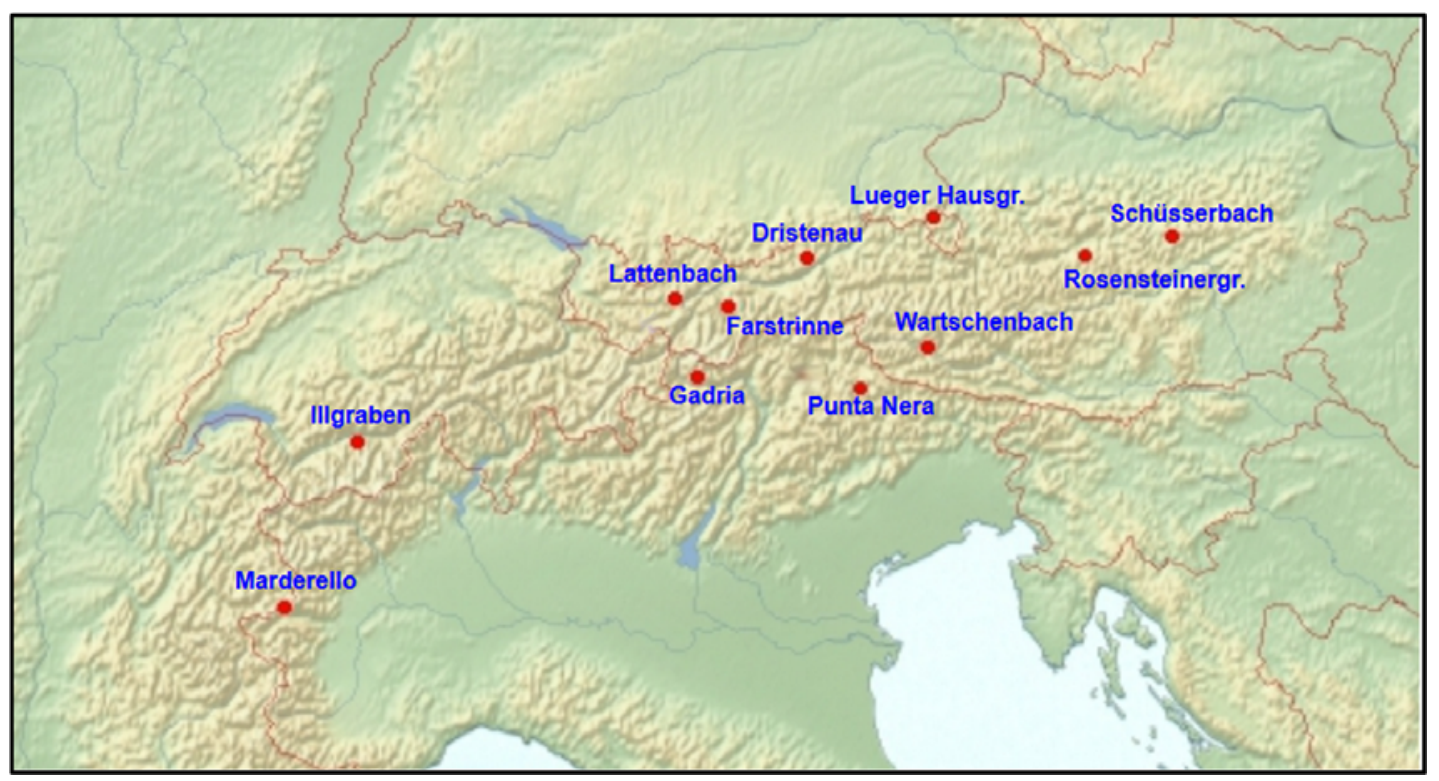

Figure 6: Overview of the test sites since 2013

In the period from 2013 to 2017 the Tyrolese torrents Lattenbach, Dristenau and Farstrinne and the Schüsserbach in Styria were equipped with the system. At the east Tyrolese test site Wartschenbach the system was operational in 2013, and from 2015 to 2017 . The system has been running at Illgraben, the Gadria and the catchment Marderello since 2015 and the Bavarian torrent Lueger Hausgraben is equipped with the system since summer 2016. In 2017 the detection system has also been installed at Punta Negra closed to Cortina d'Ampezzo (Italy) and at the Rosensteinergraben in Styria, Austria.

\subsection{Lattenbach}

The Lattenbach torrent in Tyrol, with a catchment area of $5.3 \mathrm{~km}^{2}$, is a monitoring site for debris flows operated by the Institute of Mountain Risk Engineering (BOKU, Vienna; Hübl et al. 2006). It is a very active torrent located in a geologic fault zone, thus it has a large supply of loose sediment. Three monitoring stations are installed along the torrent which are equipped with flow height (radar gauges), geophones, video cameras and meteorological monitoring stations, for example the amount and intensity of precipitation, air temperature, air moisture and radiation. Two of this station are 
installed closed together near the village Grins and a third monitoring station is installed down at the village Pians (Figure 7). At monitoring Station 2 also a 2D-Laser scanner in combination with a debris flow Puls-Doppler Radar (IBTP-Koschuch, (Koschuch et al., 2015)) for surface velocity can be used for a accurate estimation of the discharge and the total volume of debris flows. Since 2013, the detection system consisting of a Chaparral infrasound sensor and a SM-4 geophone (changed in 2014 to a SG-5 geophone) is installed at the test site near the monitoring Station 2. In 2015 the infrasound sensor was changed to an Electret-microphone and a second system, also based on a Electret-microphone and a SG-5 geophone, has been installed around $90 \mathrm{~m}$ upstream at Station 1.
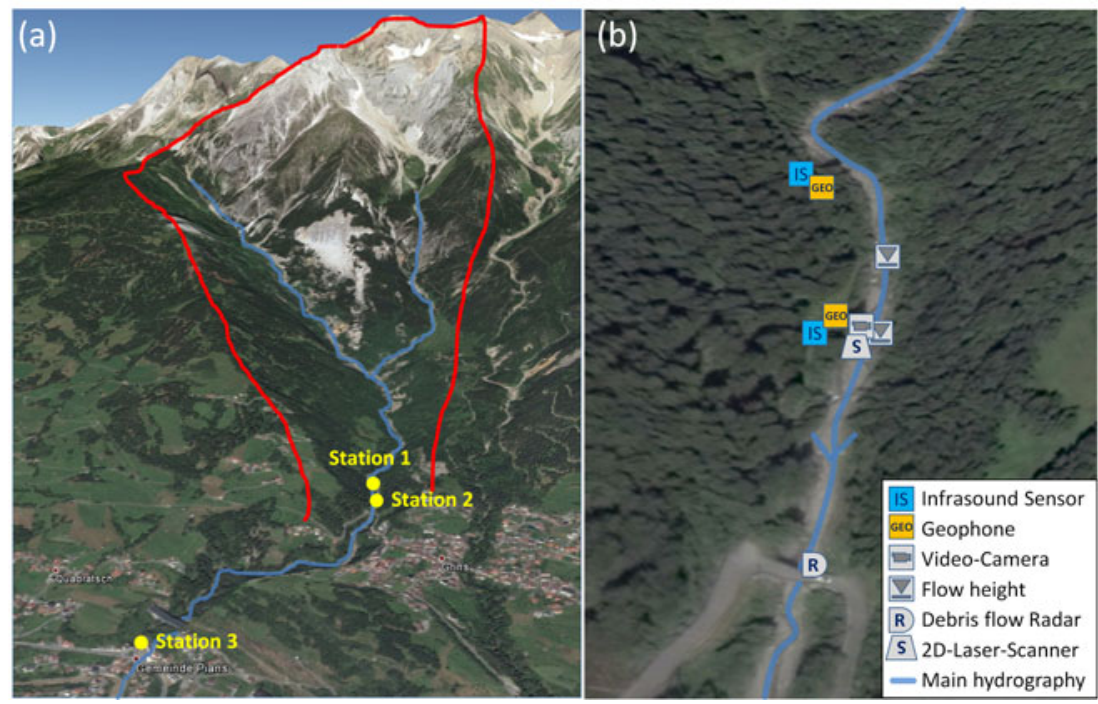

Figure 7: (a) Overview of the test site Lattenbach (red line: catchment area); (b) Closer view of the monitoring Station 1 und 2 and sensor setup (Source: Google Maps).

\subsection{Dristenau}

The Dristenau torrent with a catchment area about $9.9 \mathrm{~km}^{2}$ is located in the northern limestone alps near Pertisau in Tyrol. Frequent sediment transport and small debris floods occur in this torrent. Three monitoring stations (Figure 8) equipped with precipitation gauge, video camera, and flow height radar were installed, two in the upper part of the torrent and one closed to the village Pertisau. The detection system provided with a MK-224 infrasound sensor and a SM-4 geophone (which has been replaced with a SM6 geophone in 2015), has been installed in June 2013 closed to monitoring Station 1 (Figure 8b). During the season 2015 also a detection system based on a MK-224 and a SM-6 geophone was installed downstream at Station 2. 

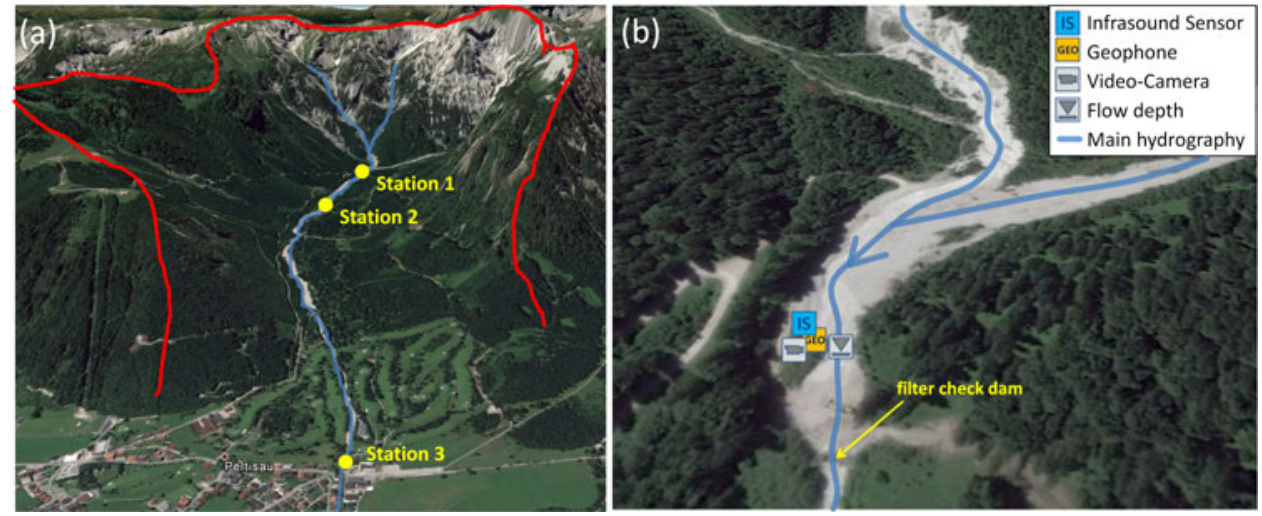

Figure 8: (a) Overview of the test site Dristenau (red line: catchment area); (b) Closer view of the monitoring Station 1 and sensor setup (Source: Google Maps).

\subsection{Farstrinne}

In 2013 the detection system has been installed at the torrent Farstrinne. This torrent is located near Umhausen in the Ötztal in Tyrol and has a catchment area of about $5.5 \mathrm{~km}^{2}$. The detection system equipped with a Chaparral infrasound sensor and a SG-5 geophone has been installed on the top of the dam of the upper retention basin (Figure 9). In August 2014, a debris flow Puls-Doppler Radar (IBTP-Koschuch, (Koschuch et al., 2015)) and a video camera have been also installed there.
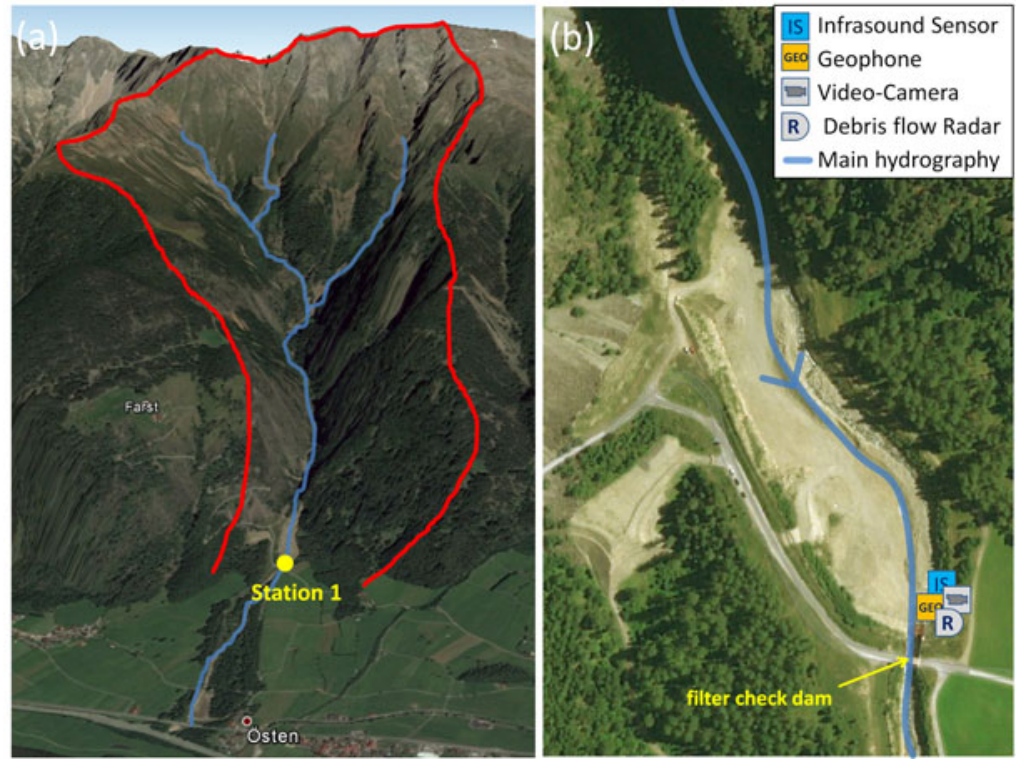

Figure 9: (a) Overview of the test site Farstrinne (red line: catchment area); (b) Closer view of the monitoring Station 1 and sensor setup (Source: Google/Bing Maps). 


\subsection{Wartschenbach}

After extreme events in 1995 and 1997 the Wartschenbach near Lienz in East Tyrol several active measures has been constructed and also monitoring stations as passive measures has been developed. The catchment area of $2.5 \mathrm{~km}^{2}$ extends form $2113 \mathrm{~m}$ a.s.l. down to the Lienzer valley at $670 \mathrm{~m}$ a.s.l. (Angerer et al. 2000). Since 2000 two stations, which are equipped with ultrasonic gauge and video cameras, are in operation and since 2013 also one of the infrasound/seismic detection systems has been installed at Station 2 (Figure 10). This system consist of a MK-224 infrasound sensor and a SM-4 geophone and has been installed on the top of the filter check dam "Griessmannsperre" around $130 \mathrm{~m}$ above the village "Wartschensiedlung".
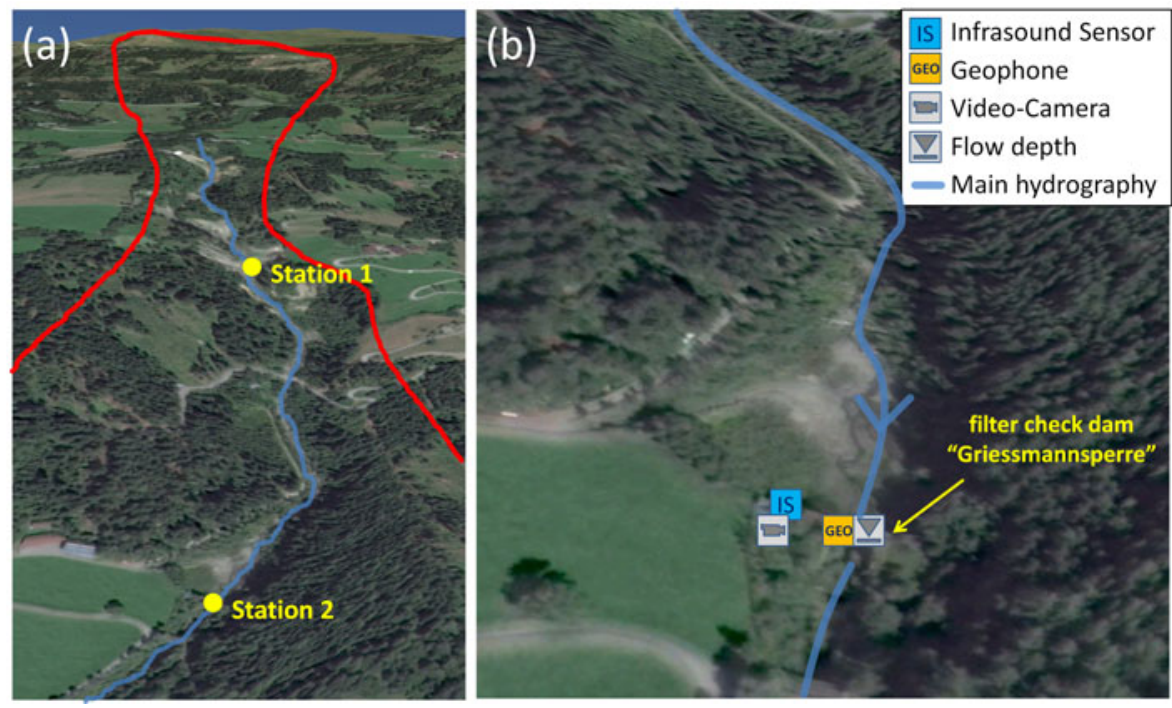

Figure 10: (a) Overview of the test site Wartschenbach (red line: catchment area); (b) Closer view of the monitoring Station 2 and sensor setup (Source: Google Maps).

\subsection{Schüsserbach}

The Schüsserbach is locate in the south-east of the Ennstaler Alpen closed to the village Radmer (Styria). The catchment area of $0.7 \mathrm{~km}^{2}$ extends from the summit "Lugauer" at $2217 \mathrm{~m}$ a.s.l down to $790 \mathrm{~m}$ a.s.l. where it flows into the Radmerbach (Figure 11). The torrent has been equipped with the detection system in August 2013. In the first years a MK-224 infrasound microphone was used, before the infrasound sensor has been changed to a Electret-microphone in 2017. As geophone a SG-5 was installed. Beside this detection system a warning system of the company SOMMER is installed at this test site, which detects debris flows based on flow height (radar sensor) and a geophone. 

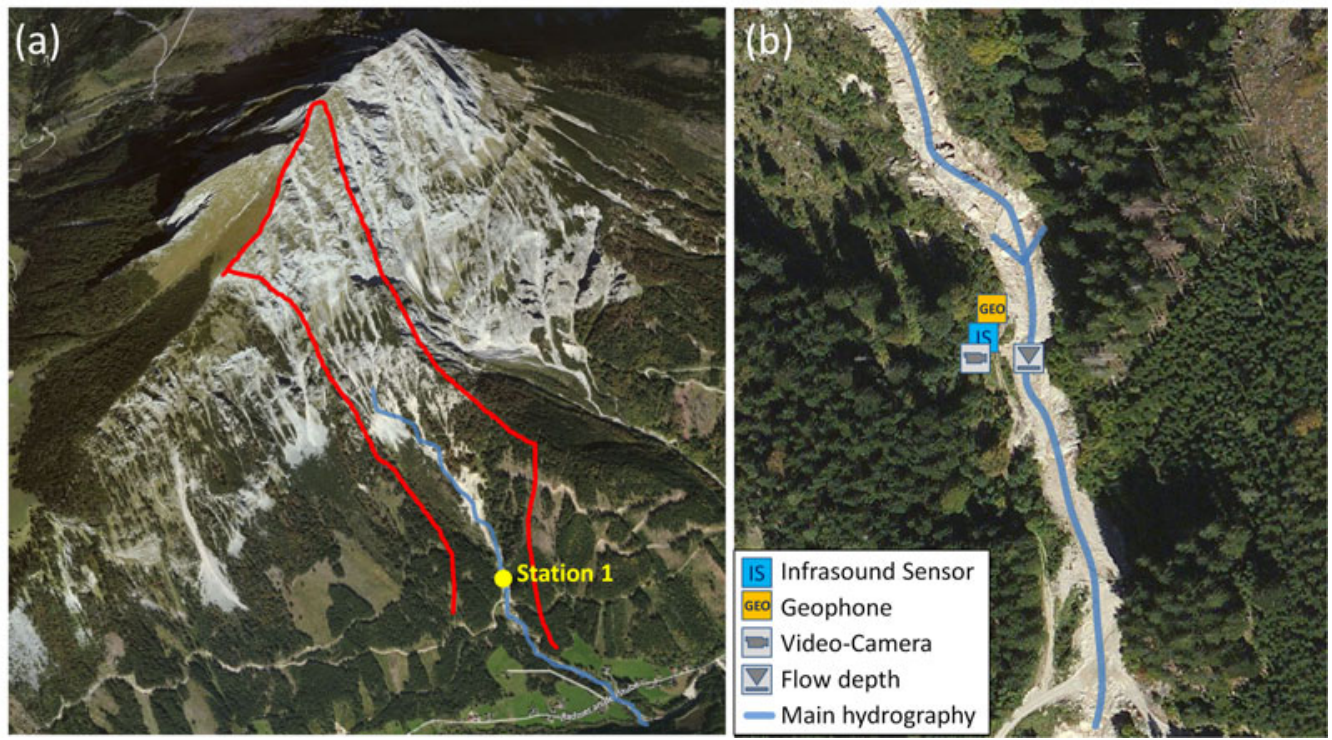

Figure 11: (a) Overview of the test site Schüsserbach (red line: catchment area); (b) Closer view of the monitoring Station 1 and sensor setup (Source: Google/Bing Maps).

\subsection{Gadria}

The Gadria-Strimm basins are located in the Vinschgau-Venosta valley, $30 \mathrm{~km}$ west of Meran-Merano in the North-eastern Italian Alps. In the catchment with an area of $6.3 \mathrm{~km}^{2}$ an average of 1-2 events occur per year, with volumes from 700 to $40,000 \mathrm{~m}^{3}$ per event (Comiti et al. 2014). The monitoring systems consists of rain gauges, radar sensors, geophones, video cameras, piezometers and soil moisture probes. Sensors have been installed in spring 2011 both in the Gadria and in the Strimm basins but the core of the monitoring lies within the Gadria as this is the channel featuring debris flows. Debris flow depth is monitored by radar sensors at 3 cross-sections along the Gadria main channel and vertical geophones have been installed at the same locations of the radar sensors in the Gadria channel since 2012. In order to provide visual information on debris flow characteristics, a series of video cameras with spotlights have been installed at the filter check dam and at other crucial locations. The detection system, which consists of an Electret-microphone and a SM-6 geophone, has been installed at the torrent since 2015 (Figure 12). 

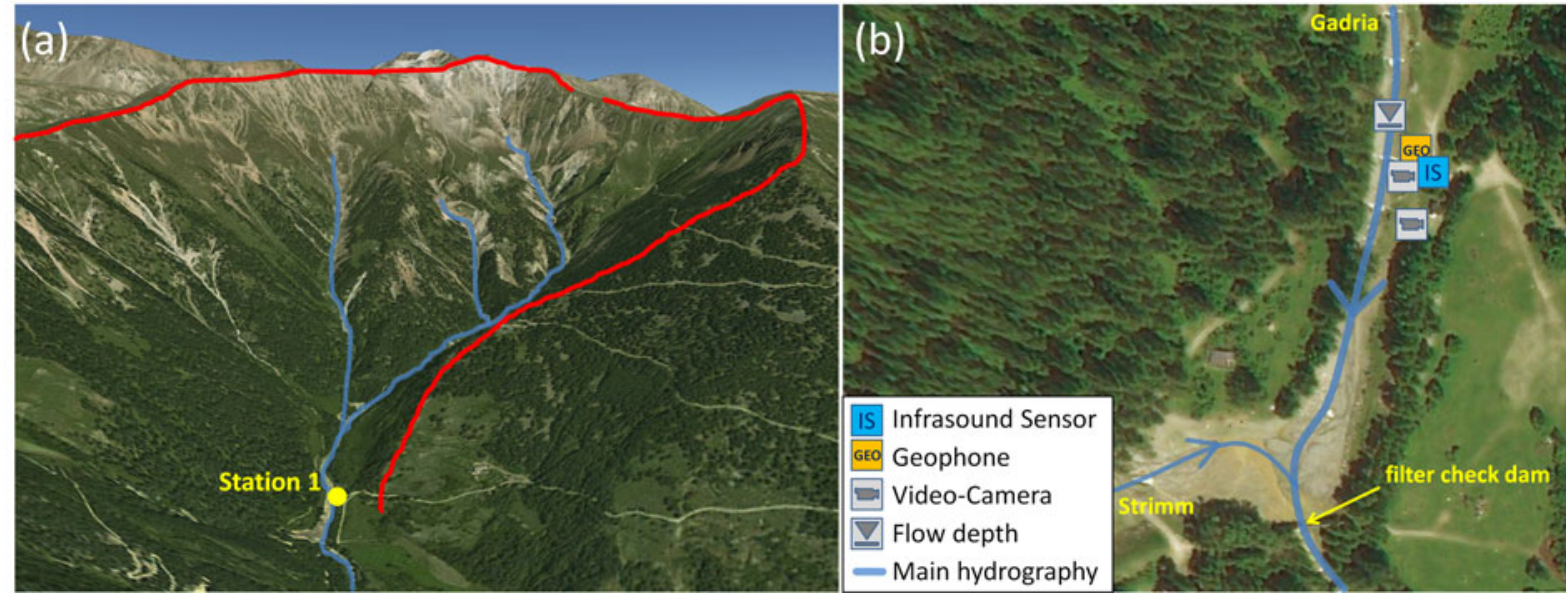

Figure 12: (a) Overview of the test site Gadria (red line: catchment area); (b) Closer view of the monitoring Station 1 and sensor setup (Source: Google/Bing Maps).

\subsection{Illgraben}

In 2015 the system has been installed at the Illgraben, which is located near Leuk in the canton Vallis in Switzerland. The catchment area of $9.5 \mathrm{~km}^{2}$ extends from the summit of the Illhorn at $2716 \mathrm{~m}$ a.s.l. down to the Rhône valley at $610 \mathrm{~m}$ a.s.l.. This is one of the most active debris flow catchments in the Alps (McArdell 2009, Badoux et al. 2009), where up to seven debris flow or debris flood events with an annual sediment discharge of several hundred thousand metric tonnes (Schlunegger et al. 2009) occur in this catchment every year, with a great variability of flow properties. The test site is well equipped with ultrasonic and radar level sensors, geophones, force plates and video cameras along the whole channel. Since 2015 two of the infrasound/seismic detection systems have been installed at the Illgraben catchment (Figure 13). One of them is placed in the upper catchment area directly at the canyon rim (Station 1 in the overview at Figure 13a). This station, which was only installed in the season 2015 and 2016, was equipped with a Chaparral infrasound sensor and a SG-5 geophone. The other station (Station 2) comprises of an Electret-microphone and a SM-6 geophone and is located down in the valley close to the channel mouth at check dam 27.

\subsection{Marderello}

The Marderello catchment is located in the north-western Italian Alps as an east tributary to the Cenischia valley. It has a catchment area of $6.61 \mathrm{~km}^{2}$ where the upper basin altitude is at $3538 \mathrm{~m}$ a.s.l. at the Rocciamelone Mt. and reaches down to the village Novalesa at an altitude of $900 \mathrm{~m}$ a.s.l. with an average slope gradient of $60 \%$. Frequent mud 

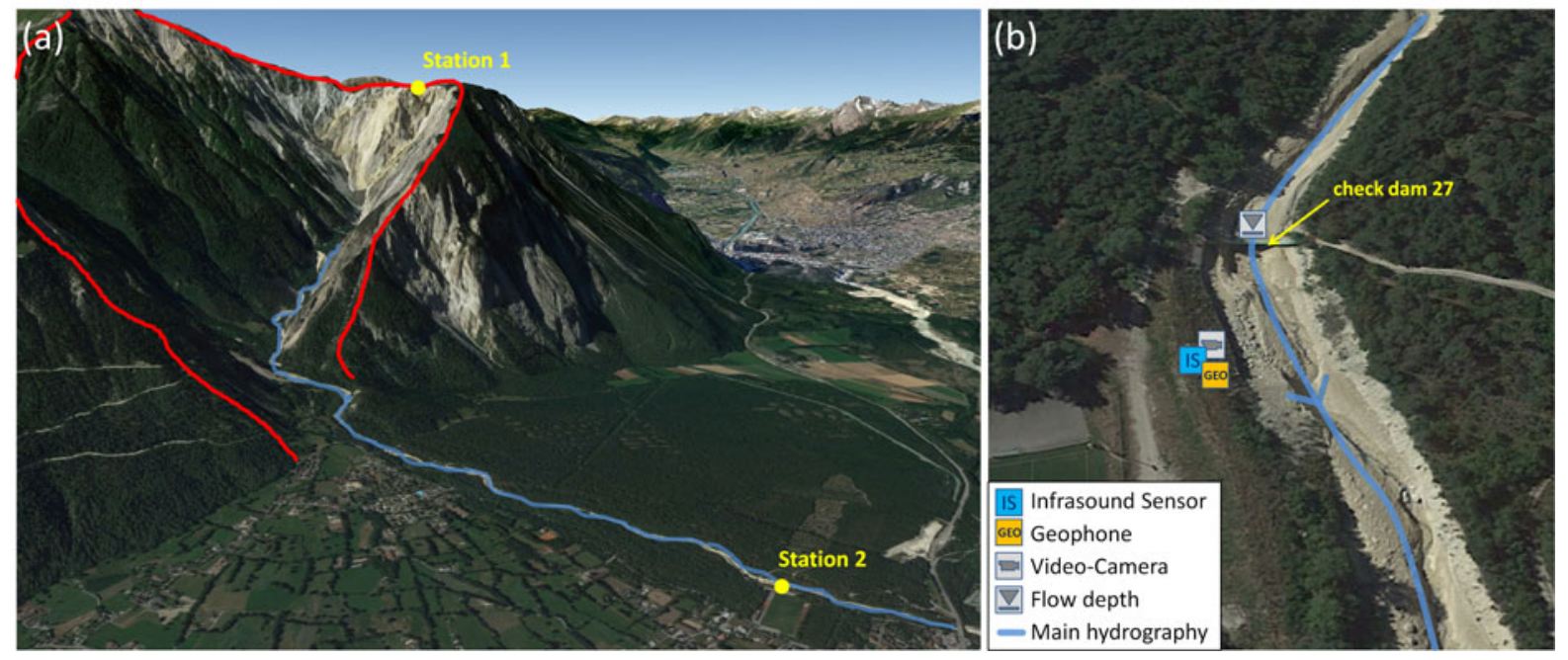

Figure 13: (a) Overview of the test site Illgraben (red line: catchment area); (b) Closer view of the monitoring Station 2 and sensor setup (Source: Google Maps).

flows and debris flow events occur at this catchment so first monitoring activities were started in 1994 and in 2013 the monitoring system was improved. The equipment at the site includes one ultrasonic gauge, two rainfall stations, three video cameras and four geophones (Turconi et al. 2015). In the year 2015 the detection system based on a Chaparral Model 24 infrasound sensor and a geophone of the type Sercel SG-5 was installed at the lower part of the catchment close to the indicated monitoring Station 1 in Figure 14. On regional distinctions of this test site is the cascade which is about $450 \mathrm{~m}$ upstream to the monitoring station.
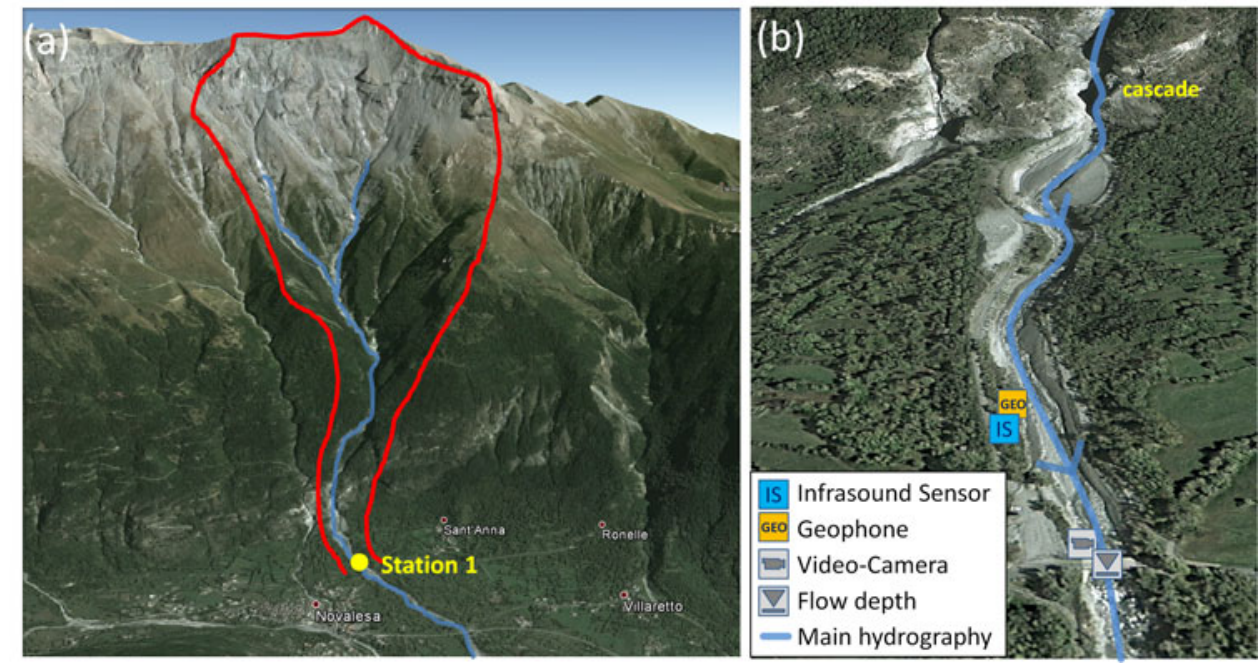

Figure 14: (a) Overview of the test site Marderello (red line: catchment area); (b) Closer view of the monitoring Station 1 and sensor setup (Source: Google Maps). 


\subsection{Lueger Hausgraben}

Since 2016 also the Bavarian test site Lueger Hausgraben is equipped with the detection system. This small catchment, with an area of $0.2 \mathrm{~km}^{2}$, endangers the state road B21 near Bad Reichenhall (Figure 15). In 2016 two rockfall-nets has been installed inside the catchment to protect the road. This rockfall-nets has been equipped with load cells for wire rope measuring to identify the anchor forces in case of an event. The detection system is used for the triggering of the whole measurement system. The installed system consist of one Electret-microphone and three SG-5 geophones, which can be used to test array processing methods for debris flows and to determine the front velocity of an event.
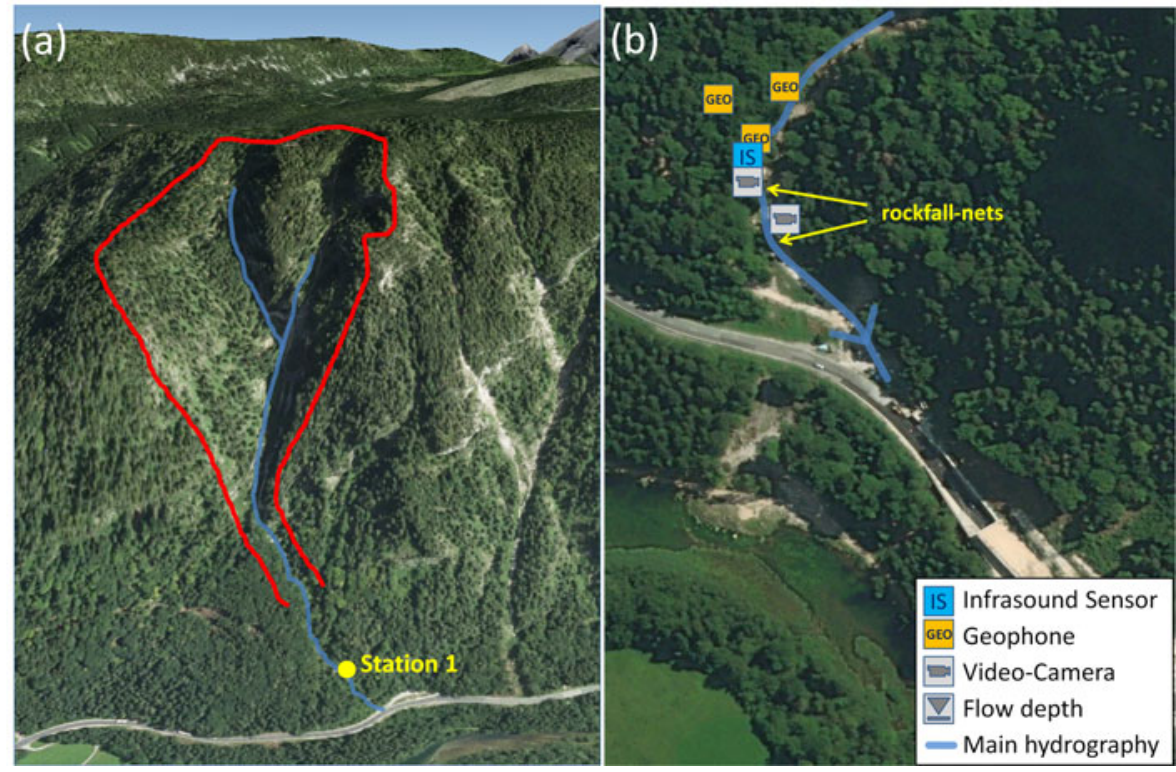

Figure 15: (a) Overview of the test site Lueger Hausgraben (red line: catchment area); (b) Closer view of the monitoring Station 1 and sensor setup (Source: Google/Bing Maps).

\subsection{Punta Negra}

In 2017 the catchment Punta Negra has been equipped with the detection system (Figure 16). This very active torrent near Cortina d'Ampezzo in north Italy has a catchment area of around $0.4 \mathrm{~km}^{2}$ and is equipped with very different monitoring systems like tilt sensors (for warning purpose - controlling a traffic light at the state road) flow height measurement, video camera and meteorological stations. The detection system installed in the middle part of the torrent consists of a Electret-microphone and a SM-6 geophone. 


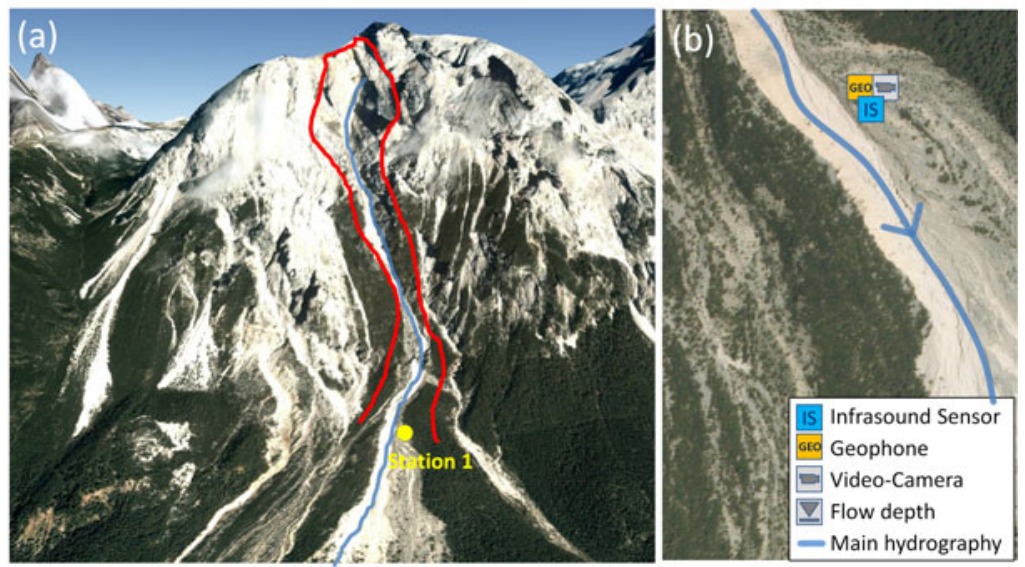

Figure 16: (a) Overview of the test site Punta Negra (red line: catchment area); (b) Closer view of the monitoring Station 1 and sensor setup (Source: Google Maps).

\subsection{Rosensteinergraben}

After a debris flow at the Rosensteinergraben in June 2017, which has damaged the state road B75 (Glattjoch-road) between Donnersbach and Donnersbachwald (Styria, Austria), a warning system that controls a traffic light at the B75 has been installed at this catchment. The Rosenstienergraben is part of the Wölzer Tauern and has a catchment area of $3.3 \mathrm{~km}^{2}$ with a total length of $3552 \mathrm{~m}$ (Figure 17). The warning system consists of the system MOSES (Torrent and Avalanche Control, WLV), which is based on a flow height and velocity radar, in combination with the detection system based on a Electret-microphone and a SM-6 geophone. In case of an event both system can trigger over a radio link the traffic light which is located on the B75 around $600 \mathrm{~m}$ downstream.

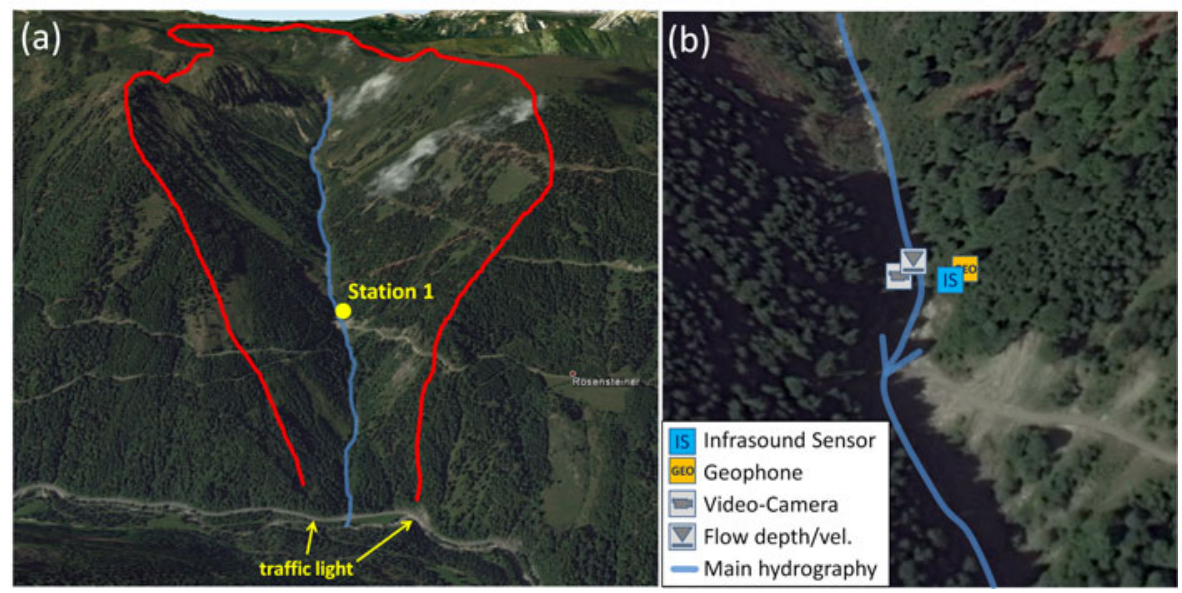

Figure 17: (a) Overview of the test site Rosensteinergraben (red line: catchment area); (b) Closer view of the monitoring Station 1 and sensor setup (Source: Google Maps). 


\section{Example Events}

\subsection{Events Lattenbach}

This section describes four events which occurred in 2015 and 2016 at the test site Lattenbach. The first two debris flows shown here were recorded in the night from the 09.08.2015 to 10.08.2015. The presented signals of this debris flows (Figure 20 and Figure 21) are from the upper Station 1 so the depicted flow depth was recorded about $90 \mathrm{~m}$ downstream of the station. The signals of the upper Station 1 is only used for this both events, because Station 2 did not work properly during that time. All other presented events of the Lattenbach are examples from Station 2 since this can be better compared to the flow depth which is recorded closed to that station. At 20:03 CET the first debris flow with a total volume of $11600 \mathrm{~m}^{3}$ and a peak discharge of $50 \mathrm{~m}^{3} / \mathrm{s}$ occurred. The first event (Figure 20) was detected by the system at $3665 \mathrm{~s}$ for Level 1 and $3685 \mathrm{~s}$ for Level 2 which results in an early detection time of $15 \mathrm{~s}$ for Level 1 before the event passes the sensor site (at $3680 \mathrm{~s}$ ) and the Level 2 detection was $5 \mathrm{~s}$ after the passing. The maximum infrasound amplitudes was registered with $776 \mathrm{mPa}$ at $16 \mathrm{~Hz}$ and the maximum seismic amplitude of $113 \mu \mathrm{m} / \mathrm{s}$ were recorded at $29 \mathrm{~Hz}$. If the method for the discharge estimation presented at Section 2.4 is applied to the infrasound signal, the peak discharge is calculated to $41 \mathrm{~m}^{3} / \mathrm{s}$ and the total volume to $13430 \mathrm{~m}^{3}$. Figure 18 compares the discharge and total volume estimation based on the infrasound signal to the discharge calculated on the 2D-Laser scanner data and the velocity measured by the Puls Doppler radar. The total volume can be determined by summing up the discharge over the event time. This method results in an underestimation of the discharge based on the infrasound signal for the first time section of the debris flow and an overestimation in the second part of the debris flow duration.

A few hours later at 23:01 CET the second debris flow occurred at the Lattenbach (Figure 21). This second event was a bit lager than the first one with a peak discharge of $69 \mathrm{~m}^{3} / \mathrm{s}$ and a total volume of $18500 \mathrm{~m}^{3}$. This event could be detected by the detection algorithm at $3540 \mathrm{~s}$ for Level 1 and $3546 \mathrm{~s}$ for Level 2 which results in a early detection time of $0 \mathrm{~s}$ and $-6 \mathrm{~s}$ respectively (passing of the event at $3540 \mathrm{~s}$ ). So both events could only be detected by the algorithm when they already passes the sensor site. The maximum infrasound amplitudes was again measured at $16 \mathrm{~Hz}$ with $859 \mathrm{mPa}$ and the maximum seismic amplitudes was $134 \mu \mathrm{m} / \mathrm{s}$ at $22 \mathrm{~Hz}$. If the calculated discharge based on the infrasound signal and the measured discharge of this event is compared over the event duration (Figure 19) a wide variance is obvious. The resuming total volume is overestimated by 
over $9000 \mathrm{~m}^{3}$ with the method based on the infrasound signals, while the peak discharge is underestimated with a value of $49 \mathrm{~m}^{3} / \mathrm{s}$.

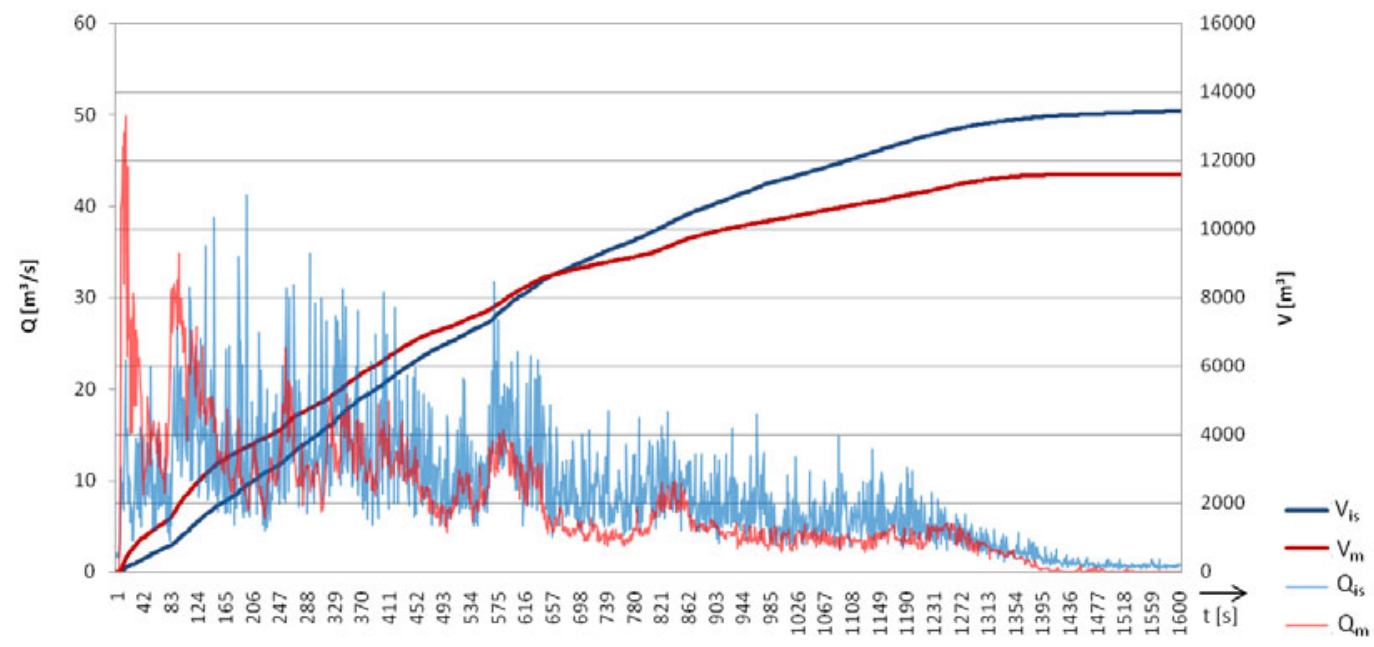

Figure 18: Calculated discharge $\left(\mathrm{Q}_{\mathrm{is}}\right)$ and calculated volume $\left(\mathrm{V}_{\text {is }}\right)$ based on infrasound data compared to measured discharge $\left(\mathrm{Q}_{\mathrm{m}}\right)$ and measured volume $\left(\mathrm{V}_{\mathrm{m}}\right)$ of the debris flow at Lattenbach on 09.08.2015.

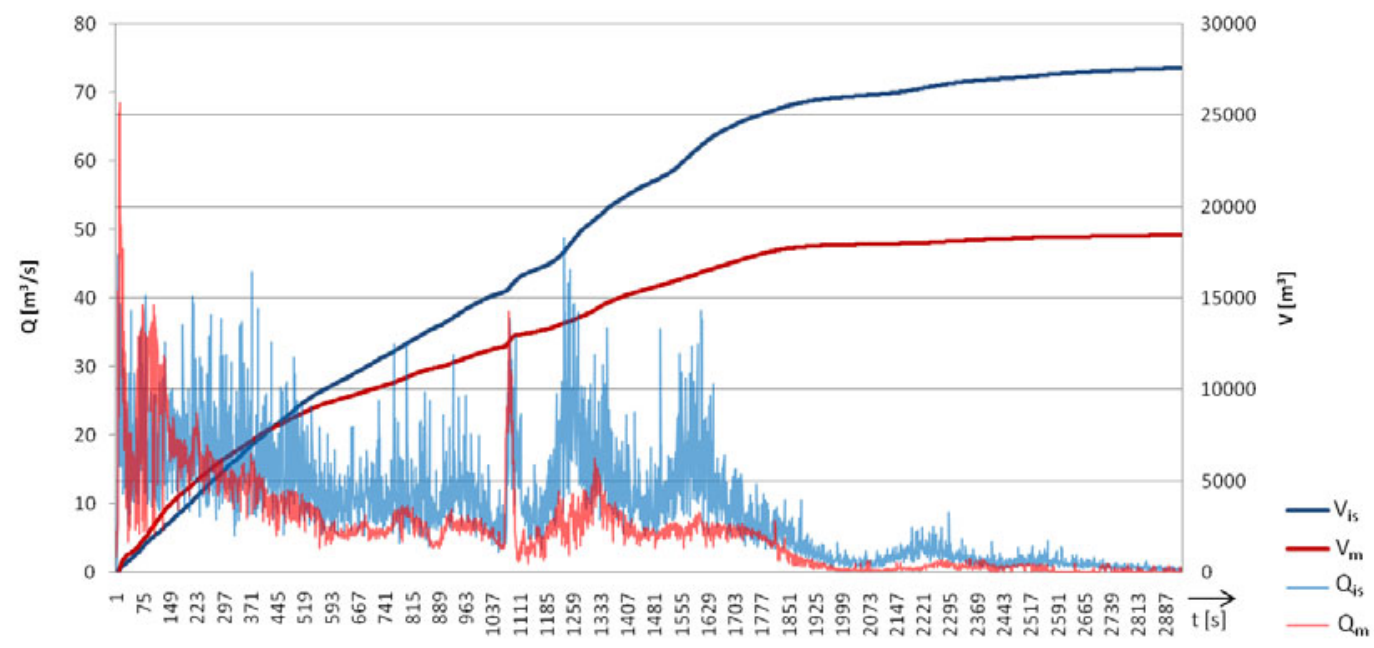

Figure 19: Calculated discharge $\left(\mathrm{Q}_{\mathrm{is}}\right)$ and calculated volume $\left(\mathrm{V}_{\text {is }}\right)$ based on infrasound data compared to measured discharge $\left(\mathrm{Q}_{\mathrm{m}}\right)$ and measured volume $\left(\mathrm{V}_{\mathrm{m}}\right)$ of the debris flow at Lattenbach on 10.08.2015. 
a)

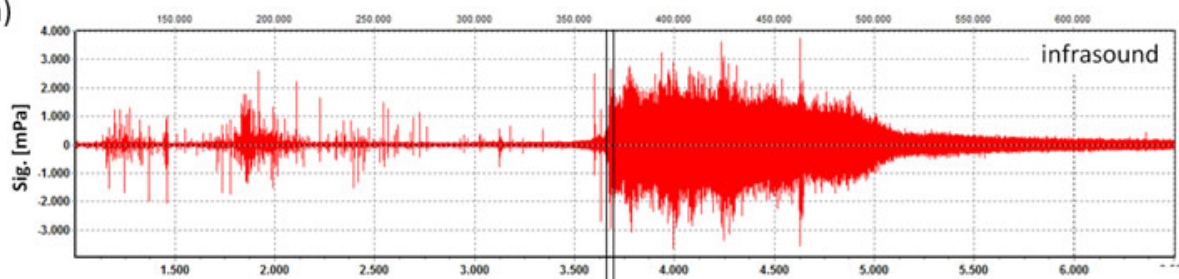

b)

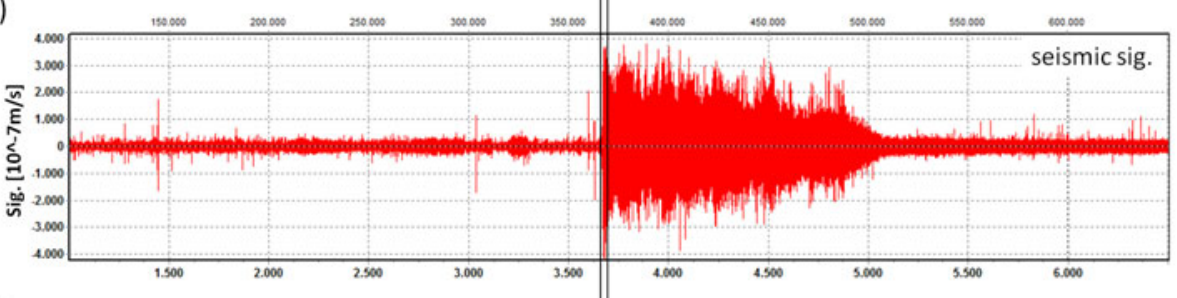

c)

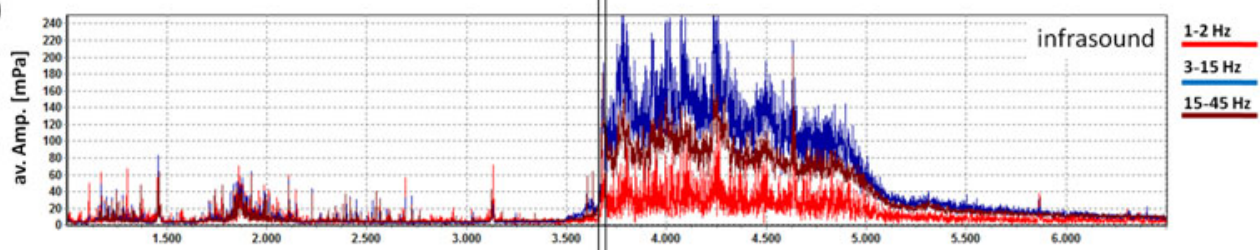

d)

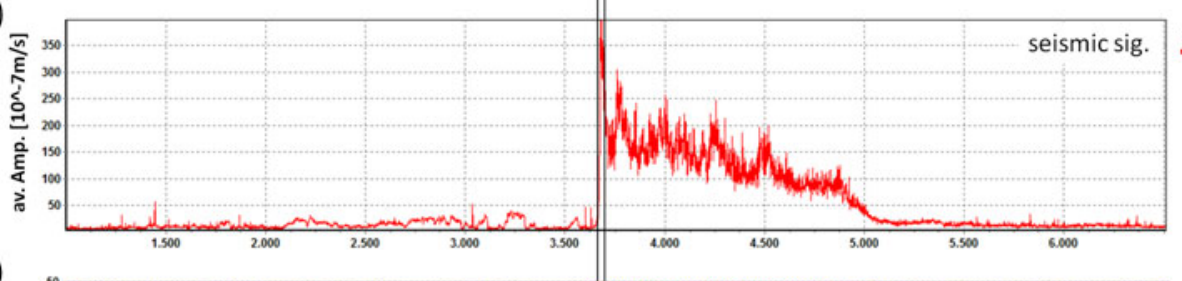

$10-30 \mathrm{~Hz}$

e)

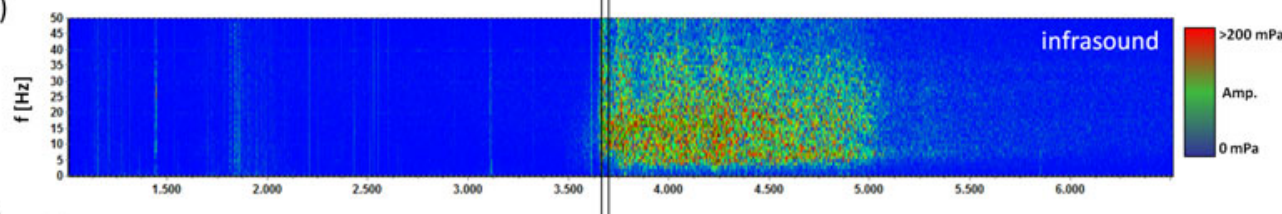

f)
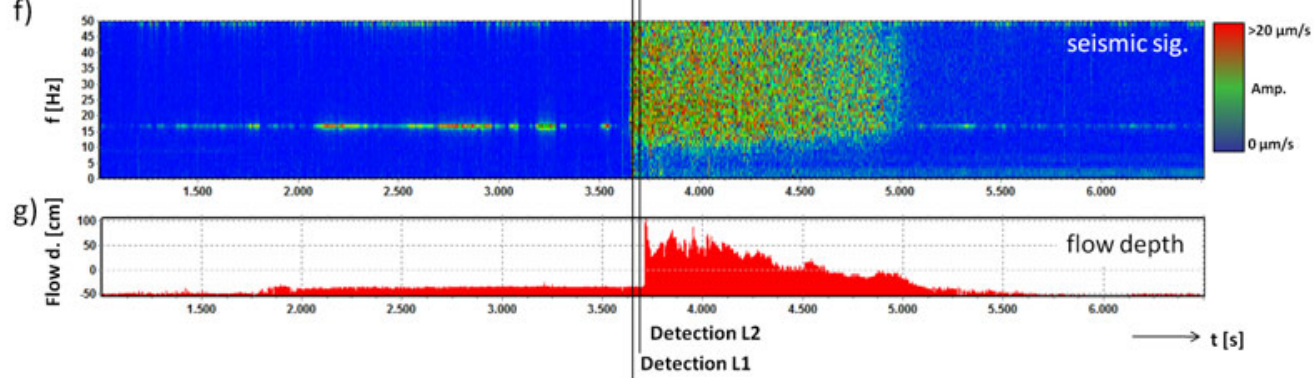

Figure 20: Infrasound and seismic data of the debris flow monitored at the test site Lattenbach (Station 1) on 09.08.2015. Signals are represented with a common base of time. (a) Infrasound time series; (b) Seismogram; (c) Average amplitude of the three frequency bands of the infrasound signal; (d) Average amplitude of the frequency band of the seismic signal; (e) Running spectrum of the infrasound signal; (f) Running spectrum of the seismic signal; (g) Flow depth ( $\sim 90$ m downstream); Lines: time of first detection for Level 1 and Level 2. 
a)

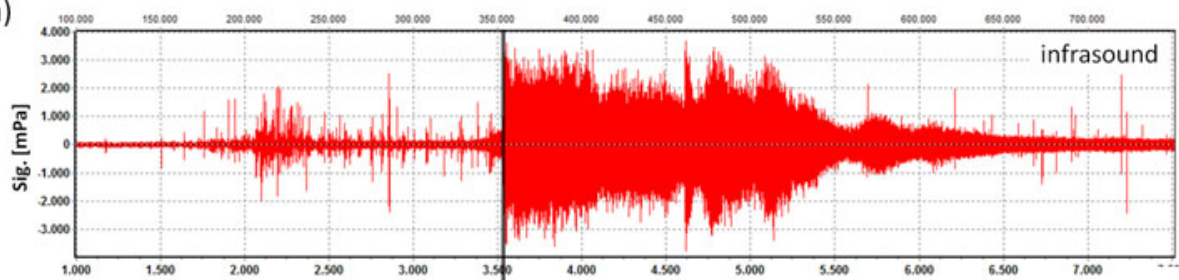

b)

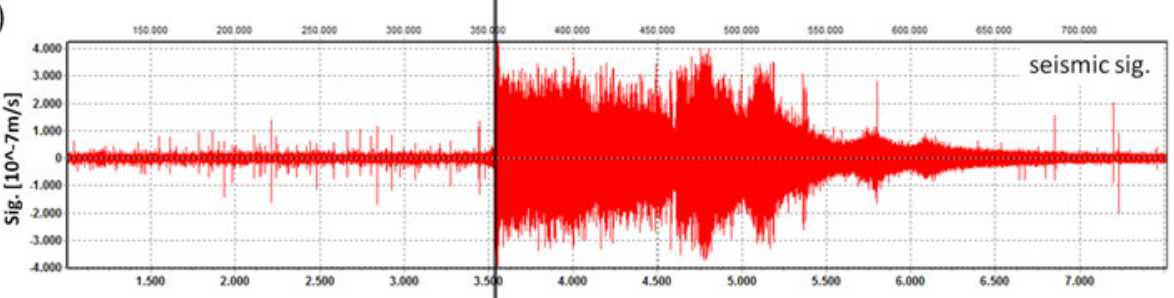

c)

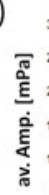

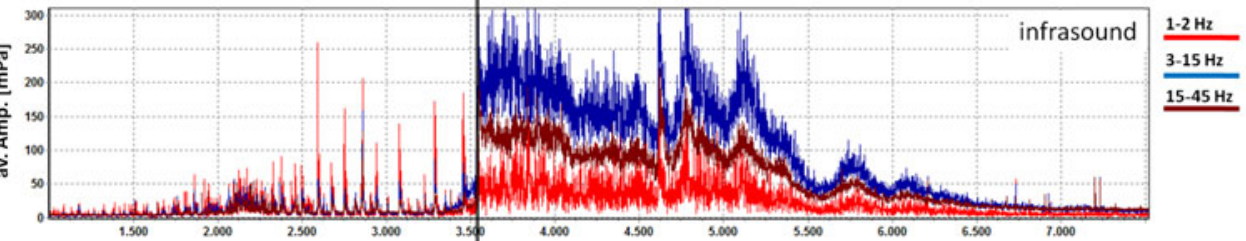

d)

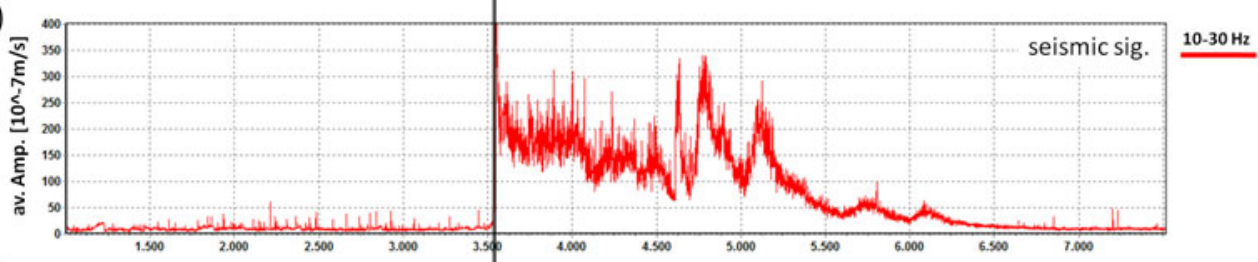

e)
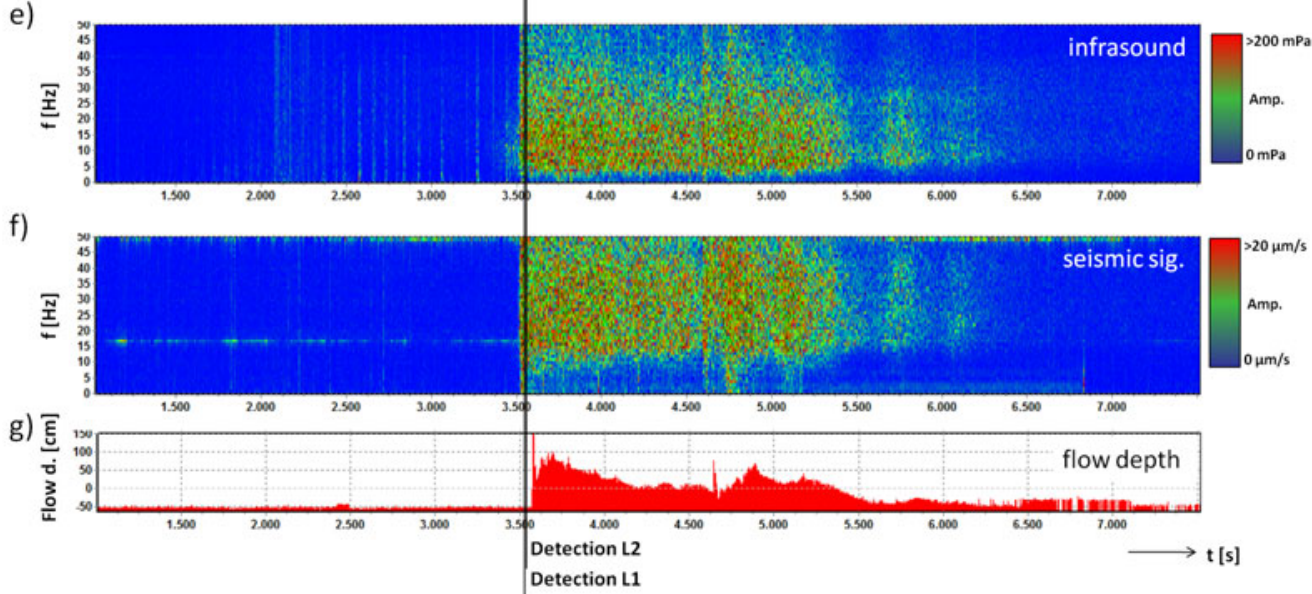

Figure 21: Infrasound and seismic data of the debris flow monitored at the test site Lattenbach (Station 1) on 10.08.2015. Signals are represented with a common base of time. (a) Infrasound time series; (b) Seismogram; (c) Average amplitude of the three frequency bands of the infrasound signal; (d) Average amplitude of the frequency band of the seismic signal; (e) Running spectrum of the infrasound signal; (f) Running spectrum of the seismic signal; (g) Flow depth ( $~ 90$ m downstream); Lines: time of first detection for Level 1 and Level 2. 
Only six days later on the 16.08.2015 a third event occurred at the Lattenbach (Figure 23). This event was smaller then the two events on 09.08.2015 and was more like a mud flow process. The detection algorithm could identify this event at $2912 \mathrm{~s}$ (Level 1) and $2938 \mathrm{~s}$ (Level 2) and therefore this event was detected $40 \mathrm{~s}$ and $14 \mathrm{~s}$ respectively, before passing of the sensor site $(2952 \mathrm{~s})$. The maximum seismic amplitudes was registered at $25 \mathrm{~Hz}$ with $55 \mu \mathrm{m} / \mathrm{s}$ and the maximum infrasound signals were $471 \mathrm{mPa}$ at $6 \mathrm{~Hz}$.

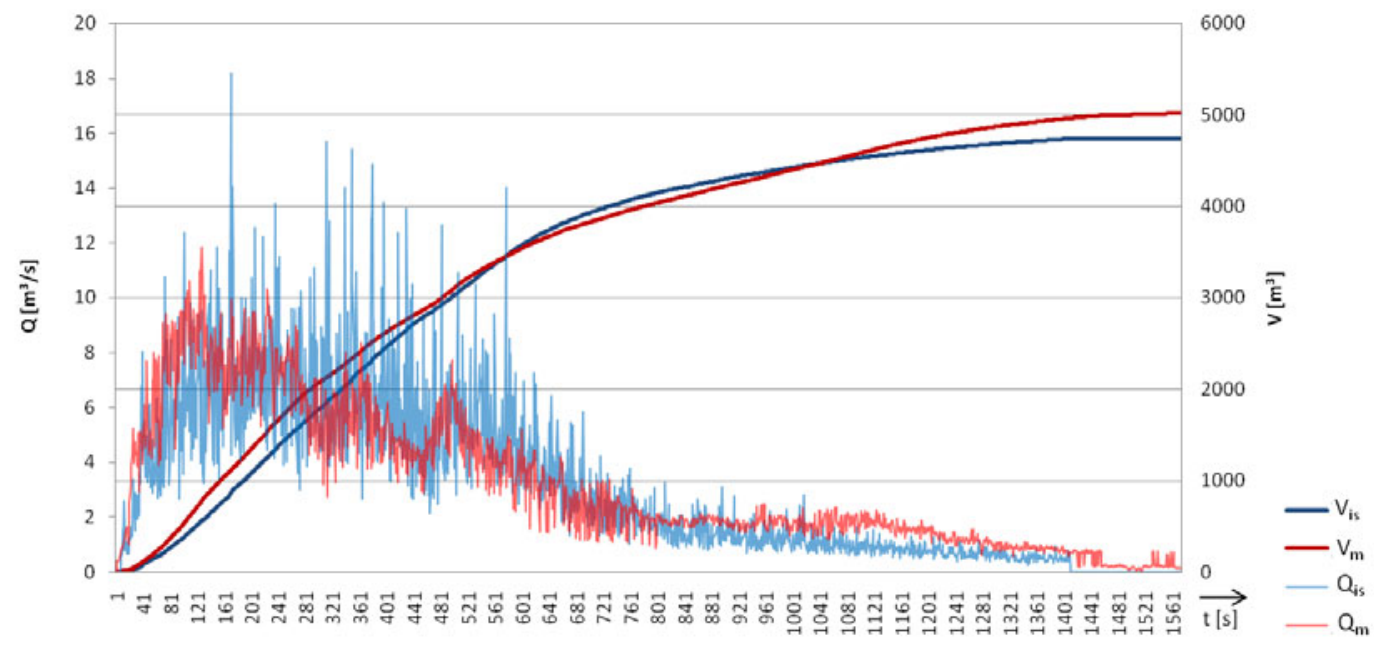

Figure 22: Calculated discharge $\left(\mathrm{Q}_{\mathrm{is}}\right)$ and calculated volume $\left(\mathrm{V}_{\text {is }}\right)$ based on infrasound data compared to measured discharge $\left(\mathrm{Q}_{\mathrm{m}}\right)$ and measured volume $\left(\mathrm{V}_{\mathrm{m}}\right)$ of the debris flow on 16.08.2015.

The peak discharge calculated based on the infrasound signal was $18 \mathrm{~m}^{3} / \mathrm{s}$ which overestimate the measured peak discharge with $12 \mathrm{~m}^{3} / \mathrm{s}$. The calculation of the discharge and the total volume fits very well with the measured discharge and the total volume of $5000 \mathrm{~m}^{3}$ (Figure 22). 
a)

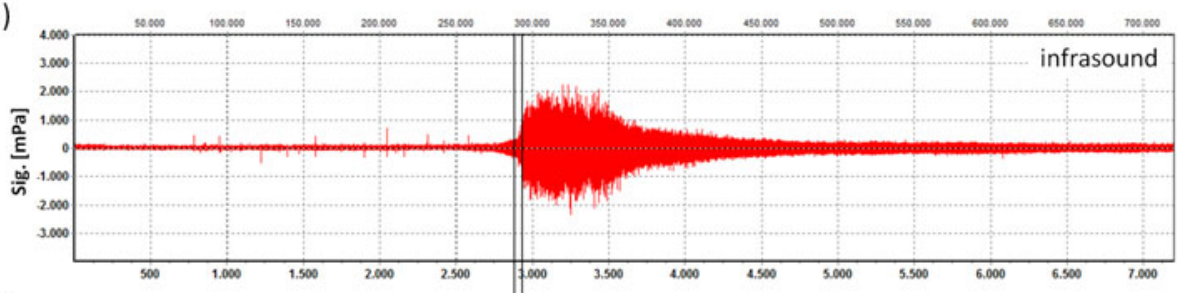

b)
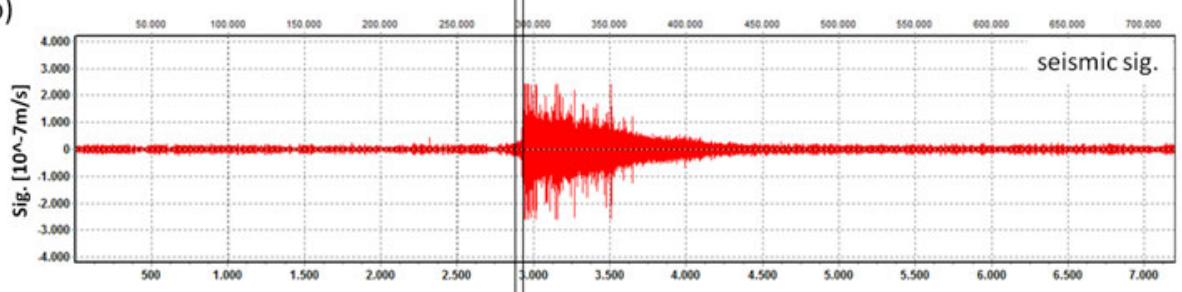

c)

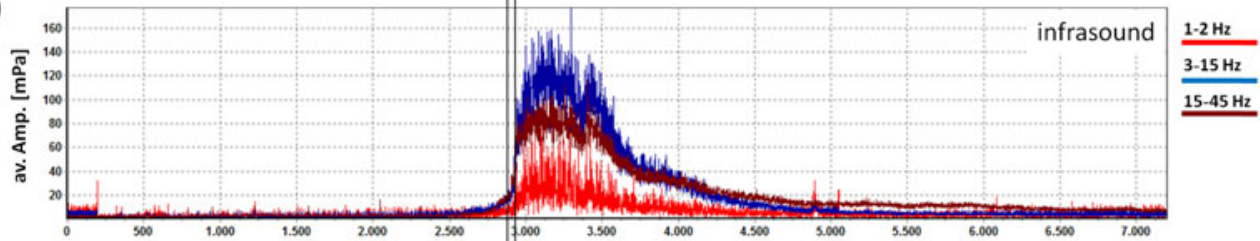

d)

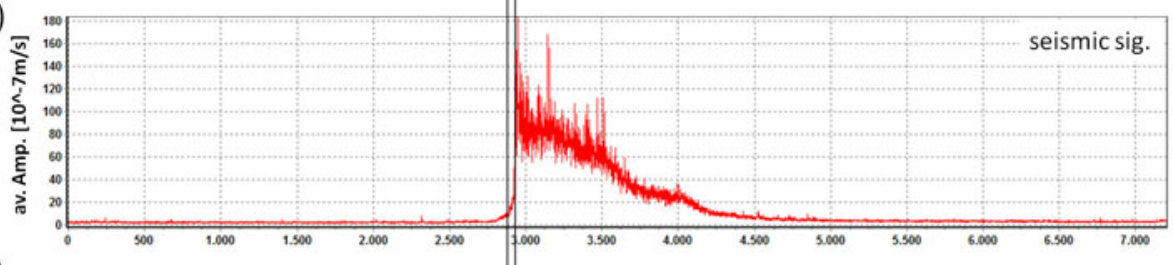

e)
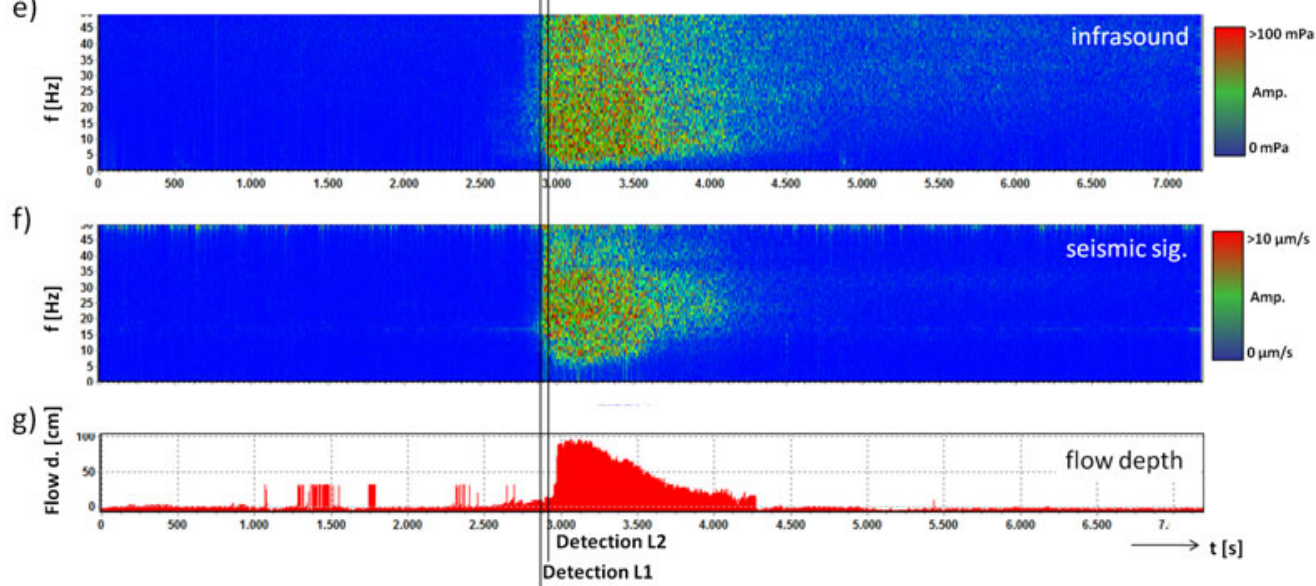

Figure 23: Infrasound and seismic data of the debris flow monitored at the test site Lattenbach (Station 2) on 16.08.2015. Signals are represented with a common base of time. (a) Infrasound time series; (b) Seismogram; (c) Average amplitude of the three frequency bands of the infrasound signal; (d) Average amplitude of the frequency band of the seismic signal; (e) Running spectrum of the infrasound signal; (f) Running spectrum of the seismic signal; (g) Flow depth; Lines: time of first detection for Level 1 and Level 2. 
In 2016 one large event occurred at the Lattenbach on 10.09.2016 at 18:54 CET (Figure 25). This event with a duration of $4000 \mathrm{~s}$ consists of more than 40 surges and had a total volume of $46100 \mathrm{~m}^{3}$. The event was detected by the warning system at $3164 \mathrm{~s}$ for Level 1 and $3176 \mathrm{~s}$ for Level 2, which results in an early warning time of $16 \mathrm{~s}$ (Level 1) and $4 \mathrm{~s}$ (Level 2). The maximum infrasound amplitudes of $1776 \mathrm{mPa}$ was recorded at $12 \mathrm{~Hz}$ and the maximum seismic amplitudes of $185 \mu \mathrm{m} / \mathrm{s}$ occurred at $25 \mathrm{~Hz}$.

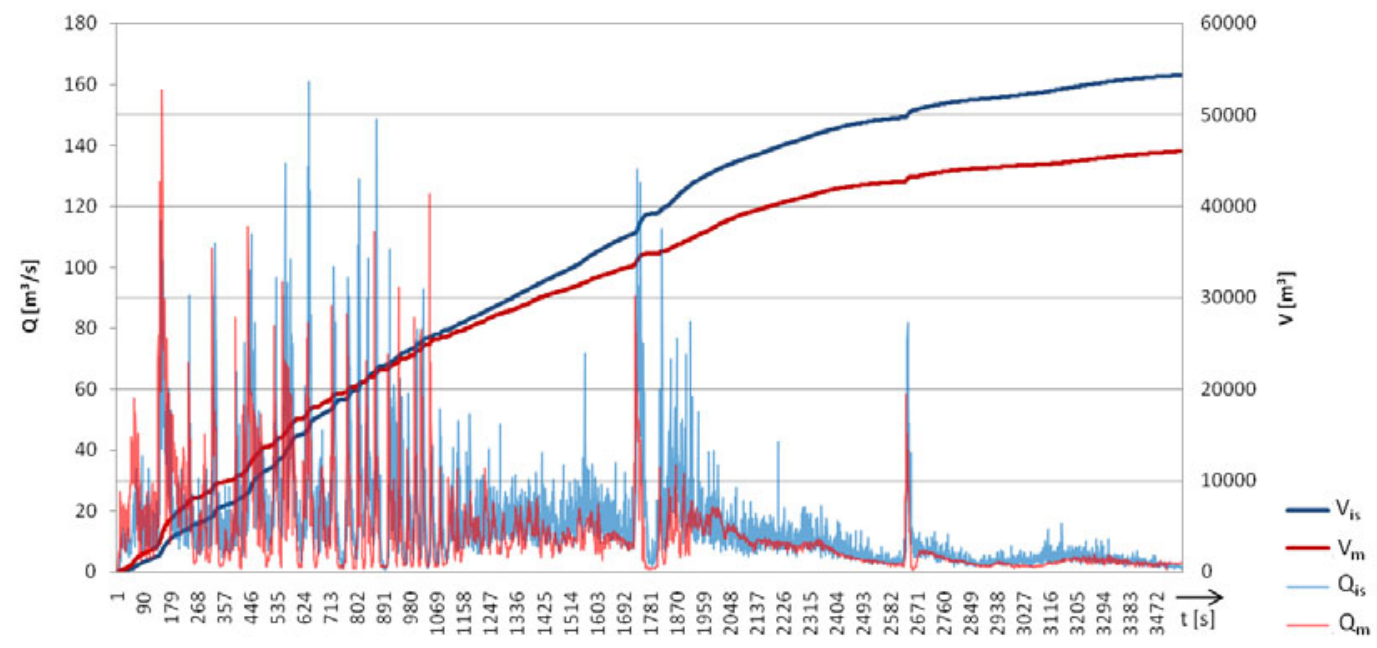

Figure 24: Calculated discharge $\left(\mathrm{Q}_{\text {is }}\right)$ and calculated volume $\left(\mathrm{V}_{\text {is }}\right)$ based on infrasound data compared to measured discharge $\left(\mathrm{Q}_{\mathrm{m}}\right)$ and measured volume $\left(\mathrm{V}_{\mathrm{m}}\right)$ of the debris flow on 10.09.2016.

If the measured discharge and its resulting total volume is compared to the calculated discharge and total volume it shows a good correlation for the first turbulent part of the debris flow, but the discharge calculation based on the infrasound signal overestimates the discharge for the second smother part of the event (Figure 24). So the resulting overestimation of the total volume is about $8000 \mathrm{~m}^{3}$. However, the peak discharge estimated based on the infrasound signal of $161 \mathrm{~m}^{3} / \mathrm{s}$ fits very well with the measured peak discharge of $158 \mathrm{~m}^{3} / \mathrm{s}$. 
a)

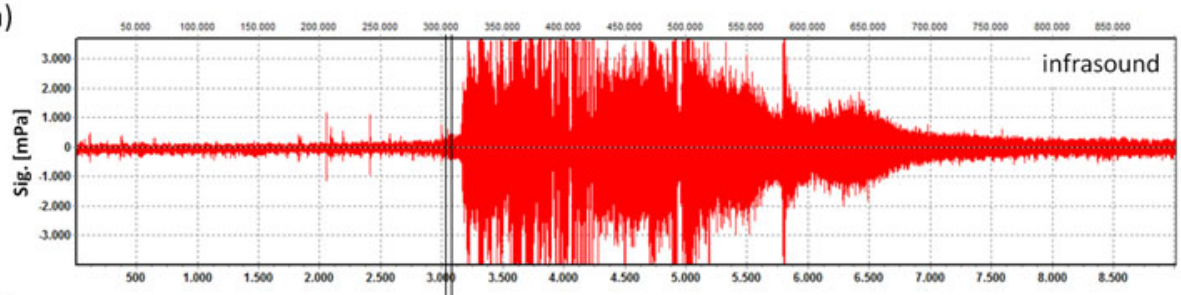

b)

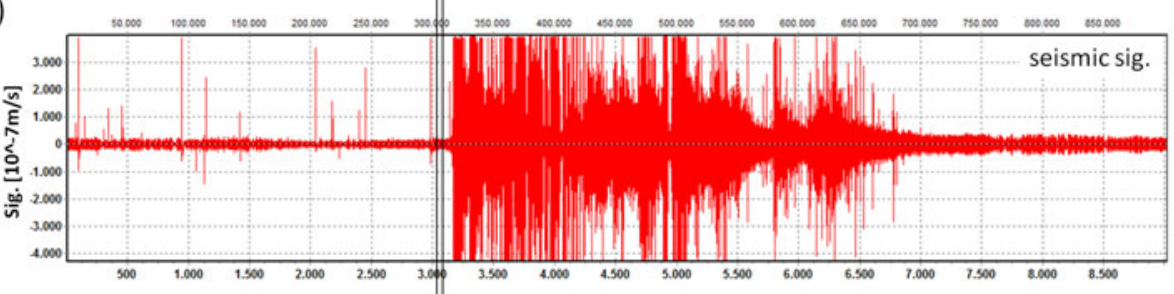

c)

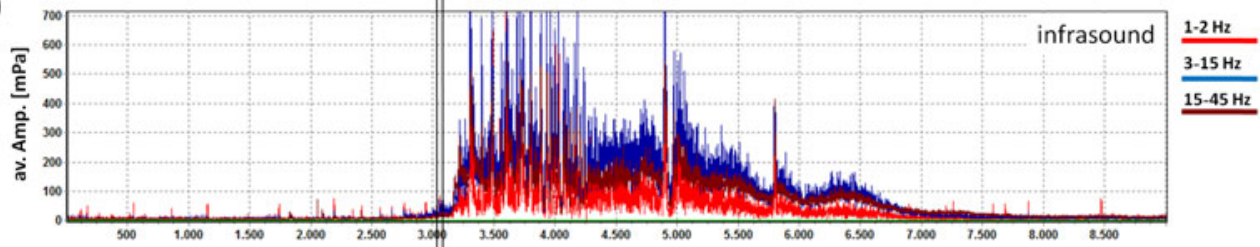

d)

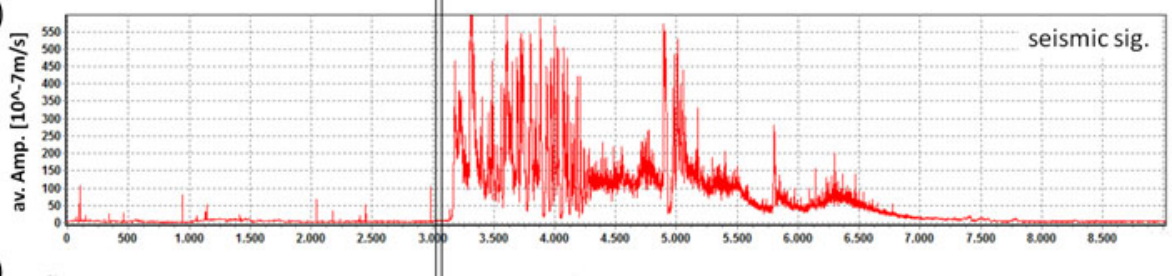

$10-30 \mathrm{~Hz}$

e)

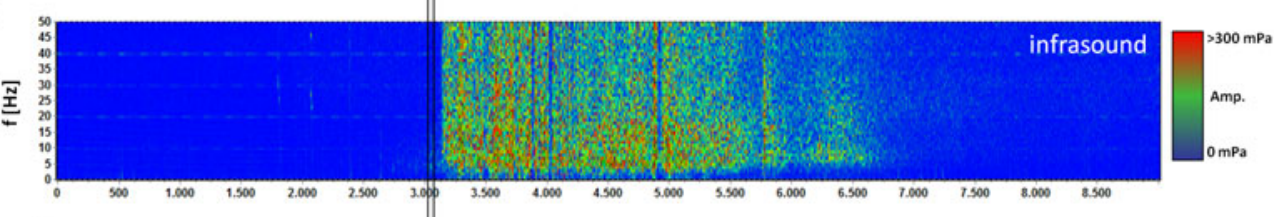

f)
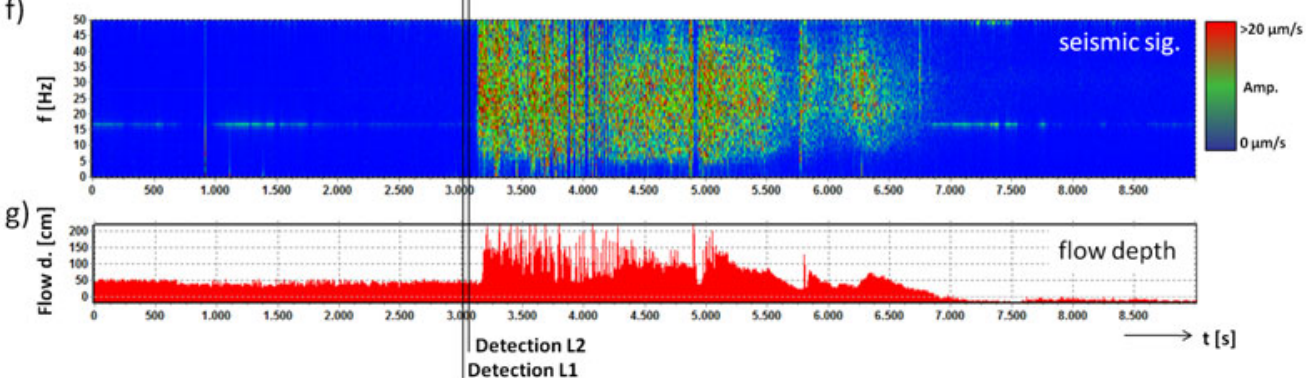

Figure 25: Infrasound and seismic data of the debris flow monitored at the test site Lattenbach (Station 2) on 10.09.2016. Signals are represented with a common base of time. (a) Infrasound time series; (b) Seismogram; (c) Average amplitude of the three frequency bands of the infrasound signal; (d) Average amplitude of the frequency band of the seismic signal; (e) Running spectrum of the infrasound signal; (f) Running spectrum of the seismic signal; (g) Flow depth; Lines: time of first detection for Level 1 and Level 2. 


\subsection{Events Farstrinne}

This debris flood at the test site Farstrinne was recorded on the 04.08.2015. The event was detected by the detection algorithm at $2443 \mathrm{~s}$ at Level 1 and $2567 \mathrm{~s}$ at Level 2 (Figure 27). The passing of the event can be estimated based on the seismic signal at second 2580 which results in an early warning time of $137 \mathrm{~s}$ for Level 1 and $13 \mathrm{~s}$ for Level 2 . The maximum seismic amplitudes were recorded at $10 \mathrm{~Hz}$ with $113 \mu \mathrm{m} / \mathrm{s}$ and the maximum infrasound amplitudes was $326 \mathrm{mPa}$ at $43 \mathrm{~Hz}$, which is in a very high fregency range that indicats a debris flood process. If the magnitude estimation presented in Section 2.4 is applied to this signals, the peak discharge can be estimated with $9 \mathrm{~m}^{3} / \mathrm{s}$ and the total volume is calculated to $1839 \mathrm{~m}^{3}$. Figure 26 shows the basin of the Farstrinne before, during and after the debris flood.
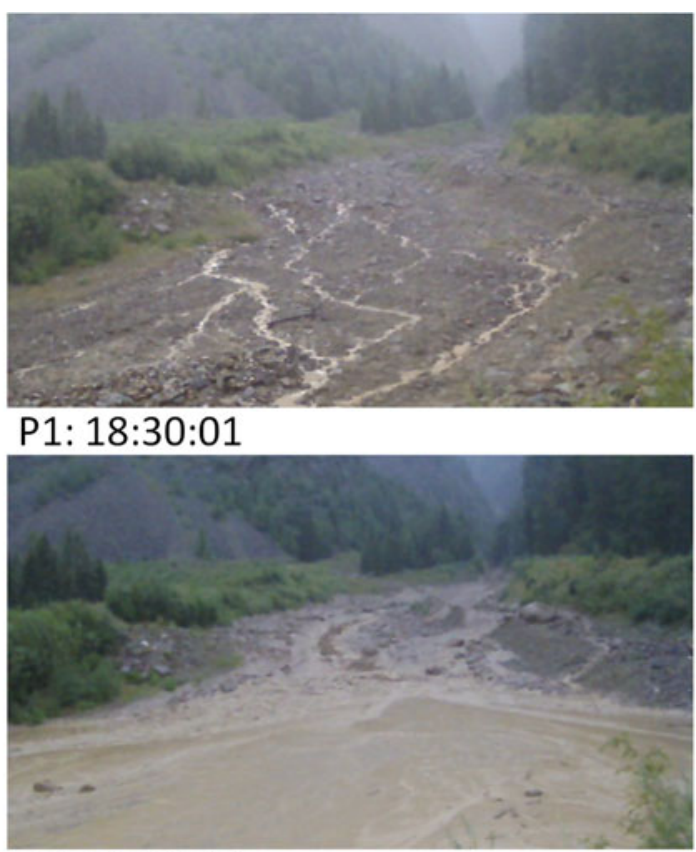

P3: 19:00:01
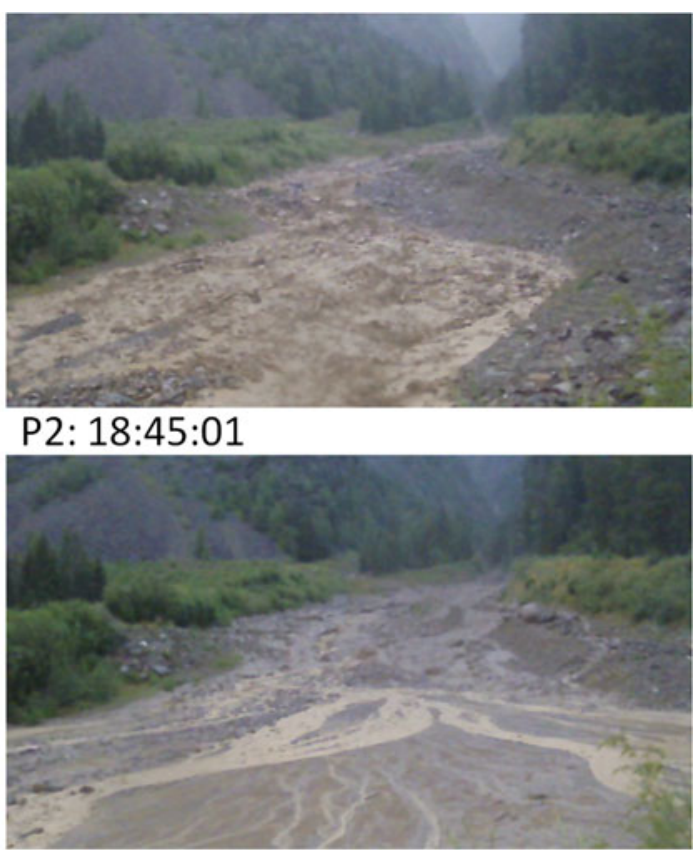

P4: 19:30:01

Figure 26: Pictures before (P1), during (P2,P3) and after (P4) the event at Farstrinne on 04.08.2015 (Time: CET). 
a)

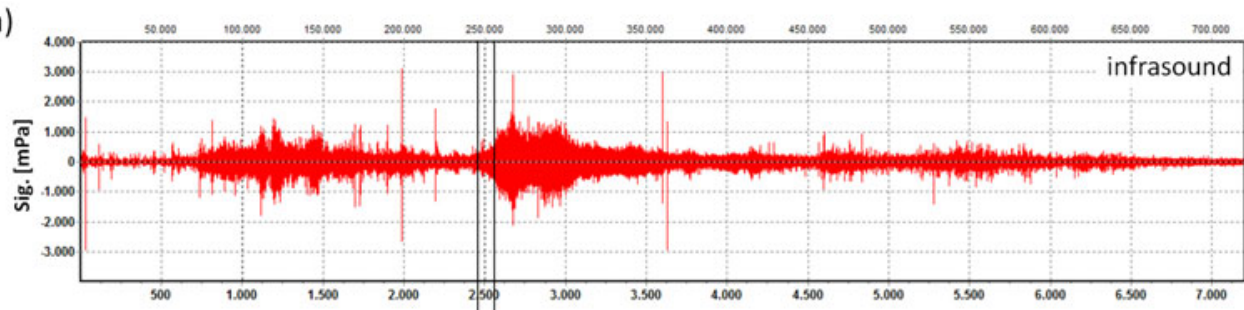

b)

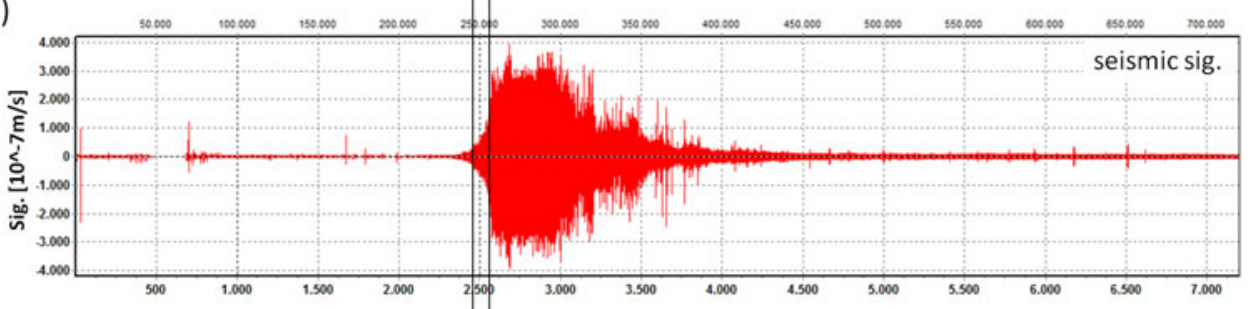

c)

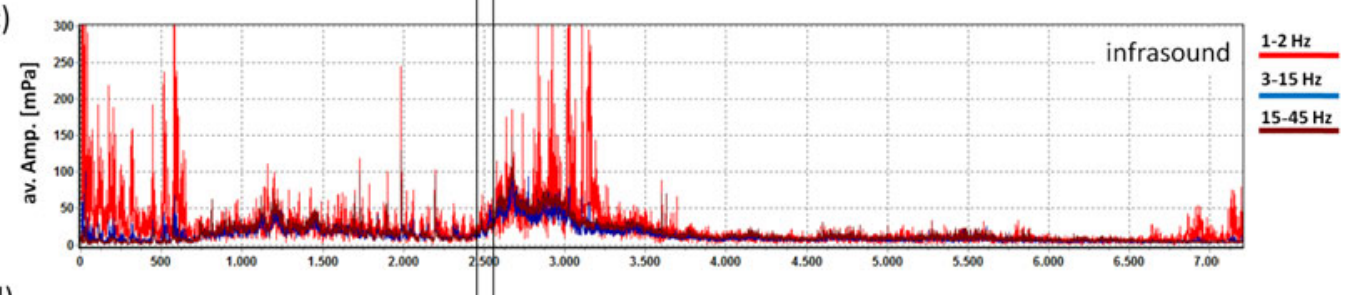

d)

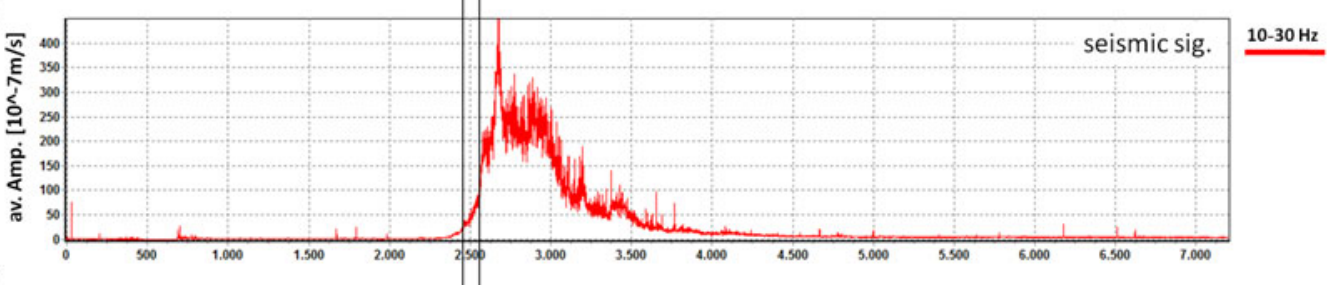

e)

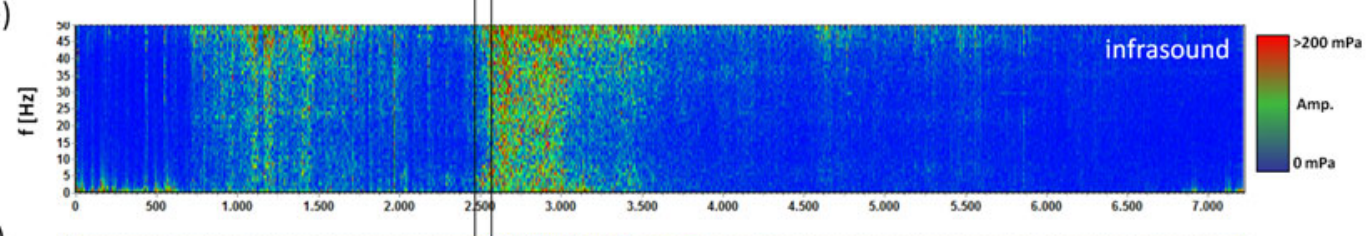

f)

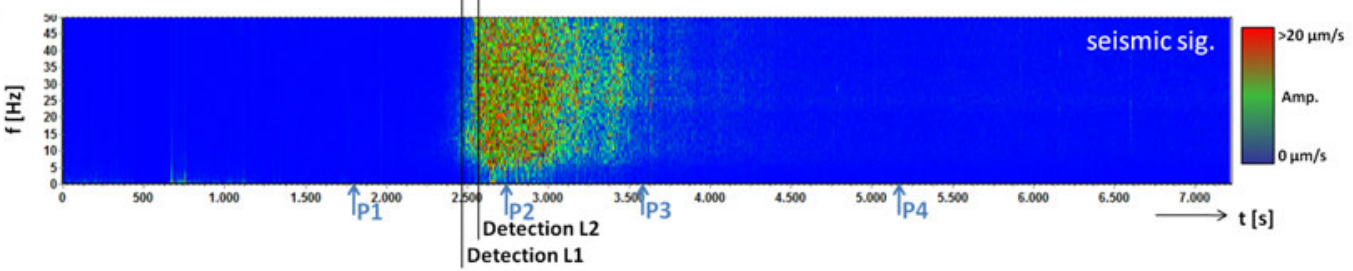

Figure 27: Infrasound and seismic data of the debris flow monitored at the test site Farstrinne on 04.08.2015. Signals are represented with a common base of time. (a) Infrasound time series; (b) Seismogram; (c) Average amplitude of the three frequency bands of the infrasound signal; (d) Average amplitude of the frequency band of the seismic signal; (e) Running spectrum of the infrasound signal; (f) Running spectrum of the seismic signal; Lines: time of first detection for Level 1 and Level 2; Arrows P1-P4: point in time of the photos (Figure 26). 


\subsection{Events Schüsserbach}

On the begin of the summer 2016 two events occurred at the catchment Schüsserbach. The first event started at 16:29 CET on the 28.05.2016 and the second one followed a few hours later at 20:05 CET. The first debris flow (Figure 29) was detected by the algorithm at $1768 \mathrm{~s}$ for Level 1 and at $1773 \mathrm{~s}$ for Level 2 , which results in a early detection of $6 \mathrm{~s}$ before the event passes the sensor site at $1768 \mathrm{~s}$ for Level 1 . The Level 2 detection was $5 \mathrm{~s}$ after the passing. The maximum infrasound amplitudes were identified with $480 \mathrm{mPa}$ at $17 \mathrm{~Hz}$ and the maximum seismic amplitudes were identified at $26 \mathrm{~Hz}$ with $116 \mu \mathrm{m} / \mathrm{s}$. Significant for this event are the high infrasound amplitudes (between $1000 \mathrm{~s}$ and $1400 \mathrm{~s}$ ) before the event reached the system site, which might results from a initial process, for example a landslide in the upper catchment. Figure 28 shows a excerpt of the video taken from the first event before and during the passing of the debris flow front.

The second event (Figure 30) has been detected $49 \mathrm{~s}$ before the passing of the event at $3965 \mathrm{~s}$ for Level 1 and $5 \mathrm{~s}$ before passing for Level 2. This following event was much smaller then the first event and had a maximum infrasound amplitude of $230 \mathrm{mPa}$ at $32 \mathrm{~Hz}$ and a maximum seismic amplitude of $33 \mu \mathrm{m} / \mathrm{s}$ at $25 \mathrm{~Hz}$. The high noise overlaying the events infrasound signal might results from the heavy precipitation and the already existing higher discharge in the channel.
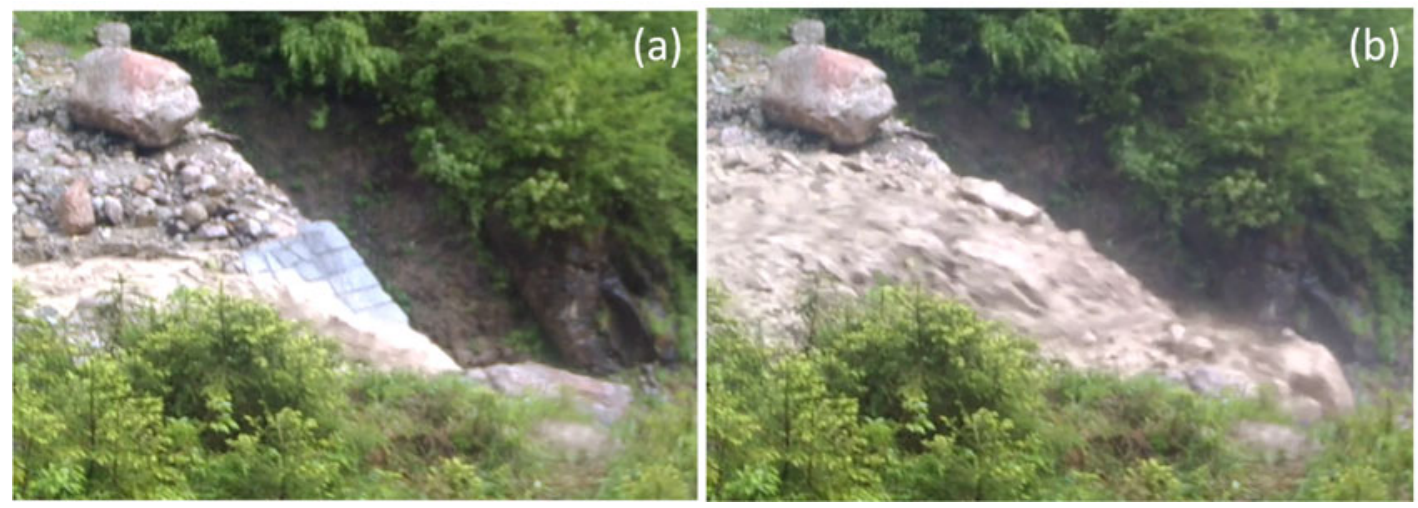

Figure 28: Pictures of the debris flow at Schüsserbach on 28.05.2016. (a) short time before the event; (b) the front of the debris flow. 
a)

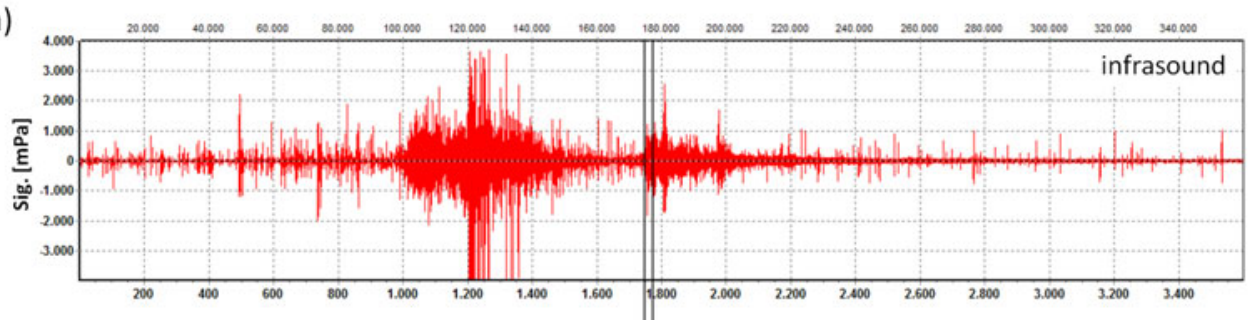

b)

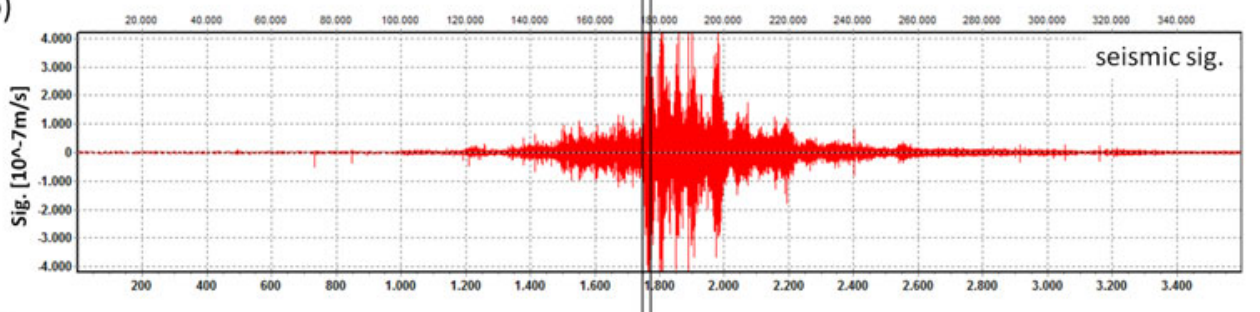

c)

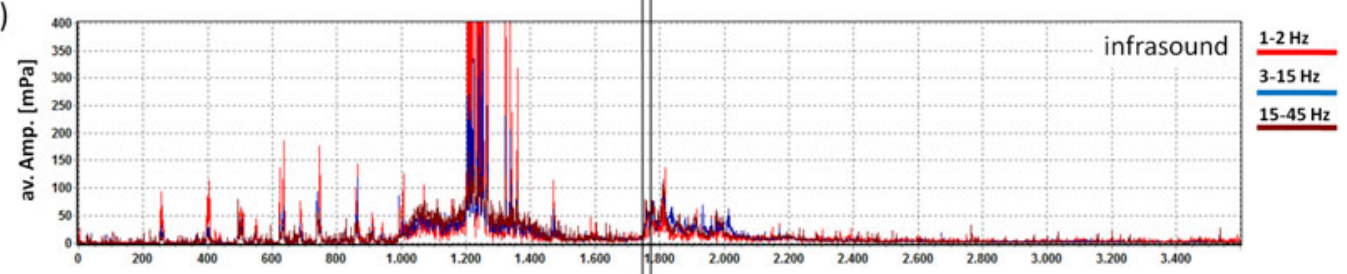

d)

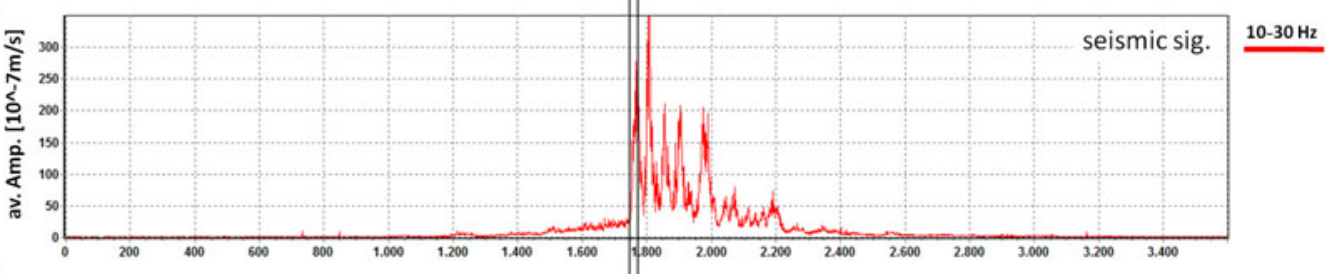

e)
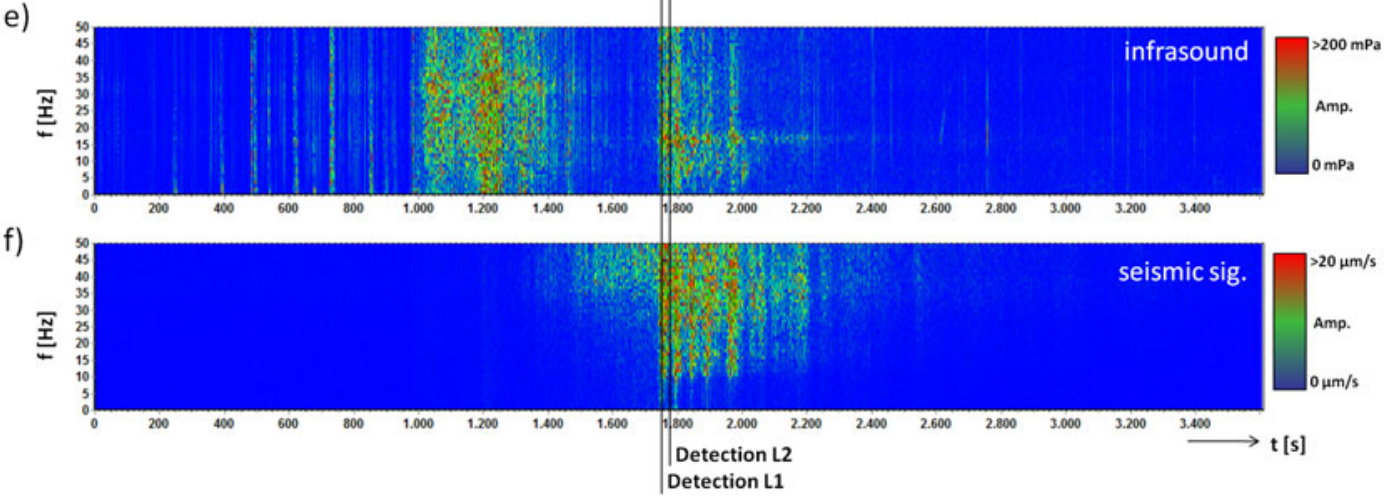

Figure 29: Infrasound and seismic data of the debris flow monitored at the test site Schüsserbach on 28.05.2016. Signals are represented with a common base of time. (a) Infrasound time series; (b) Seismogram; (c) Average amplitude of the three frequency bands of the infrasound signal; (d) Average amplitude of the frequency band of the seismic signal; (e) Running spectrum of the infrasound signal; (f) Running spectrum of the seismic signal; Lines: time of first detection for Level 1 and Level 2. 
a)

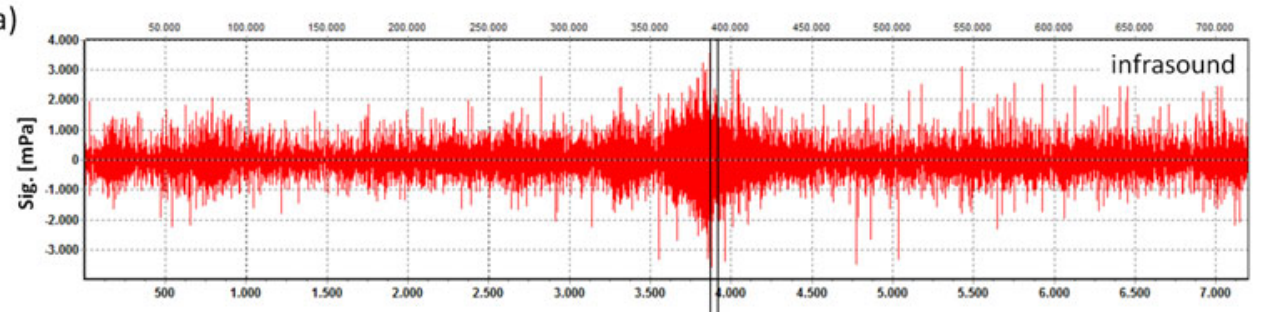

b)

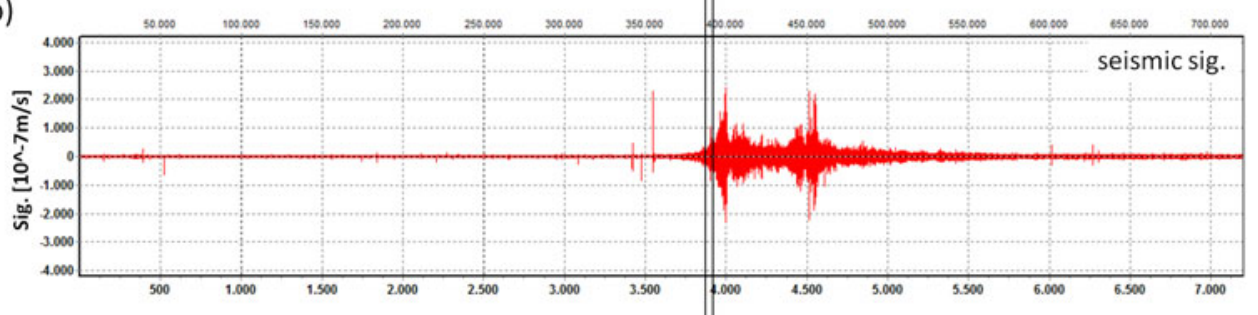

c)

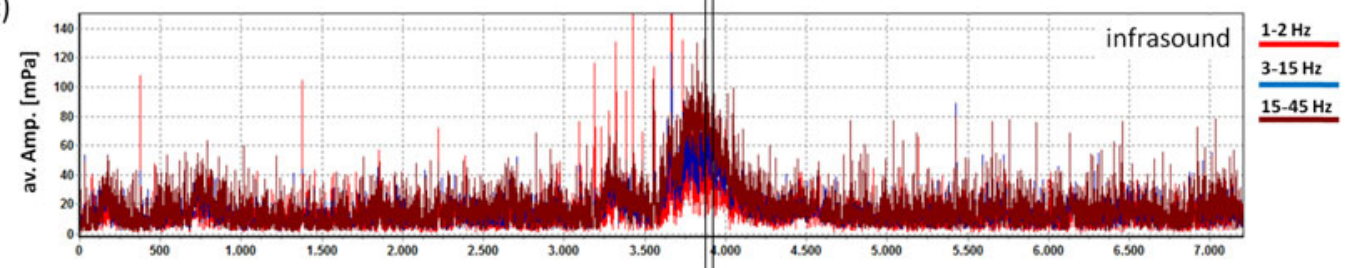

d)

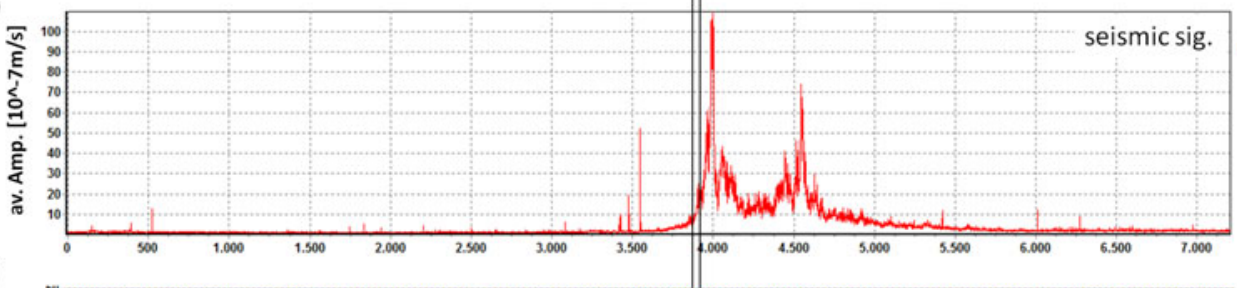

e)
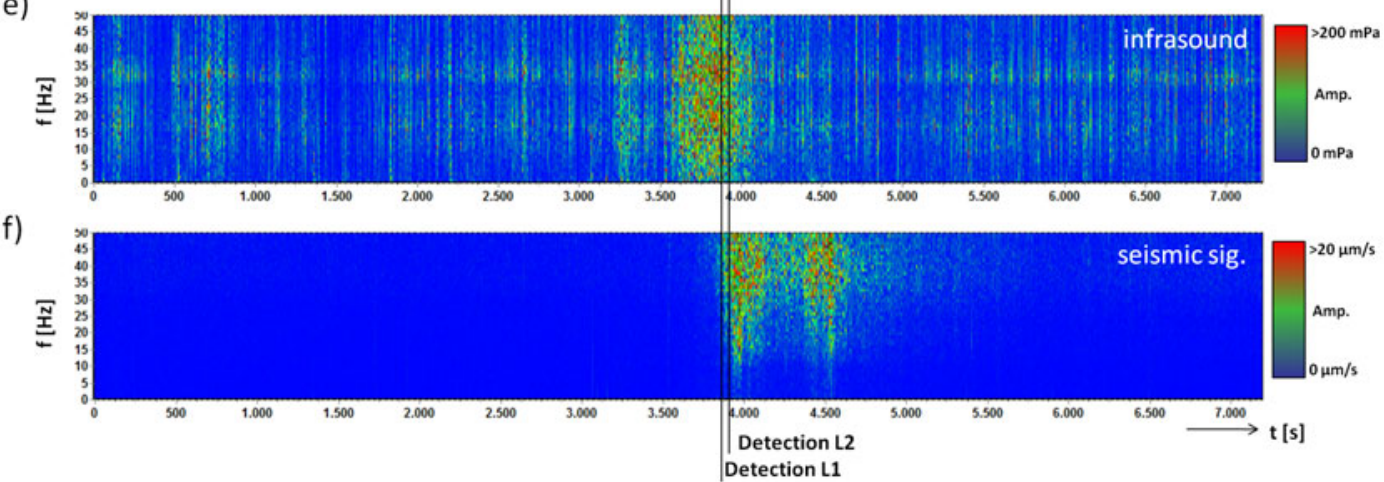

Figure 30: Infrasound and seismic data of the debris flood monitored at the test site Schüsserbach on 28.05.2016. Signals are represented with a common base of time. (a) Infrasound time series; (b) Seismogram; (c) Average amplitude of the three frequency bands of the infrasound signal; (d) Average amplitude of the frequency band of the seismic signal; (e) Running spectrum of the infrasound signal; (f) Running spectrum of the seismic signal; Lines: time of first detection for Level 1 and Level 2. 


\subsection{Events Gadria}

On the 08.06.2015 a debris flow was recorded at the test site Gadria in South Tyrol (Figure 32). This event with a total volume of $9850 \mathrm{~m}^{3}$ and a duration of over $3000 \mathrm{~s}$ occurred in several surges. The algorithm detected this event at $1052 \mathrm{~s}$ for Level 1 and $1096 \mathrm{~s}$ for Level 2 which was $98 \mathrm{~s}$ (Level 1) and 54s (Level 2) before passing the sensor site (at $1150 \mathrm{~s}$ ). The maximum infrasound amplitudes were up to $651 \mathrm{mPa}$ at $37 \mathrm{~Hz}$ and the maximum seismic amplitudes were at $26 \mathrm{~Hz}$ with $156 \mu \mathrm{m} / \mathrm{s}$. Although it was a debris flow the peak frequencies of the infrasound signal was in the higher debris flood frequency range $(>15 \mathrm{~Hz})$ which phenomenon is significant for this site. If we use the method for the estimation of the magnitude, we come up with a peak discharge of $30 \mathrm{~m}^{3} / \mathrm{s}$ and a total volume of $8309 \mathrm{~m}^{3}$ which fits very well to the measured volume. In Figure 31 pictures of different surges of this event are presented. In 2016 a event with similar characteristic occurred on 12.07.2016 (Figure 33). This debris flow was a much smaller than the event in 2015 with a total volume of $1500 \mathrm{~m}^{3}$. It was detected by the system at $3224 \mathrm{~s}$ for Level 1 and $3288 \mathrm{~s}$ for Level 2 which results in an early detection time of $76 \mathrm{~s}$ (Level 1) and $12 \mathrm{~s}$ (Level 2). The maximum seismic amplitudes registered for this event were $120 \mu \mathrm{m} / \mathrm{s}$ at $25 \mathrm{~Hz}$ and the maximum infrasound amplitudes were $564 \mathrm{mPa}$ at $34 \mathrm{~Hz}$. The peak discharge calculated based on the infrasound signals is about $24 \mathrm{~m}^{3} / \mathrm{s}$ and the total volume is estimated to $1929 \mathrm{~m}^{3}$.
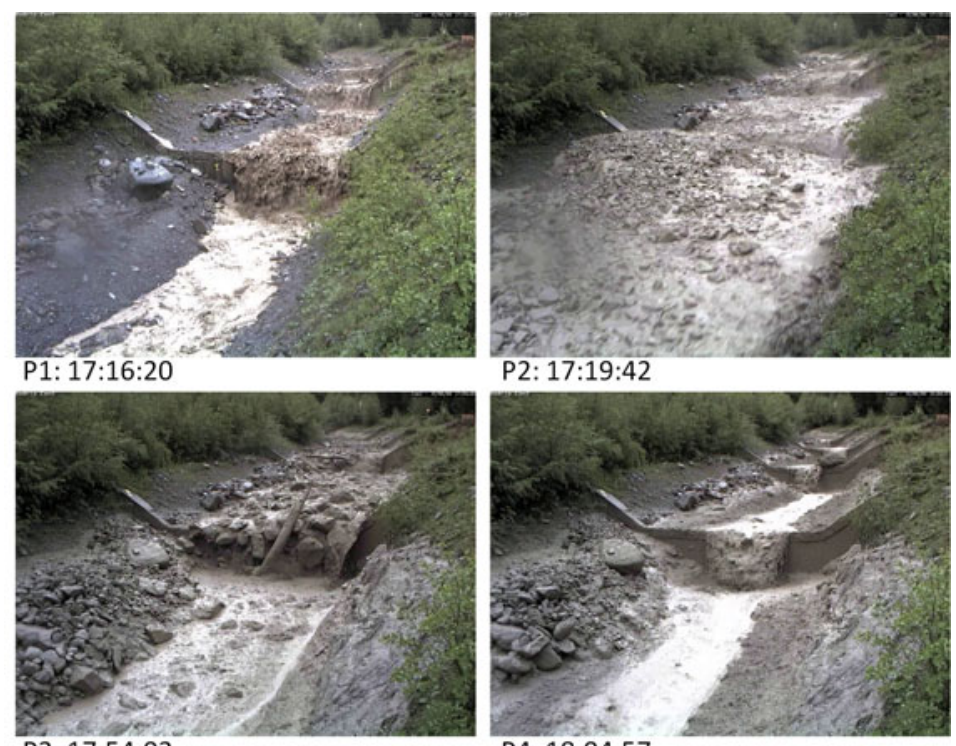

$\mathrm{P} 2: 17: 19: 42$

P3: 17:54:03

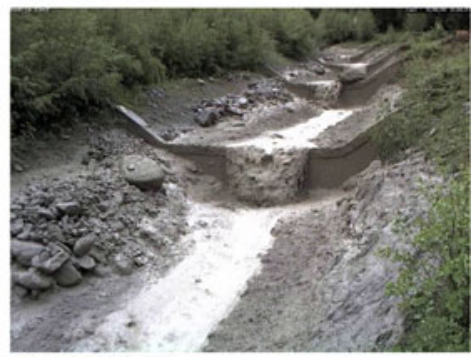

P4: 18:04:57

Figure 31: Pictures of the event at Gadria on 08.06.2015: arriving of the first surge (P1), peak of first surge (P2), arriving of the fifth surge (P3), end of the last surge (P4) (Time: CET). 
a)

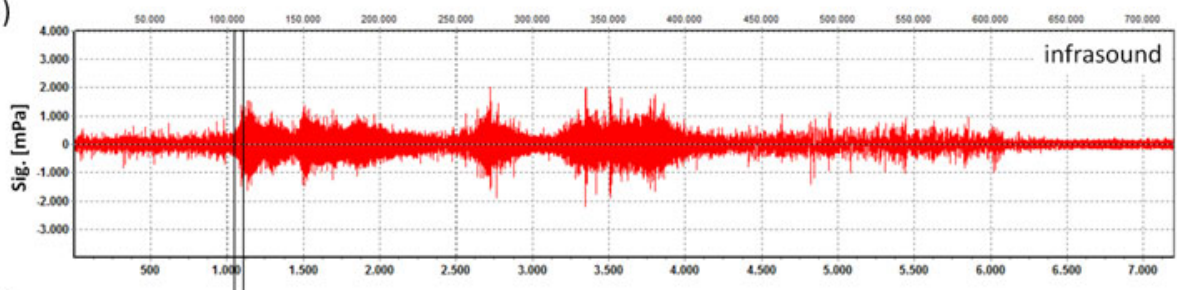

b)

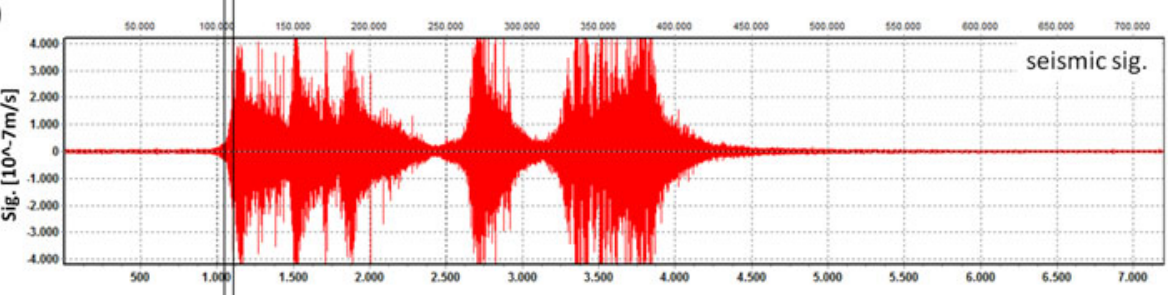

c)

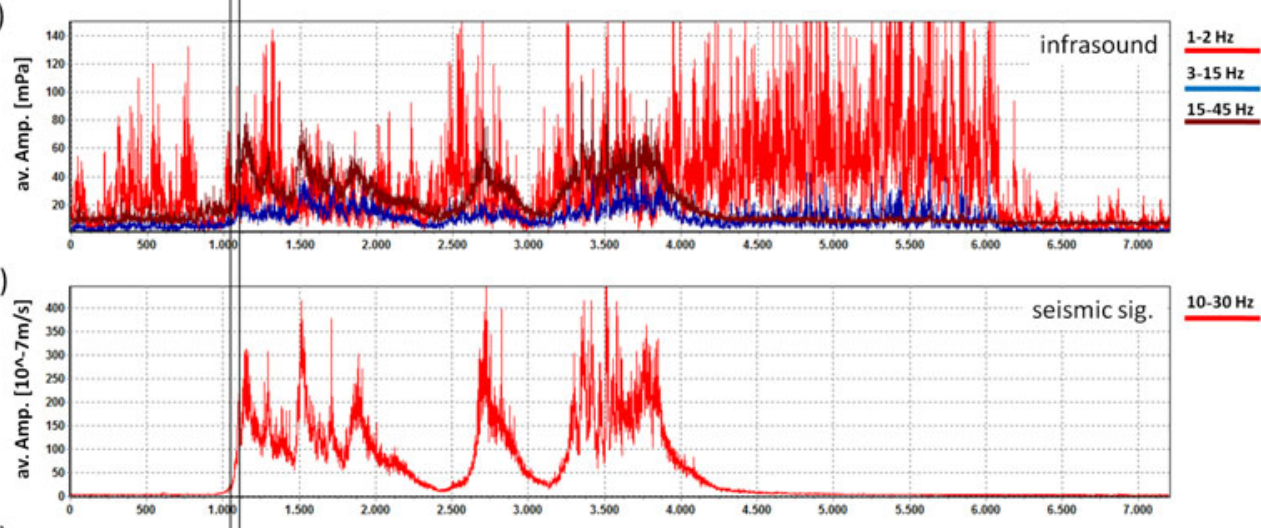

e)

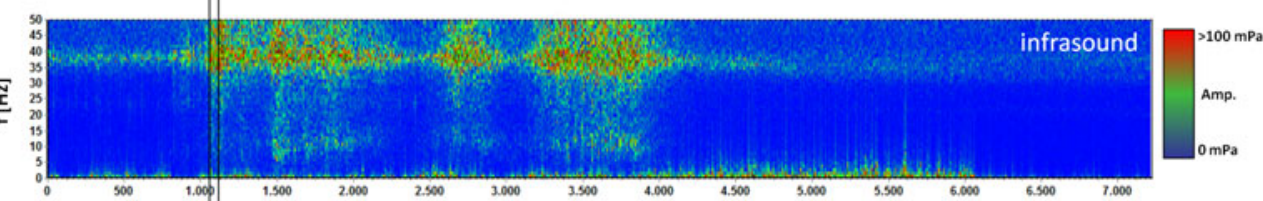

f)
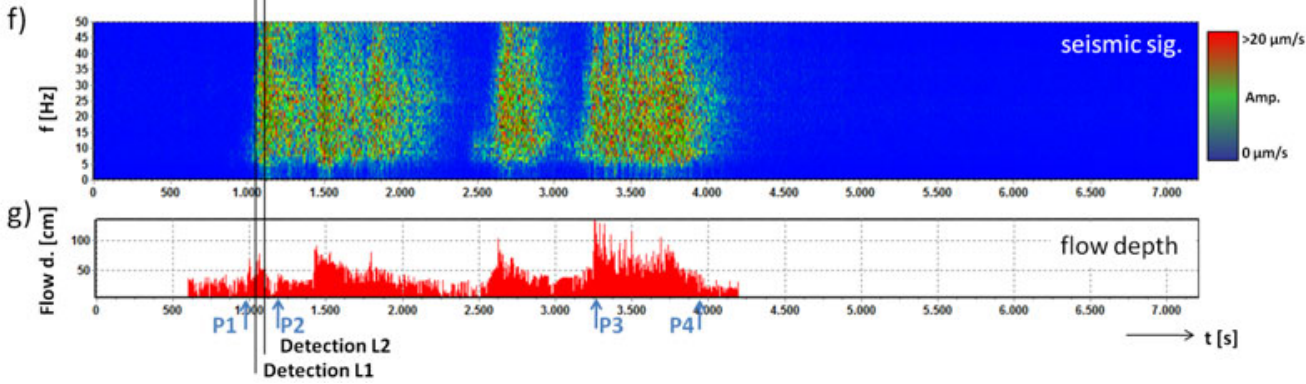

Figure 32: Infrasound and seismic data of the debris flow monitored at the test site Gadria on 08.06.2015. Signals are represented with a common base of time. (a) Infrasound time series; (b) Seismogram; (c) Average amplitude of the three frequency bands of the infrasound signal; (d) Average amplitude of the frequency band of the seismic signal; (e) Running spectrum of the infrasound signal; (f) Running spectrum of the seismic signal; (g) Flow depth; Lines: time of first detection for Level 1 and Level 2; Arrows P1-P4: point in time of the photos (Figure 31.) 
a)

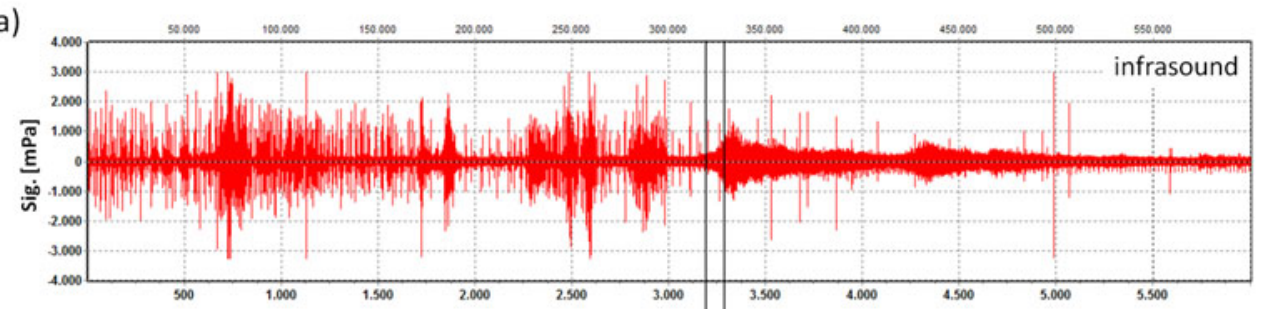

b)

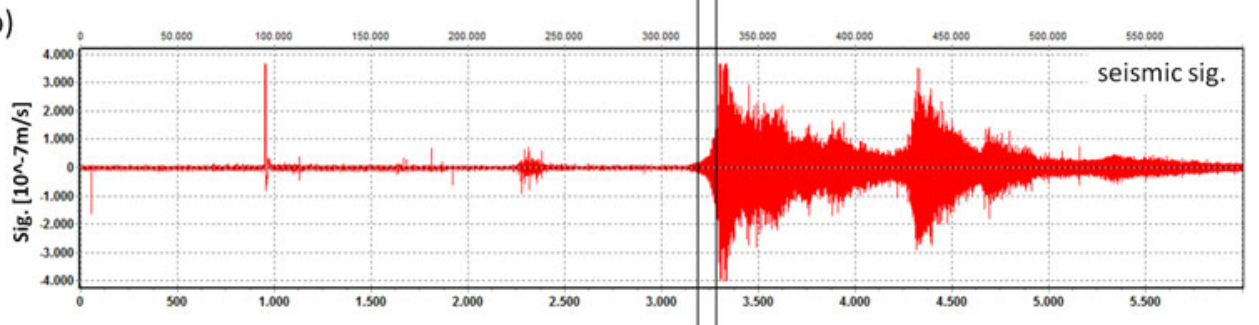

c)

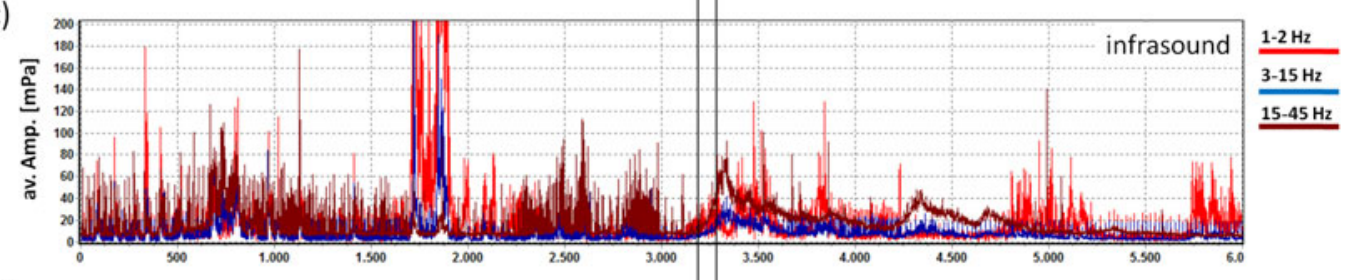

d)

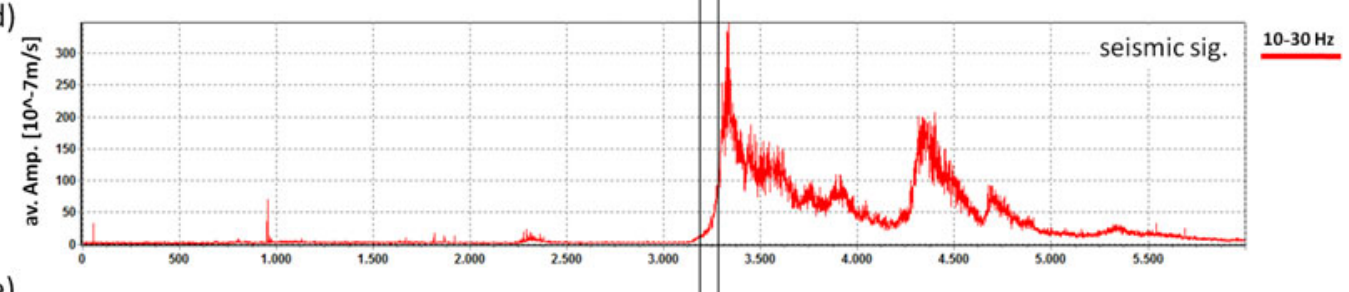

e)
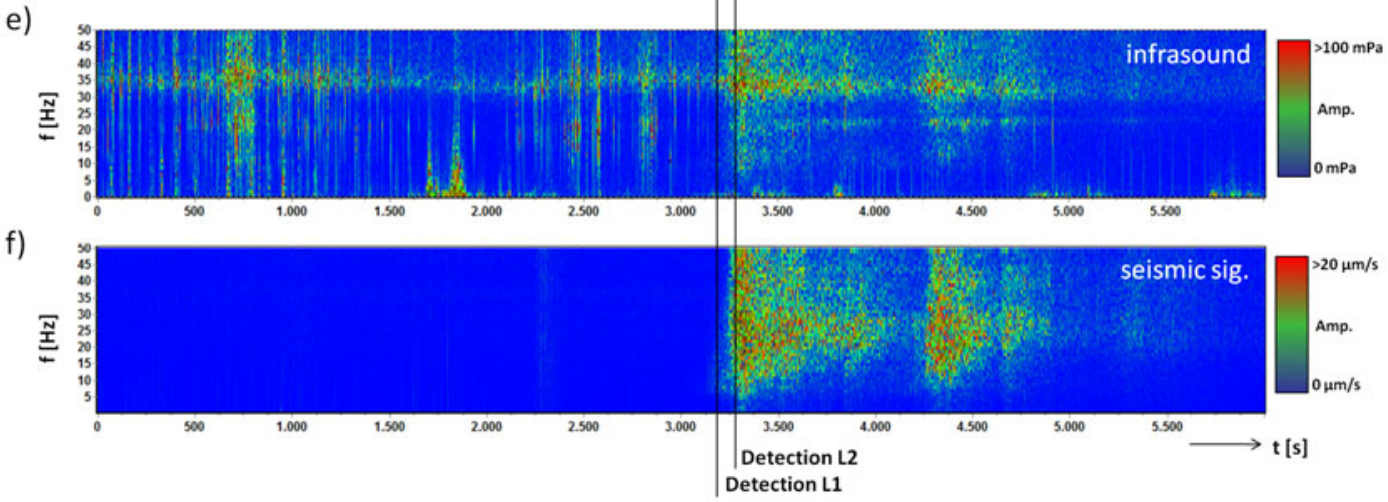

Figure 33: Infrasound and seismic data of the debris flow monitored at the test site Gadria on 12.07.2016. Signals are represented with a common base of time. (a) Infrasound time series; (b) Seismogram; (c) Average amplitude of the three frequency bands of the infrasound signal; (d) Average amplitude of the frequency band of the seismic signal; (e) Running spectrum of the infrasound signal; (f) Running spectrum of the seismic signal; Lines: time of first detection for Level 1 and Level 2. 


\subsection{Events Illgraben}

At the very active catchment Illgraben four events occurred in 2015 (22.07.2015, 10.08.2015, 14.08.2015 and 15.08.2015) and five events took place in the season 2016 (29.05.2016, 2 events on 12.07.2016, 22.07.2016 and 09.08.2016). For this section two different events has been chosen to represent the wide variance of the process types. The data of the two presented events here were recorded at the station at check dam 27 down at the channel ((Station 2). The first event which occurred on 15.08.2015 was a flash flood with a distinct front (Figure 35). This event was detected by the detection algorithm $61 \mathrm{~s}$ before passing (at $2800 \mathrm{~s}$ ) for Level 1 and $27 \mathrm{~s}$ after passing for Level 2 (later detection due to the small size of the first surge). The maximum seismic amplitudes were registered at $16 \mathrm{~Hz}$ with $58 \mu \mathrm{m} / \mathrm{s}$ and the maximum infrasound amplitudes occurred at $3 \mathrm{~Hz}$ with $223 \mathrm{mPa}$. This low infrasound amplitudes might results from the high viscosity of the flow. The total volume of this event was $2000 \mathrm{~m}^{3}$ which is a bit overestimated by the calculation based on infrasound data with $3814 \mathrm{~m}^{3}$ and also the peak discharge of $3 \mathrm{~m}^{3} / \mathrm{s}$ is overestimated with $5 \mathrm{~m}^{3} / \mathrm{s}$.

The second event presented here was a classic debris flow which occurred on 22.07.2016 (Figure 36). The front of the debris flow consist of very large boulders and was moving with $3,4 \mathrm{~m} / \mathrm{s}$ (Figure 34). This event was identified by the system at $3495 \mathrm{~s}$ (Level 1) and $3629 \mathrm{~s}$ (Level 2) which results in an early detection time of $165 \mathrm{~s}$ and $31 \mathrm{~s}$, respectively. The maximum infrasound amplitudes of $1197 \mathrm{mPa}$ occurred at a low frequency of $4 \mathrm{~Hz}$ and the maximum seismic amplitudes were registered at $17 \mathrm{~Hz}$ with $241 \mu \mathrm{m} / \mathrm{s}$. The total volume of this event was over $10000 \mathrm{~m}^{3}$ which fits very good with the calculated total volume of $10004 \mathrm{~m}^{3}$. Also the estimation of the peak discharge with $84 \mathrm{~m}^{3} / \mathrm{s}$ shows a good aproximation to the measured peak discharge between $50-90 \mathrm{~m}^{3} / \mathrm{s}$.

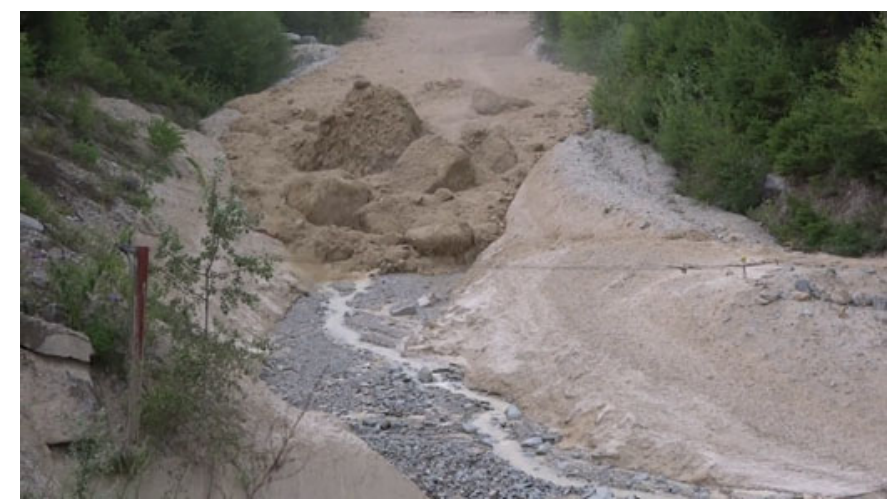

Figure 34: Picture of the debris flow front of the event on 22.07.2016 at Illgraben. 


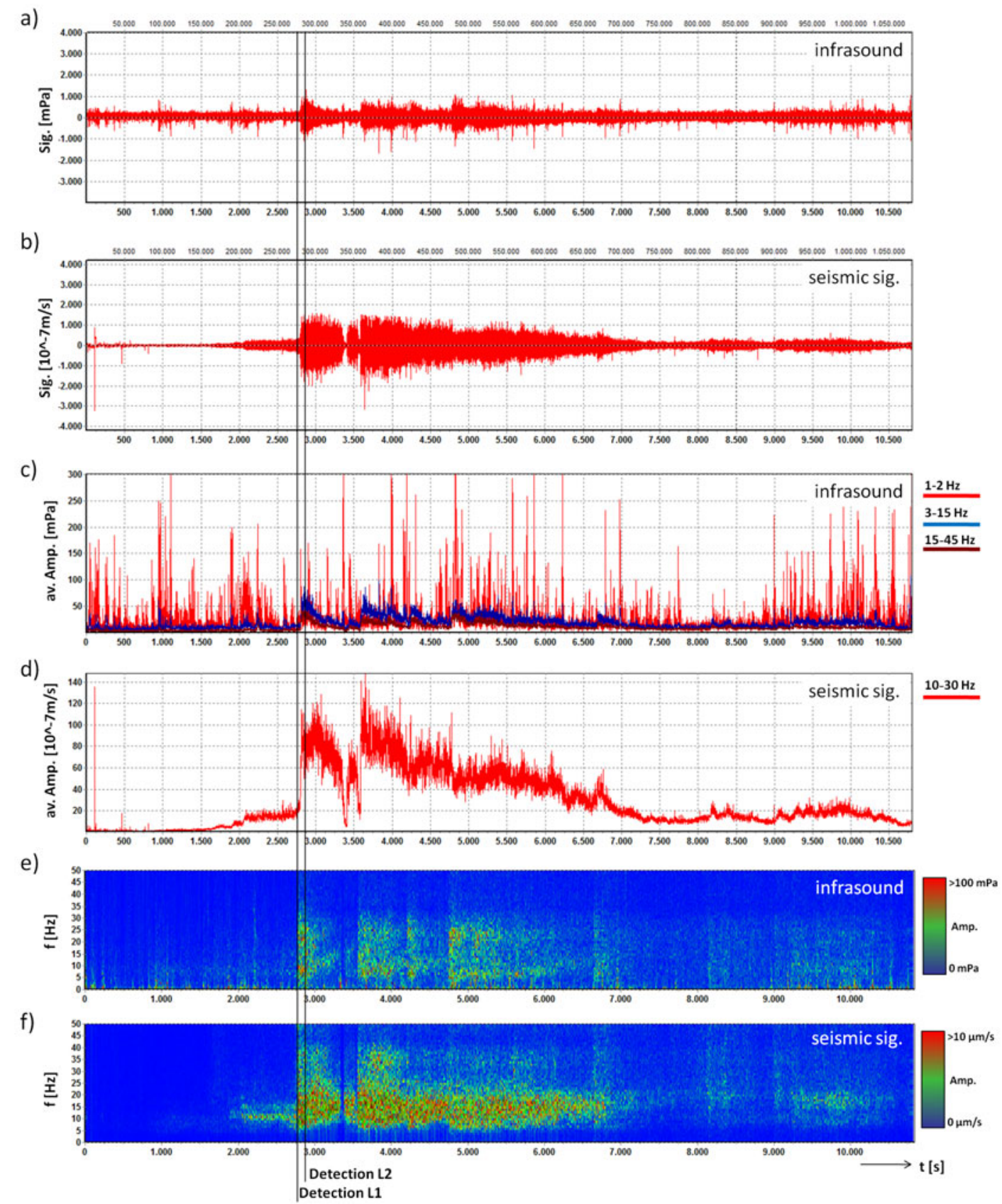

Figure 35: Infrasound and seismic data of the flash flood monitored at the test site Illgraben (Station 2) on 15.08.2015. Signals are represented with a common base of time. (a) Infrasound time series; (b) Seismogram; (c) Average amplitude of the three frequency bands of the infrasound signal; (d) Average amplitude of the frequency band of the seismic signal; (e) Running spectrum of the infrasound signal; (f) Running spectrum of the seismic signal; Lines: time of first detection for Level 1 and Level 2. 
a)

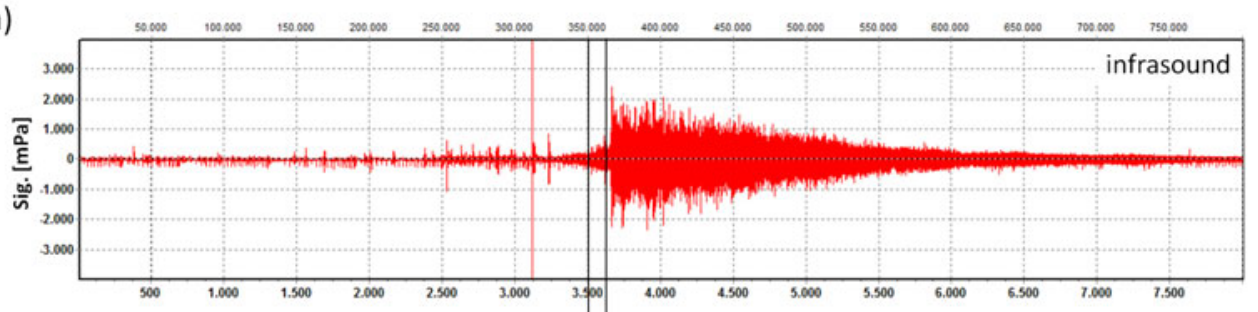

b)

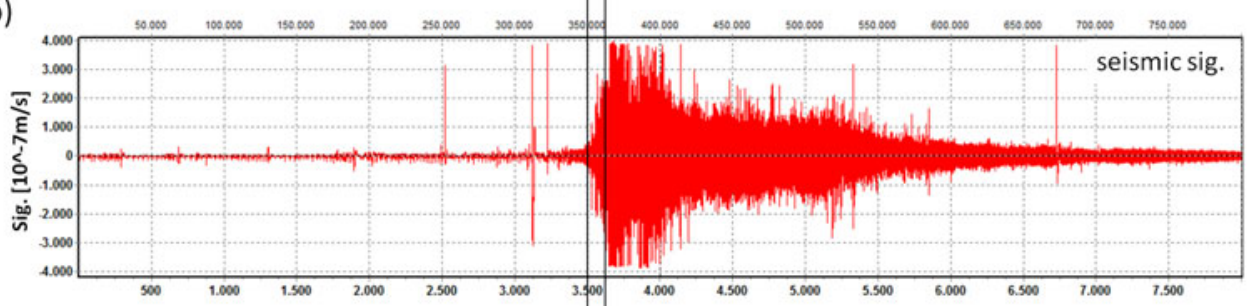

c)

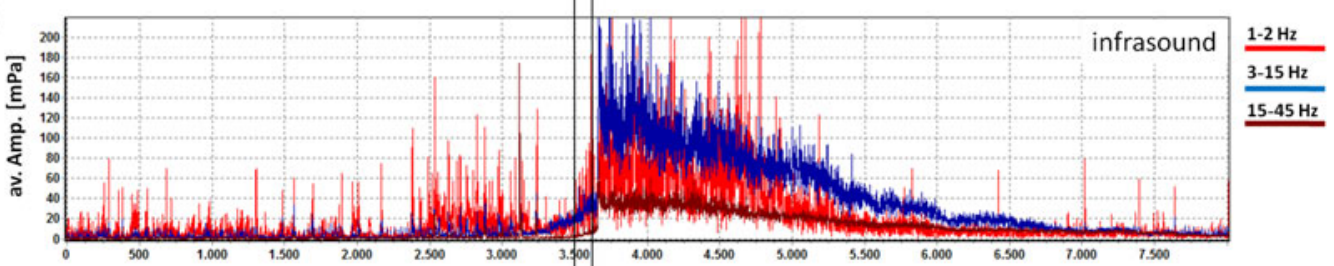

d)

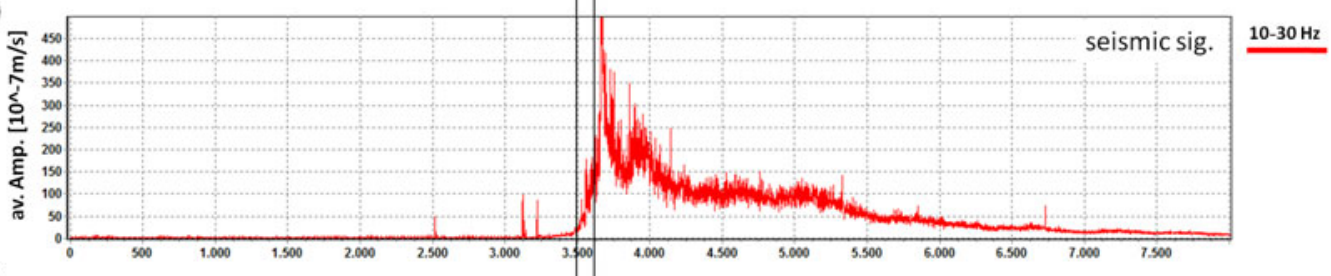

e)
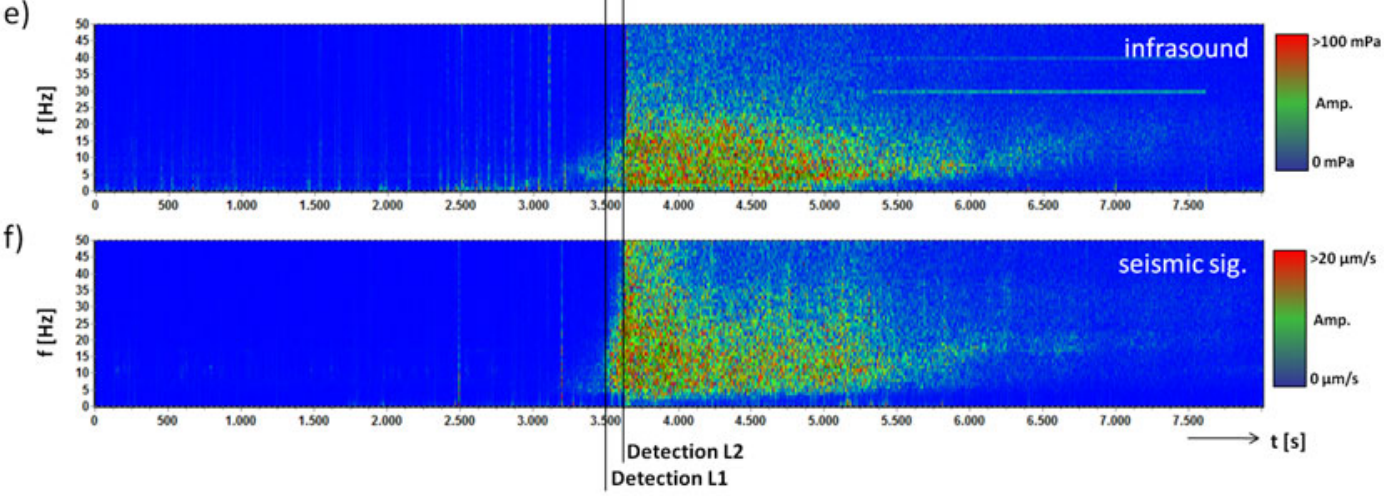

Figure 36: Infrasound and seismic data of the debris flow monitored at the test site Illgraben (Station 2) on 22.07.2016. Signals are represented with a common base of time. (a) Infrasound time series; (b) Seismogram; (c) Average amplitude of the three frequency bands of the infrasound signal; (d) Average amplitude of the frequency band of the seismic signal; (e) Running spectrum of the infrasound signal; (f) Running spectrum of the seismic signal; Lines: time of first detection for Level 1 and Level 2. 


\subsection{Events Marderello}

Beside some smaller flood processes, two major events have been recorded during the operation time of the detection system at Marderello. One of this events was a mudflow recorded on the 09.08.2015 and has been chosen as example.

The mudflow at Marderello was recorded beginning at 14:00. The total discharge of this mudflow was approximately $50000 \mathrm{~m}^{3}$ with a event duration of around $4500 \mathrm{~s}$. The infrasound and seismic signals of this event are shown in Figure 37. Significant for this event are the high amplitudes of the infrasound signal in the low frequency range $(<5 \mathrm{~Hz})$ between second 2800 and 4400, while the seismic amplitudes are rather low in this time window. We suppose that this phenomenon was due to the joint-effect of (i) the passing of the mudflow at the waterfall in the upper area, between seconds 3000 and 3500 and of (ii) the very low velocity of the first half of the flow, between seconds 3500 and 4500 . Waterfall produced infrasound has been identified with peak frequencies below $5 \mathrm{~Hz}$ (Johnson et al. 2006), and a possible misleading effect of the Marderello waterfall on the seismic signal was already observed for previous events (Coviello et al. 2015). The largest amplitudes of the infrasound signal occur in the lowest frequency band at $3 \mathrm{~Hz}$ with $749 \mathrm{mPa}$ and the maximum amplitude of the seismic signals was recorded at $23 \mathrm{~Hz}$ with $76 \mu \mathrm{m} / \mathrm{s}$. The detection algorithm detects this event at $3048 \mathrm{~s}$ for Level 1 and $3688 \mathrm{~s}$ for Level 2. If we use the flow height recorded by the ultrasonic gauge around $50 \mathrm{~m}$ downstream of the detection system and adapt this point in time according to the distance between the monitoring stations and the estimated velocity of the mudflow, we estimate the event arrival at $3690 \mathrm{~s}$. This results in an early detection time of $642 \mathrm{~s}$ at Level 1 and $2 \mathrm{~s}$ at Level 2. This long early detection time for Level 1 can be achieved due to the low flow velocity of this mud flow. 
a)

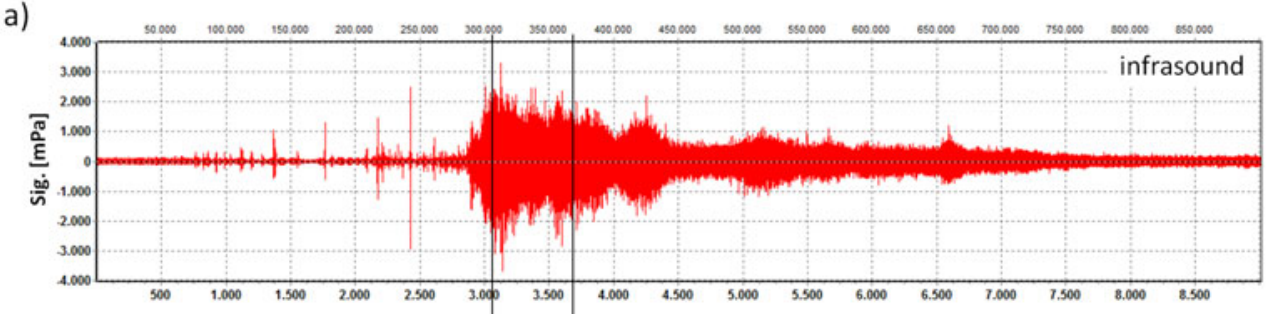

b)

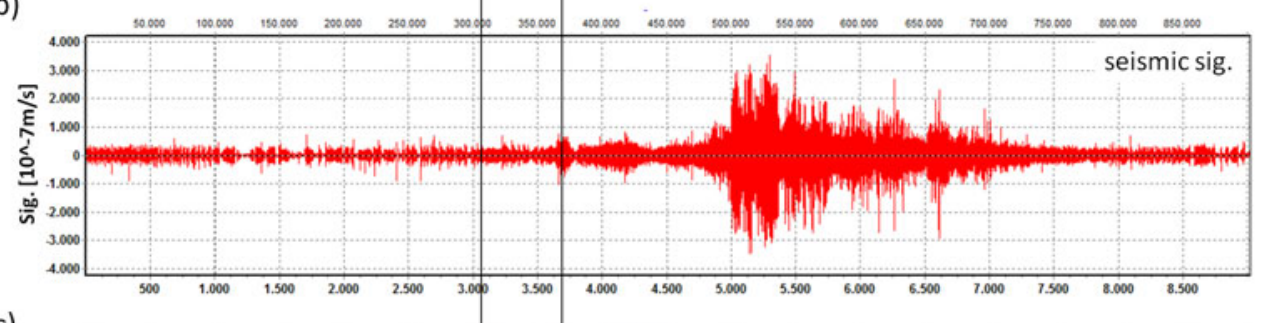

c)

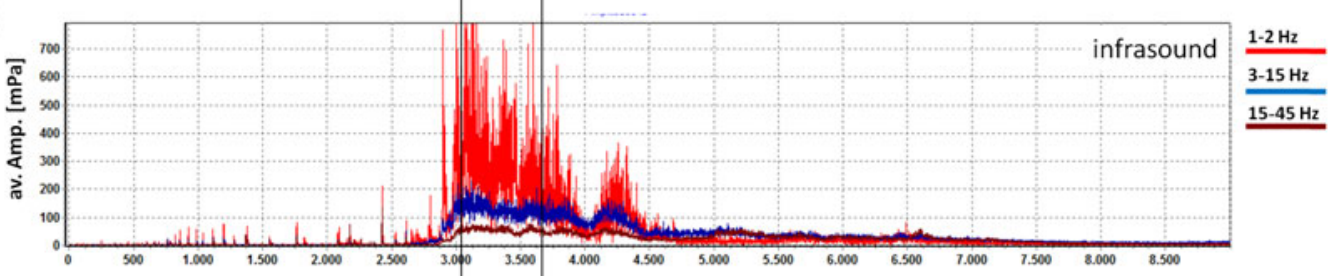

d)
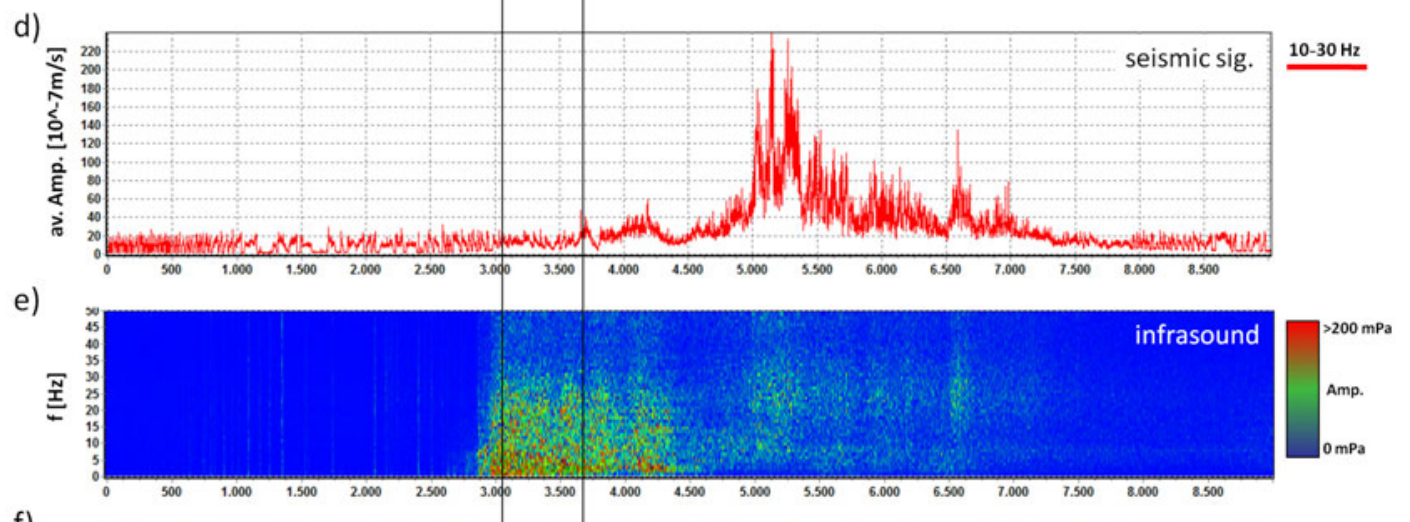

f)

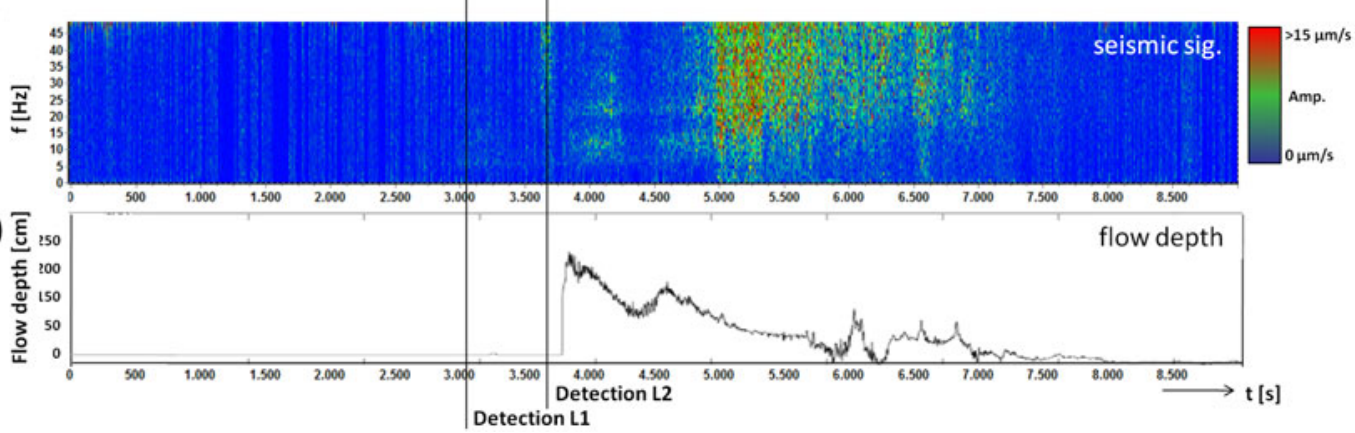

Figure 37: Infrasound and seismic data of the mud flow monitored at the Marderello test site on 09.08.2015. Signals are represented with a common base of time. (a) Infrasound time series; (b) Seismogram; (c) Average amplitude of the three frequency bands of the infrasound signal; (d) Average amplitude of the frequency band of the seismic signal; (e) Running spectrum of the infrasound signal; (f) Running spectrum of the seismic signal; (g) Flow depth ( 50 m downstream); Lines: time of first detection for Level 1 and Level 2. 


\section{Results and Discussion}

For the evaluation of the detection algorithm the numbers of the detected events, false alarms and missed events for all test sites from 2013 to 2017 are analysed (Table 4). The events are split in two different types: higher discharge with sediment transport and debris floods / debris flows. For the detections we distinguish between Level 1 detections, which are mostly in the category of sediment transport processes or small debris floods and Level 2 detections which are usually "fully developed" debris flows and debris floods. For some detections it was not possible to classify the signals due to missing data for evaluation or other technical problems, so they are separately listed as "non classifiable events".

Most of the events from 2013 to 2017 were higher discharge processes (71) whereas 17 events could not be detected. Since most of the undetected events in this class were smaller events, a detection of these events is not necessarily required in contrast to the debris flow and debris flood events. The detection of these processes is obligatory and 29 Level 2 events were detected (except one event on Schüsserbach, where the geophone was damaged at the start of the event) and also nearly all Level 1 events could be detected (11 out of 14). During the entire operation time of $103788 \mathrm{~h}$ only 14 false alarms were registered and 14 detections could not clearly be classified (Figure 38). Most of the false alarms were registered at Punta Negra, where the station is very exposed to wind. Might the infrasound detection criterion for avoiding false alarm due to wind, has to be improved.

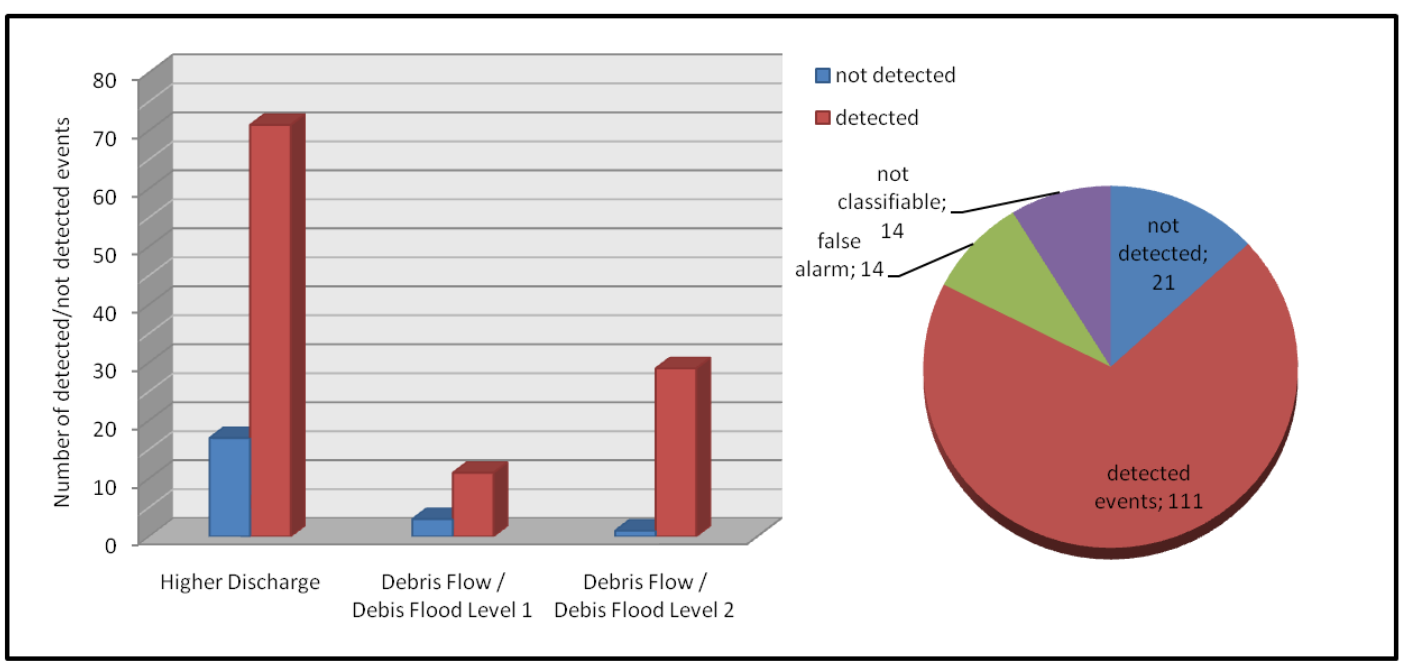

Figure 38: Summary of event detections and undetected events for all test sites from 2013 to 2017

The time between the detection and the passing of the main surge at the sensor site 


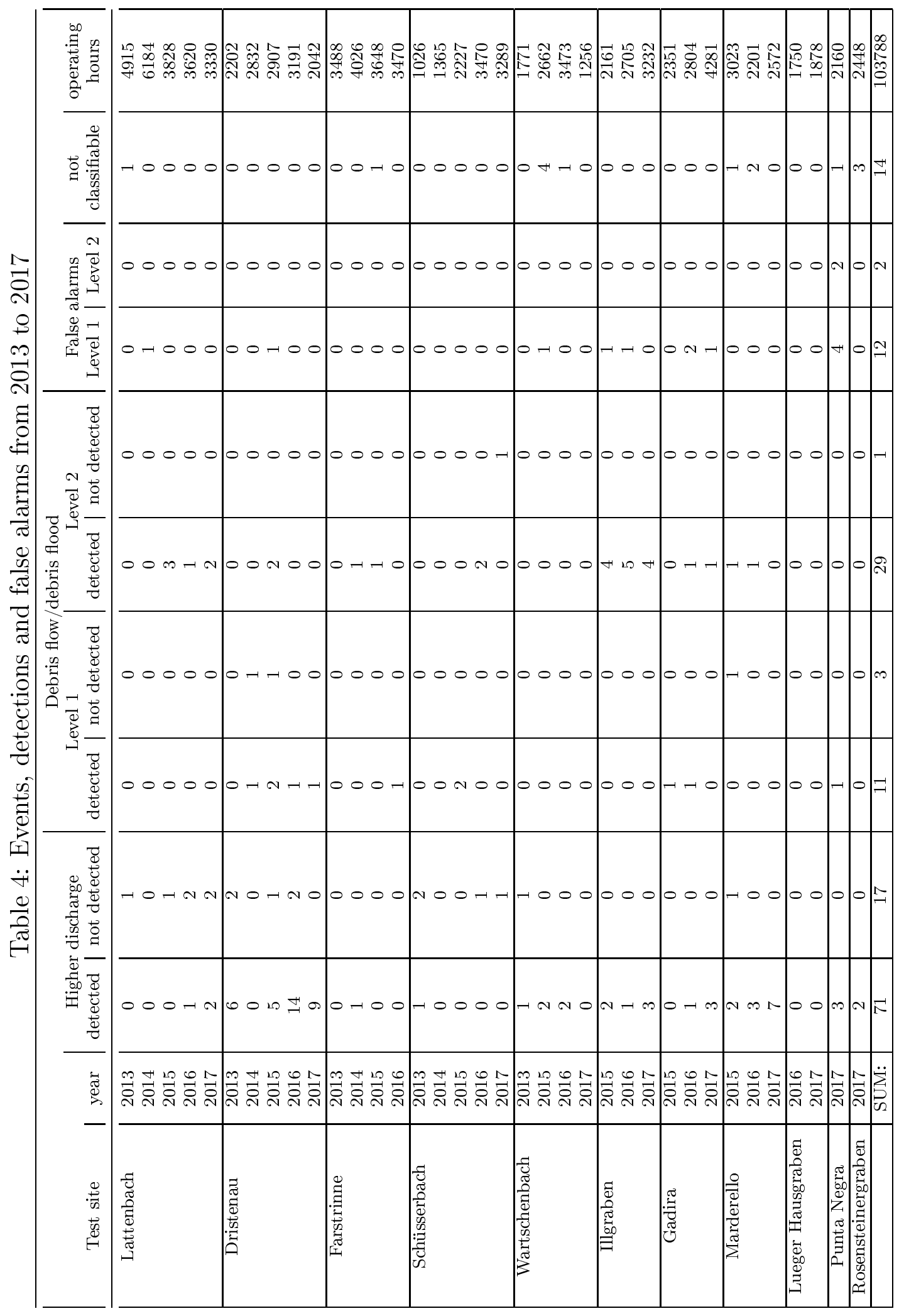


(mostly indicated with the maximum seismic and infrasonic amplitudes), which is further called "early warning time" are another factor which can be used to evaluate the system. Therefor we compare the average early warning times of Level 2 events of the debris flow or debris flood type for all test sites (Figure 39).

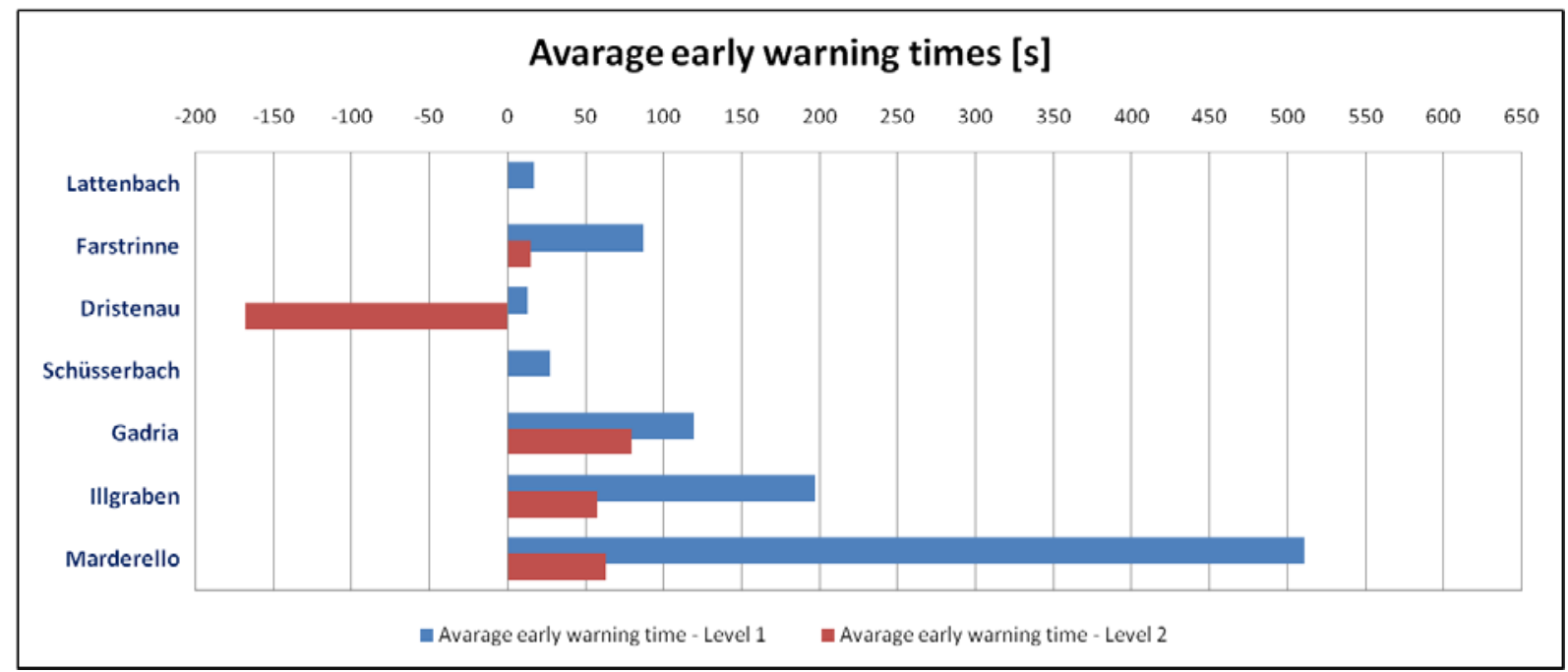

Figure 39: Overview average early warning times for all events listed in Table 5.

Table 5: Average early warning times for Level 2 debris flow/debris flood at different test sites.

\begin{tabular}{|l|c|c|c|}
\hline & $\begin{array}{c}\text { Early warning time } \\
\text { Level 1 [s] }\end{array}$ & $\begin{array}{c}\text { Early warning time } \\
\text { Level 2 [s] }\end{array}$ & $\begin{array}{c}\text { Number of } \\
\text { events }\end{array}$ \\
\hline Lattenbach & 17 & 1 & 5 \\
Farstrinne & 87 & 15 & 2 \\
Dristenau & 13 & -168 & 4 \\
Schüsserbach & 28 & 0 & 2 \\
Gadria & 120 & 79 & 3 \\
Illgraben & 197 & 57 & 8 \\
Marderello & 511 & 63 & 2 \\
\hline
\end{tabular}

This evaluation shows the large variance between the different test sites, where the average early warning times at Marderello are the longest with nearly ten minutes (at Level 1) compared to the average early warning times at Dristenau, where events are only detected a few seconds before passing. The Level 2 detections are closer to the passing of the main surge for most recorded events and at the test site Dristenau this time is even negative. This late Level 2 detection time is manly caused by the smaller event size at this test site, where Level 2 detections are often results of later surges. Another reason is that at the test site Dristenau, the position of the monitoring station is close to the valley end where events are generated, as described in Schimmel et al. 2016. 


\section{Conclusion}

This work demonstrates the potential for combining seismic and infrasound measurements for the development of an automatic rapid detection and identification system for debrisflow related disaster. The proposed detection system based on one infrasound sensor, one co-located geophone and a microcontroller is inexpensive, portable and easy to install and can be extended to an early warning system for different kinds of alpine mass movements. So in 2017 already a first application as warning system has been installed at the Rosensteinergraben, where a traffic light at the state road was controlled by this system. As such, the combination of infrasound and seismic sensors increases detection probability and reduces false alarms. It was possible to automatically detect all larger debris flows and debris floods in the period from 2013 to 2017 at eleven different test sites, while only 14 false alarms were registered in this time period. However, sensor equipment and installation location have to be chosen carefully and parameters of the detection algorithm may have to be adapted to the particular application and the background noise of the site. Analyses of different event types and different magnitudes have shown a dependency of the peak frequency range on the viscosity and a relation of the maximum infrasound and seismic amplitudes to the event magnitude. Consequently, a first estimation of the maximum discharge and the total volume based on the seismic or infrasound data is possible, whereby the infrasound amplitude seems to be a better approach for such a magnitude estimate. However, further research based on a large databases of different well categorized events at different test sites will be necessary for a reliable event identification. In summary, this work confirmed that debris flows and debris floods produce seismic and infrasonic signal characteristics that are reproducible at different experimental sites and under different environmental conditions and it shows promising results for the automatic detection and identification of alpine mass movements based on a combination of seismic and infrasound sensors. 


\section{References}

Abancó, C.,Hürlimann, M., Fritschi, B., Graf, C., Moya, J. (2012), Transformation of Ground Vibration Signal for Debris-Flow Monitoring and Detection in Alarm Systems, Sensors Vol. 12(4), 4870-4891, doi: 10.3390/s120404870.

Adam V., Chritin V., Rossi M., Van Lancker E. (1997): Infrasonic monitoring of snow avalanche activity: what do we know? where do we go from here, IAV Engineering, IGS97-paper 26A084, www.iav.ch

Alasonati, P., Wassermann, J., Ohrnberger, M. (2006): Signal classification by wavelet-based hidden Markov models: application to seismic signals of volcanic origin, Mader, H.M., Coles, S.G., Conner, C.B. and Conner, L.J. (eds), Statistics in Volcany, 161-173, Geological Society, London

Angerer, H., Hübl, J., Kohl, B., Markart, G., Pichler, A., Poscher, G:,Sönser, Th. (2000): Multidisziplinäre Prozessanalyse in einem Wildbacheinzugsgebiet am Beispiel des Wartschenbaches in Osttirol; In: Interpraevent 2000 - Villach, Band 3, Seite 3 - 17

Arattano, M. (2003), Monitoring the presence of the debris-flow front and its velocity through ground vibrations detectors. Proceedings of the Third International Conference on DebrisFlow Hazards Mitigation: Mechanics, Prediction and Assessment, 731-743, Millpress, Rotterdam

Arattano, M., Marchi, L., and Cavalli, M. (2012), Analysis of debris-flow recordings in an instrumented basin: confirmations and new findings, Nat. Hazards Earth Syst. Sci., 12, 679686, doi:10.5194/nhess-12-679-2012.

Arattano, M., Abancó, C., Coviello, V., Hürlimann, M. (2014), Processing the ground vibration signal produced by debris flows: the methods of amplitude and impulses compared, Computers \& Geosciences, Volume 73, December 2014, Pages 17-27, ISSN 0098-3004, http://dx.doi.org/10.1016/j.cageo.2014.08.005.

Badoux, A.,Graf, C., Rhyner, J., Kuntner, R., McArdell, B. W. (2009), A debris-flow alarm system for the Alpine Illgraben catchment: design and performance, Natural Hazards, Vol.49(3), 517-539, doi: 10.1007/s11069-008-9303-x.

Bennett, G.L., Molnar, P., Eisenbeiss, H., McArdell, B.W. (2012), Erosional power in the Swiss Alps: characterization of slope failure in the Illgraben. Earth Surf. Process. Landforms, 37: 1627-1640. doi:10.1002/esp.3263

Berger, C., McArdell, B.W., Schlunegger, F. (2011), Direct measurement of channel erosion by debris flows, Illgraben, Switzerland, J. Geophys. Res., 116, F01002, doi:10.1029/2010JF001722.

Bessason, B., Eiríksson, G., Thórarinsson, Ó., Thórarinsson, A., Einarsson, S. (2007), Automatic detection of avalanches and debris flows by seismic methods. Journal of Glaciology. 53. 461472. $10.3189 / 002214307783258468$. 
Biescas B., Dufour F., Furdada G., Khazaradze G., Suriñach E. (2003), Frequency content evolution of snow avalanche seismic signals, Surv. Geophys., 24(5-6), 447-464.

Burtin, A., Hovius, N., McArdell, B. W., Turowski, J., Vergne, J. (2014), Seismic constraints on dynamic links between geomorphic processes and routing of sediment in a steep mountain catchment. Earth Surface Dynamics, 2, pp. 21-33.

Chritin , V., Rossi, M., Bolognesi, R. (1996), Acoustic detection system for operational avalanche forecasting. Proceeding of International Snow Science Workshop, Banff, Alberta, 129-1336

Chou H.T., Cheung Y.L., Zhang S.C. (2007), Calibration of infrasound monitoring systems and acoustic characteristics of debris-flow movements by field studies. Institute of Mountain Hazards and Environment, Chinese Academy of Science and Ministry of Water resources

Chou, H.T., Chang, Y.L. and Zhang, S.X. (2010), Acoustic signals and geophone response of rainfall-induced debris flows. J. of Chinese Institute of Engineers

Comiti, F., Marchi, L., Macconi, P., Arattano, M., Bertoldi, G., Borga, M., Brardinoni, F., Cavalli, M., D'Agostino, V., Penna, D. and Theule, J.: A new monitoring station for debris flows in the European Alps: first observations in the Gadria basin, Nat. Hazards, 73(3), 1175-1198, doi:10.1007/s11069-014-1088-5, 2014.

Coviello, V., Arattano, M., Turconi, L. (2015), Detecting torrential processes from a distance with a seismic monitoring network. Natural Hazards 78(3), 2055-2080

Hsu, L., Finnegan, N.J., Brodsky, E.E. (2011), A seismic signature of river bedload transport during storm events, Geophys. Res. Lett., 38, L13407, doi:10.1029/2011GL047759.

Huang C., Yin H., Shieh C. (2003), Experimental study of the underground sound generated by debris flow. Proc. of the Third Int. Conference on Debris-Flow Hazards Mitigation: Mechanics, Prediction and Assessment, Vol.2, 743-753. Millpress, Rotterdam

Huang, C.-J., Yin, H.-Y., Chen, C.-Y., Yeh, C.-H., Wang, C.-L. (2007), Ground vibrations produced by rock motions and debris flows. Journal of Geophysical Research: Earth Surface, 112, F02014, doi: 10.1029/2005JF000437

Hübl, J., Moser, M. (2006): Risk Management in Lattenbach: a case study from Austria. In: Lorenzini, G., Brebbia, C.A, Emmanouloudis, D.E. (Eds.), Monitoring, Simulation, Prevention and Remediation of Dense and Debris Flows, 333-342; WIT Press, Southampton; ISBN 1-84564-169-8.

Hübl, J., Schimmel, A., Kogelnig, A., Suriñach, E., Vilajosana, I., McArdell, B.W. (2013), A review on acoustic monitoring of debris flow, International Journal of Safety and Security Engineering, Vol. 3, No. 2, 105-115; ISSN 2041-9031

Hunger, O., Evans S.G., Bovis, M.J., Hutchinson, J.N. (2001), A Review of the Classification of Landslides of the Flow Type, Environmental and Engineering Geoscience, Vol. VII, No. 3, August 2001, pp. 221-238.

Johnson, J.B., Lees, J., Yepes, H. (2006). Volcanic eruptions, lightning, and a waterfall: Differentiating the menagerie of infrasound in the Ecuadorian jungle. Geophysical Research Letters 33. doi: $10.1029 / 2005$ GL025515. 
Kean, J.W., Coe, J.A., Coviello, V., Smith, J.B., McCoy, S.W., Arattano, M. (2015), Estimating rates of debris flow entrainment from ground vibrations, Geophys. Res. Lett., 42, 6365-6372, doi:10.1002/2015GL064811.

Koschuch, R., Jocham, P., Hübl, J. (2015), One Year Use of High-Frequency RADAR Technology in Alpine Mass Movement Monitoring: Principles and Performance for Torrential Activities, Engineering Geology for Society and Territory- Volume 3, Edition: 1st, Chapter: 14, 69-72

Kogelnig, A., Hübl, J. (2009), Infrasound Monitoring of Debris Flow at Lattenbach, Austria. In: European Geosciences Union (Ed.), Geophysical Research Abstracts, Vol. 11, EGU2009-2573, EGU General Assembly 2009, Wien

Kogelnig A., Hübl J., Suriñach E., Vilajosana I., McArdell B.W. (2014), Infrasound produced by debris flow: Propagation and frequency content evolution. Nat. Hazards Vol. 70(3), 17131733, doi: $10.1007 / \mathrm{s} 11069-011-9741-8$.

Kogelnig, A. And Suriñach, E., Vilajosana, I. , Hübl, J. , Sovilla, B. , Hiller, M. and Dufour, F. (2011), On the complementariness of infrasound and seismic sensors for monitoring snow avalanches, Natural Hazards and Earth System Sciences, 11, 2355-2370.

Kogelnig, A. (2012), Development of acoustic monitoring for alpine mass movements, PhD Thesis, University of Natural Resources and Life Sciences (BOKU), Vienna, Institute of Mountain Risk Engineering

Leprette, B., Martin, N., Glangeaud, F., Navarre, J.P. (1998): Three-Component Signal Recognition Using Time, Time-Frequency, and Polarization Information-Application to Seismic Detection of Avalanches, IEEE Transactions on Signal Processing, Vol 46, No.1, 83-102.

Lin, C. H., Kumagai, H., Ando, M., Shin, T. C.(2010): Detection of landslides and submarine slumps using broadband seismic networks, Geophys. Res. Lett., 37, L22309, doi:10.1029/2010gl044685

Liu, D., Leng, X., Wei, F., Zhang, S., Hong, Y. (2015), Monitoring and recognition of debris flow infrasonic signals, Journal of Mountain Science, Vol. 12(4), 797-815, doi: 10.1007/s11629-0153471-4.

McArdell, B. W. (2009): Field observations of debris flow properties at the Illgraben catchment, Switzerland. In 2009 Portland GSA Annual Meeting.

Marchetti, E., Ripepe, M., Ulivieri, G. and Kogelnig, A. (2015), Infrasound array criteria for automatic detection and front velocity estimation of snow avalanches: towards a real-time early-warning system, Natural Hazards and Earth System Sciences, 15, 2545-2555,

Pierson, T. C. (1986), Flow behavior of channelized debris flows, Mount St. Helens, Washington, Hillslope Processes, A. D. Abrahams, 269-296, Allen and Unwin, Winchester, Mass.

Pilger, C., Bittner, M. (2009), Infrasound from tropospheric sources: Impact on mesopause temperature?, Journal of Atmospheric and Solar-Terrestrial Physics, 71, 816-822.

Rabiner, L. R., Schafer, R.W. And Rader, C.M. (1969), The Chirp z-Transform Algorithm and its Application. Bell System Technical Journal, 48: 1249-1292. doi: 10.1002/j.15387305.1969.tb04268.x, 
Rickenmann, D., Hürlimann, M., Graf, C., Näf, D., Weber, D. (2001), MurgangBeobachtungsstationen in der Schweiz. Wasser, Energie, Luft. Retrieved from http://www.slf.ch/wsl/info/mitarbeitende/grafc/pdf/4110.pdf.

Schimmel, A., Hübl, J. (2015), Approach for an Early Warning System for Debris Flow Based on Acoustic Signals. In: Lollino, G. et al. (Ed.), Engineering Geology for Sciety and Territory, Volume 3, S. 55-58, doi: 10.1007/978-3-319-09054-2_11.

Schimmel, A., Hübl, J. (2016), Automatic detection of debris flows and debris floods based on a combination of infrasound and seismic signals. Landslides Vol. 13(5), 1181-1196, ISSN 1612-510X, doi: 10.1007/s10346-015-0640-z.

Schimmel, A., Hübl, J., McArdell, B., Walter F. (2018), Automatic identification of alpine mass movements by a combination of seismic and infrasound signals. Submitted to Computers and Geosciences.

Schimmel, A., Hübl, J., Koschuch, R., Reiweger, I. (2017), Automatic detection of avalanches: evaluation of three different approaches, Natural Hazards, Vol. 87(1), pp 83-102, doi: 10.1007/s11069-017-2754-1.

Schlunegger, F., Badoux, A., McArdell, B.W., Gwerder, C., Schnydrig, D., Rieke-Zapp, D., Molnar, P. (2009), Limits of sediment transfer in an alpine debris-flow catchment, Illgraben, Switzerland, Quaternary Science Reviews, Volume 28, Issue 11, Pages 1097-1105, ISSN 02773791, http://dx.doi.org/10.1016/j.quascirev.2008.10.025.

Scott E.D. (2006), Practical implementation of avalanche infrasound monitoring technology for operational utilization near Teton Pass Wyoming. Proceedings: International Snow Science Workshop

Scott, E., Hayward, C., Kubichek, R., Hamann, J., Comey, R., Pierre, J. and Mendenhall, T. (2007), Single and multiple sensor identification of avalanche generated infrasound, Cold Regions Science and Technology, 47, 159-170

Suriñach E., Sabot F., Furdada G., Vilaplana J. (2000), Study of seismic signals of artificially released snow avalanches for monitoring purpose. Phs. Chem. Earth B, 25(9), 721-727

Suriñach, E., Kogelnig, A., Vilajosana, I., Hübl, J., Hiller, M., Dufour, F. (2009), Incoporación del la señal de infrasonido a la detección y estudio de aludes de nieve y flujostorrenciales, VII SimposioNacinal sobre Taludes y LaderasInestables, Barcelona, Spain

Tsai, V. C., Minchew, B., Lamb, M P. and Ampuero, J. P. (2012), A physical model for seismic noise generation from sediment transport in rivers, Geophysical Research Letters, Vol. 39-2, 1944-8007, doi: 10.1029/2011GL050255

Turconi, L., De Kumar, S., Tropeano, D., Savio, G. (2010), Slope failure and related processes in the Mt. Rocciamelone area (Cenischia Valley, Western Italian Alps), Geomorphology, Volume 114, Issue 3, Pages 115-128, ISSN 0169-555X, http://dx.doi.org/10.1016/j.geomorph.2009.06.012. 
Turconi, L., Coviello, V., Arattano, M., Savio, G. and Tropeano, D. (2015), Monitoring Mud-Flows for Investigative and Warning Purposes: The Instrumented Catchment of RioMarderello (North-Western Italy), in Engineering Geology for Society and Territory, Vol. 3, edited by G. Lollino, M. Arattano, M. Rinaldi, O. Giustolisi, J.-C. Marechal, and G. E. Grant, pp. 85-90, Springer, Switzerland.

Thüring, M. S., Van Herwijnen, A., and Schweizer, J. (2015), Robust snow avalanche detection using supervised machine learning with infrasonic sensor arrays, Cold Reg. Sci. Technol., 111, $60-66$,

Vilajosana, I., Suriñach, E., Abellán, A., Khazaradze, G., Garcia, D. and Llosa, J. (2008), Rockfall induced seismic signals: case study in Montserrat, Catalonia, Natural Hazards and Earth System Sciences, 8(4), 805-812

Yamada, M., Matsushi, Y., Chigira, M., Mori, J. (2012): Seismic recordings of landslides caused by Typhoon Talas 2011, Japan: Geophysical Research Letters, v. 39..

Walter, F., Burtin, A., McArdell, B.W., Hovius, N., Weder, B., and Turowski, J.M. (2017), Testing seismic amplitude source location for fast debris-flow detection at Illgraben, Switzerland, Nat. Hazards Earth Syst. Sci., 17, 939-955, https://doi.org/10.5194/nhess-17-939-2017.

Zhang, S., Hong, Y., Yu, B. (2004), Detecting infrasound emission of debris flow for warning purpose, 10. Congress Interpraevement

Zschau, J., Küppers, A. (2003): Early Warning Systems for Natural Disaster Reduction, Springer Verlag, Berlin. 